RICARDO GIRNIS TOMBI

\title{
PROPOSTA DE EXTENSÃO DO PROTOCOLO PCE CONSIDERANDO PARÂMETROS DE QOT PARA ROTEAMENTO INTER-DOMÍNIOS EM REDES GMPLS
}

Dissertação apresentada à Escola Politécnica da Universidade de São Paulo para obtenção do título de Mestre em Engenharia.

São Paulo

2007 
RICARDO GIRNIS TOMBI

\section{PROPOSTA DE EXTENSÃO DO PROTOCOLO PCE CONSIDERANDO PARÂMETROS DE QOT PARA ROTEAMENTO INTER-DOMÍNIOS EM REDES GMPLS}

Dissertação apresentada à Escola Politécnica da Universidade de São Paulo para obtenção do título de Mestre em Engenharia.

Área de Concentração: Sistemas Digitais Orientadora: Profa. Dra. Regina Melo Silveira 


\section{FICHA CATALOGRÁFICA}

\section{Tombi, Ricardo Girnis}

Proposta de extensão do protocolo PCE considerando parâmetros de QoT para roteamento inter-domínios em redes GMPLS / R.G. Tombi. -- São Paulo, 2007. $146 \mathrm{p}$.

Dissertação (Mestrado) - Escola Politécnica da Universidade de São Paulo. Departamento de Engenharia de Computação e Sistemas Digitais.

1.Roteamento 2. Qualidade de transmissão (QoT) 3.Elemento de computação de rotas 4.Redes ópticas I.Universidade de São Paulo. Escola Politécnica. Departamento de Engenharia de Computação e Sistemas Digitais II.t. 


\section{DEDICATÓRIA}

Aos meus pais por todo amor e incentivo que sempre demonstraram.

À minha querida esposa, Lucia, com amor, admiração e gratidão por sua compreensão, carinho e incansável apoio ao longo do período de elaboração deste trabalho. 


\section{AGRADECIMENTOS}

À minha orientadora, Profa. Dra Regina Melo Silveira, pela sua dedicação e incentivo admiráveis, e pela orientação durante o período de realização deste trabalho.

À minha esposa Lucia, que sempre esteve ao meu lado, fornecendo seu apoio de forma incondicional. Através de sua força e de sua luz, consegui encontrar coragem para seguir em frente, principalmente nos momentos mais difíceis do caminho.

Ao apoio da família e amigos, que foi sempre um fator de motivação para a conclusão deste trabalho.

Aos professores que contribuíram de alguma forma durante este período.

E sem dúvida, a Deus, pela saúde e disposição, fundamentais para a conclusão desta etapa. E principalmente por mais esta oportunidade em minha vida. 


\section{RESUMO}

Este trabalho apresenta uma análise sobre a Arquitetutra PCE (Path Computation Element), como alternativa para o roteamento inter-domínios em redes heterogêneas, ou seja, em ambientes onde ocorre a integração do domínio óptico, das redes de transporte ópticas, com o domínio eletrônico, das redes convencionais, tratando inclusive com questões de qualidade de transmissão do sinal óptico, ou QoT (Quality of Transmission).

Os objetivos e o funcionamento do mecanismo do PCE em redes integradas são detalhados. São apresentados também os conceitos e definições das redes ópticas, bem como seus principais elementos, a proposta de interconexão das mesmas com as redes convencionais provendo uma rede única e integrada, o papel dos planos de controle, e os principais mecanismos de roteamento.

A análise do PCE foi direcionada para o comportamento do principal protocolo utilizado na sua arquitetura, denominado PCE Protocol. De forma mais específica, foi realizada a análise de suas mensagens de requisição de rotas e das mensagens de respostas a estas requisições, e sua interferência no tráfego dos enlaces das redes onde são introduzidas. A partir daí é apresentada uma proposta de extensão de parâmetros para o protocolo PCE Protocol, com o objetivo de atender necessidades específicas de QoT, baseado em estudos das particularidades das características das transmissões ópticas.

A partir destas definições, foram realizadas análises adicionais a fim de verificar o impacto com relação ao tráfego gerado em enlaces de diferentes larguras de banda, com a definição original do protocolo, e com a extensão proposta, permitindo uma comparação entre ambos.

Palavras chave: PCE. Qualidade de Transmissão (QoT). Roteamento. Redes Ópticas. Elemento de Computação de Rotas. 


\begin{abstract}
This thesis presents an analysis of Path Computation Element Architecture (PCE) as an alternative to be implemented in heterogeneous network inter-domain routing, in other words, environments where optical domains are integrated with the electronic domains of conventional networks. Also, the ability of PCE to manage issues regarding the transmission quality of the optical signal, the QoT (Quality of Transmission), is presented.

Objectives and functionality of the PCE mechanism in integrated networks is detailed. Concepts and definitions regarding optical networks and their main elements, the aim of interconnection with conventional networks to build a unified and integrated network, the role of control planes, and the main routing mechanisms are also presented.
\end{abstract}

The analysis of the PCE was focused on the behavior of its main protocol, called PCE Protocol. Specifically, the analysis was performed on both its request and response messages, in addition, the interference in the traffic of the links where these messages had been introduced was also analyzed. Afterwards, an extension of the PCE Protocol parameters was proposed based on the study of optical transmission characteristics, with the aim of meeting specific QoT requirements.

From these definitions, further analyses of the impact on the traffic in links with different bandwidths were performed, using the PCE protocol, with and without the proposed extension, allowing a comparison between them.

Keywords: PCE. Quality of Transmission (QoT). Routing. Optical Networks. Route Computation Element. 


\section{LISTA DE FIGURAS}

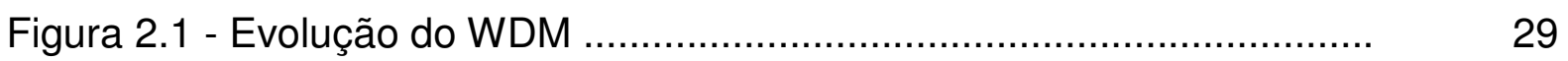

Figura 2.2 - Rede com 04 nós e 03 comprimentos de onda disponíveis....... 34

Figura 2.3 - Rede com capacidade de conversão de comprimento de onda. $\quad 35$

Figura 2.4 - Rede Singlehop............................................................... 37

Figura 2.5 - Protocolos singlehop do domínio óptico.................................... 38

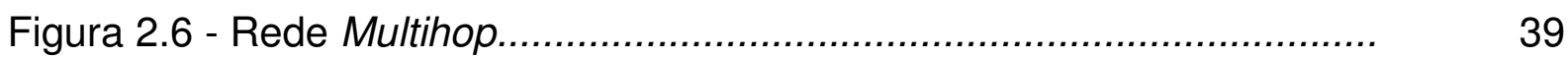

Figura 2.7 - Protocolos multihop do domínio óptico...................................... 39

Figura 2.8 - Representação das curvas dos fenômenos ópticos que ocorrem nas janelas de transmissão utilizadas na comunicação óptica.........

Figura 2.9 - Sinal deteriorado após a passagem por um enlace de fibra óptica.

Figura 2.10 - Interpretação incorreta do receptor ao receber um sinal por uma fibra óptica onde ocorreu a dispersão.

Figura 2.11 - Representação da dispersão intermodal em um enlace de fibra óptica.

Figura 2.12 - Representação da dispersão cromática em um enlace de fibra óptica.

Figura 2.13 - Representação da dispersão por modo de polarização em um enlace de fibra óptica.

Figura 3.1 - Arquiteturas de Redes IP sobre Redes Ópticas

Figura 3.2 - Rede MPLS.

Figura 3.3 - Rede GMPLS

Figura 3.4 - Rede dividida em diversas áreas.

Figura 3.5 - Rede Inter-AS.

Figura 3.6 - Rede Inter-camadas. 
Figura 3.7 - Nós da rede com capacidades de comutação distintas.

Figura 3.8 - Rede BGP e a falta de informações sobre as características dos enlaces

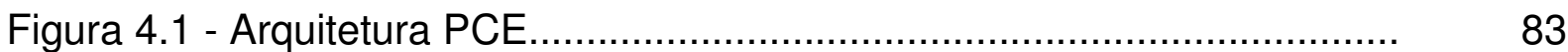

Figura 4.2 - Arquitetura com um único PCE.................................................

Figura 4.3 - Fluxograma do mecanismo de requisição de rotas e respostas da arquitetura PCE.

Figura 4.4 - Fluxo das Mensagens Open e Keepalive.

Figura 4.5 - Fluxo da Mensagem PCReq.

Figura 4.6 - Fluxo da Mensagem PCRep positiva.

Figura 4.7 - Fluxo da Mensagem PCRep negativa

Figura 4.8 - Estrutura da mensagem Open

Figura 4.9 - Estrutura da mensagem Close.

Figura 4.10 - Estrutura da mensagem PCReq.

Figura 4.11 - Estrutura da mensagem PCRep.

Figura 5.1 - Alternativas de caminhos entre dois nós

Figura 5.2 - Objeto Quality. 108

Figura 5.3 - Objeto Quality - Definição de parâmetros.

Figura 5.4 - Objeto Quality - Definição de prioridade de parâmetro.

Figura 5.5 - Objeto Quality - Definição de política

Figura 5.6 - Objeto Quality - Definição de prioridade de política.

Figura 6.1 - Cenário para análise do comportamento do PCE

Figura 6.2 - Exemplo de enlaces utilizados no POP MS da RNP.

Figura 6.3 - Exemplo de enlaces utilizados em uma rede privada

Figura 6.4 - Ocupação dos enlaces pela mensagem PCReq.

Figura 6.5 - Ocupação dos enlaces pela mensagem PCReq com a taxa 
máxima de requisições.

Figura 6.6 - Ocupação dos enlaces pela mensagem PCRep.

Figura 6.7 - Ocupação dos enlaces pela mensagem PCRep com a taxa máxima de requisições. 


\section{LISTA DE TABELAS}

Tabela 2.1 - Hierarquia Sonet/SDH...................................................... 26

Tabela 5.1 - Requisitos das aplicações com relação a QoS........................... 104

Tabela 6.1 - Enlaces utilizados nos experimentos....................................... 115

Tabela 6.2 - Taxas de requisições utilizadas nos experimentos...................... 120

Tabela 6.3 - Ocupação dos enlaces pela mensagem PCReq......................... 121

Tabela 6.4 - Ocupação dos enlaces pela mensagem PCReq com maior valor calculado e com a taxa máxima de requisições...................................... 123

Tabela 6.5 - Ocupação dos enlaces pela mensagem PCReq com taxa extrema de requisições (100 req/s) ....................................................... 124

Tabela 6.6 - Ocupação dos enlaces pela mensagem PCRep.......................... 125

Tabela 6.7 - Ocupação dos enlaces pela mensagem PCRep com maior valor calculado e com a taxa máxima de requisições...................................... 126

Tabela 6.8 - Ocupação dos enlaces pela mensagem PCRep com taxa extrema de requisições (100 req/s) ..................................................... 127

Tabela 6.9 - Ocupação dos enlaces pela mensagem PCReq estendida com a taxa máxima de requisições (10 req/s)..................................................... 128

Tabela 6.10 - Ocupação dos enlaces pela mensagem PCReq estendida com taxa extrema de requisições $(100 \mathrm{req} / \mathrm{s})$............................................................. 128 


\section{LISTA DE ABREVIATURAS}

$\begin{array}{ll}\text { ANSI } & \text { American National Standards Institute } \\ \text { AS } & \text { Autonomous System } \\ \text { ASE } & \text { Amplifier Spontaneous Emission } \\ \text { ASIC } & \text { Application-specific integrated circuit } \\ \text { ASON } & \text { Automatically Switched Optical Networks } \\ \text { ATM } & \text { Asynchronous Transfer Mode } \\ \text { BER } & \text { Bit Error Rate } \\ \text { BGP } & \text { Border Gateway Protocol } \\ \text { CCAMP } & \text { Common Control and Management Plane } \\ \text { CD } & \text { Chromatic Dispersion } \\ \text { CSPF } & \text { Constrained Shortest Path First } \\ \text { CWDM } & \text { Coarse Wavelenght Division Multiplexing } \\ \text { DWDM } & \text { Dense Wavelenght Division Multiplexing } \\ \text { EDFA } & \text { Erbium Dopped Fiber Amplifier } \\ \text { EGP } & \text { Exterior Gateway Protocol } \\ \text { ERO } & \text { Explicit Route Object } \\ \text { FSC } & \text { Fiber Switch Capable } \\ \text { FWM } & \text { Four Wave Mixing } \\ \text { GMPLS } & \text { Generalized Multiprotocol Label Switching } \\ \text { GMPLS } & \text { Generalized Multiprotocol Label Switching } \\ \text { GSM } & \text { Global System for Mobile Communication } \\ \text { IETF } & \text { Internet Engineering Task Force } \\ \text { IGRP } & \text { Interior Gateway Routing Protocol } \\ \text { IP } & \text { Internet Protocol }\end{array}$


ISIS Intermediate System to Intermediate System

ISIS-TE Intermediate System to Intermediate System - Traffic Engineering

ISP Internet Service Provider

ISUP Integrated Services Digital Network User Part

ITU-T International Telecomunications Union (Telecommunications

Standardisation Sector)

L2SC Layer-2 Switch Capable

LAN Local Area Network

LMP Link Management Protocol

LSA Link State Advertisment

LSC Lambda Switch Capable

LSP Label Switch Path

LSR Label Switched Router

MAC Media Access Control

MPLS Multiprotocol Label Switching

OADM Optical Add Drop Multiplexer

OBSAI Open Base Station Architecture Initiative

OSNR Optical Signal Noise Rate

OSPF Open Shortest Path First

OSPF-TE Open Shortest Path First - Traffic Engineering

OXC Optical Cross Connect

PCC Path Computation Client

PCE Path Computation Element

PCEP Path Computation Element Protocol

PDH Plesiochronous Digital Hierarchy

PMD Polarization Mode Dispersion 


\begin{tabular}{ll} 
POP & Point of Presence \\
PSC & Passive Star Coupler \\
PSC & Packet Switch Capable \\
PXC & Photonic Cross Connect \\
Qg & Global Q Factor \\
QoS & Quality of Service \\
QoT & Quality of Transmission \\
RIP & Routing Information Protocol \\
RNP & Rede Nacional de Pesquisas \\
RSVP & Resource Reservation Protocol \\
RSVP-TE & Resource Reservation Protocol - Traffic Engineering \\
SDH & Synchronous Digital Hierarchy \\
SFM & Self Phase Modulation \\
SONET & Synchronous Optical Network \\
SPF & Shortest Path First \\
SRLG & Shared Risk Link Group \\
SS7 & Signalling System Number 7 \\
TCP/IP & Transmission Control Protocol / Internet Protocol \\
TDM & Time Division Multiplex \\
TE & Traffic Engineering \\
TLV & Type/Length/Value \\
TM & Terminal Multiplexer \\
VCI & Virtual Channel Identifier \\
VPI & Virtual Path Identifier \\
VPN & Virtual Private Network \\
WAN & Wide Area Network \\
\hline
\end{tabular}


WDM Wavelenght Division Multiplexing

WGR Waveguide Grating Router

WR Wavelenght Router

WRS Wavelenght-routing switch

WSXC Wavelenght-selective crossconnect

XPM Cross Phase Modulation 


\section{SUMÁRIO}

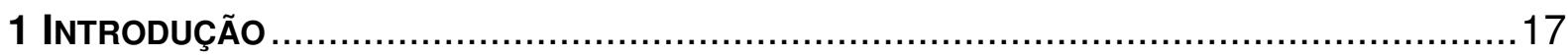

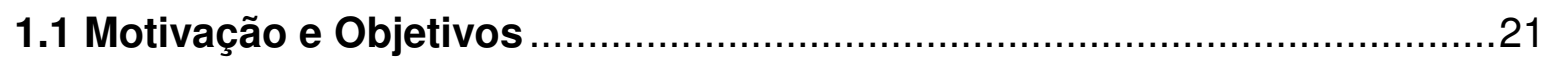

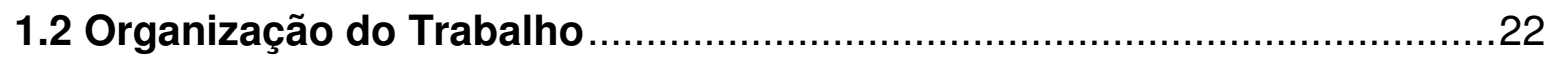

2 Definições e Conceitos Relacionados Às Redes Ópticas................................24

2.1 Transporte de Dados nas Redes Ópticas ............................................25

2.2 Elementos Habilitadores nas Redes Ópticas ........................................... 31

2.3 Disponibilidade de Comprimentos de Onda ..........................................33

2.4 Qualidade do Sinal Óptico ......................................................... 40

2.4.1 Qualidade do Sinal Óptico e Qualidade de Serviço ...........................40

2.4.2 Fatores Relevantes à Qualidade do Sinal Óptico.............................42

3 Planos de Controle e Roteamento em Redes ópticas .................................49

3.1 Serviços sobre Redes Ópticas e as Arquiteturas Multi-camadas ............49

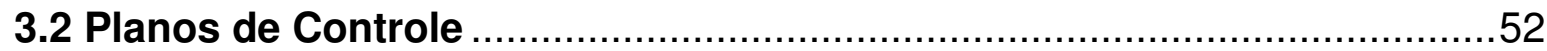

3.3 Planos de Controle e as Redes Ópticas ...........................................55

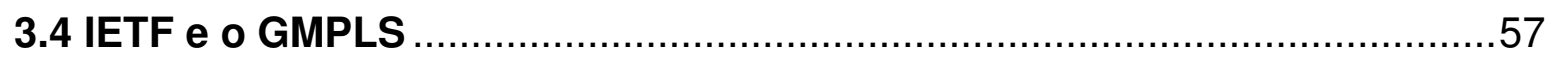

3.4.1 Extensões para o GMPLS ................................................. 61

3.4.2 Modelos de Implementação dos Planos de Controle no GMPLS.......62

3.5 Algoritmos e Protocolos de Roteamento e as Redes Integradas............63

3.5.1 Cenários Intra-domínios e Inter-domínios ...................................66

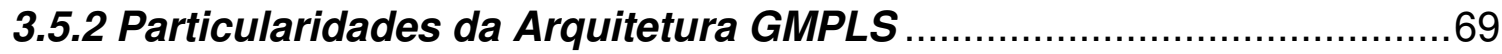

3.6 Abrangência do Mecanismo de Roteamento para as Redes Integradas ..71

3.6.1 Extensões dos Protocolos Intra-domínios para Redes Ópticas.........72

3.6.2 Extensões dos Protocolos Inter-domínios para Redes Ópticas ..........76

4 Arquitetura PCE (Path Computation Element) ....................................... 81

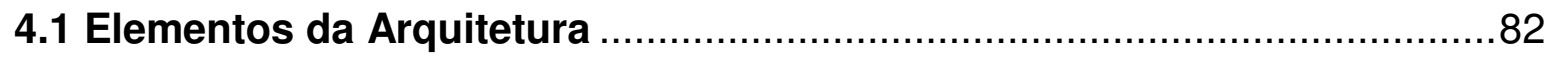

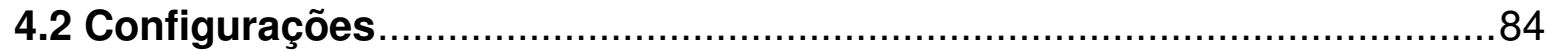

4.2.1 Computação Centralizada (Single PCE Computation).......................84

4.2.2 Computação Distribuída (Multiple PCE Computation).......................85

4.3 Comunicação entre os Elementos .................................................. 85

4.3.1 PCE Discovery Protocol ............................................................ 85

4.3.2 PCE Protocol ...................................................................... 86 
4.4 Considerações Adicionais com Relação ao PCE em Comparação ao BGP como Alternativa para o Mecanismo de Roteamento Inter-domínios .............96

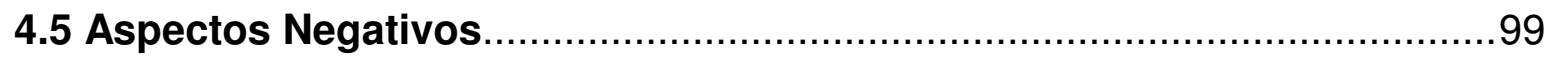

5 Proposta para Extensão do Protocolo PCE Protocol ..................................101

6 Análise do Tráfego Gerado pelo Mecanismo PCE e seu Impacto na Rede .....111

6.1 Definição do Cenário para a Análise ...................................................111

6.1.1 Elementos do Cenário ............................................................112

6.1.2 Definição dos Parâmetros e da Métrica Utilizada.............................118

6.2 Realização dos Experimentos ..........................................................119

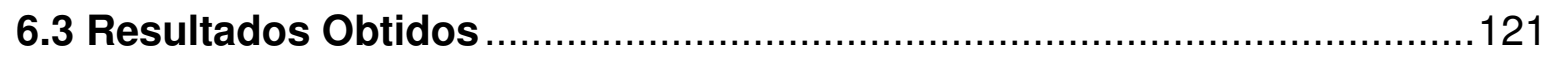

6.3.1 Comportamento da Mensagem PCReq ...........................................121

6.3.2 Comportamento da Mensagem PCRep ……...............................125

6.3.3 Comportamento da Mensagem PCReq Estendida ..........................127

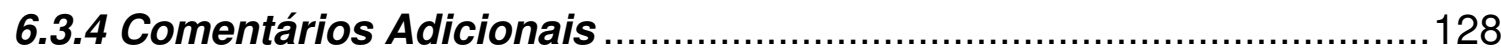

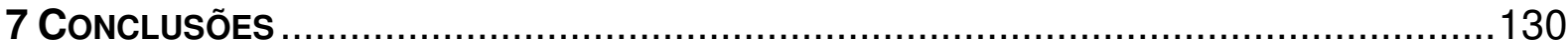

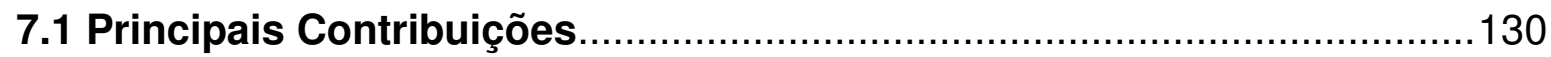

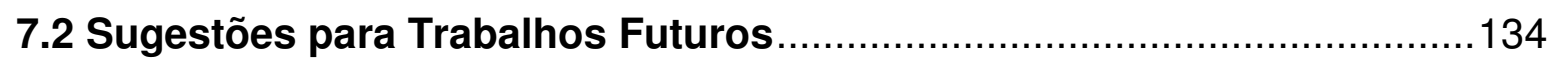

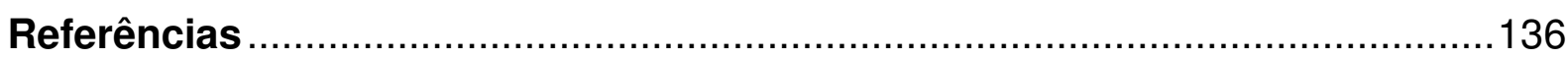

APÊNDICE A - Descrição das Mensagens PCReq e PCRep do PCE Protocol

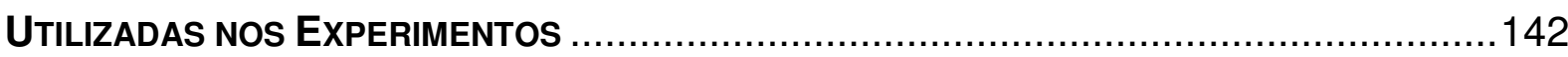




\section{INTRODUÇÃo}

O século XXI se iniciou demonstrando ser o começo da era da informação, e a partir de então verifica-se que o volume de dados que é gerado e transmitido através de meios eletrônicos é muito grande, apresentando um comportamento crescente para o futuro (KHOSROWPOUR, 2000). Este alto volume de informação, com perspectivas de crescimento, deve-se a alguns fatores, e entre eles pode-se destacar a disponibilidade cada vez maior dos recursos relacionados às tecnologias de comunicação eletrônica como os computadores, os aparelhos de telefone fixos e celulares, e todos os demais dispositivos que podem ser conectados através de algum tipo de rede de comunicação. Esta utilização pode ser realizada por toda a sociedade, incluindo órgãos públicos, empresas, instituições de ensino, saúde e a população em geral. Outro fator importante a ser destacado, que contribui consideravelmente com o aumento do volume de dados transmitidos, é a diversidade de aplicações disponíveis para os usuários destas tecnologias, que são cada vez mais elaboradas e sofisticadas, com o objetivo de atender às novas necessidades do mercado e seus usuários (DURRESI et al., 2003; ALCATEL, 2002).

Toda esta informação eletrônica está distribuída por equipamentos com as mais variadas funcionalidades e objetivos, e o aspecto mais importante é que a grande maioria destes equipamentos está interligada formando uma grande rede, possibilitando desta maneira, o acesso e a manipulação desta informação, com diferentes finalidades e resultados distintos, por todos e em qualquer localidade, dependendo obviamente das autorizações pertinentes e das políticas de segurança adotadas. Pode-se citar, por exemplo, as atividades de comércio eletrônico, home banking, entretenimento e comunicação, entre outras.

Tendo como foco, de forma particular, a largura de banda necessária nas redes de comunicação existentes atualmente, esta explosão do uso da informação faz aumentar continuamente a demanda por este recurso, especialmente quando se trata de comunicação multimídia, ou triple-play, onde uma variedade de tráfego com características distintas, como os tráfegos de dados simples, dados gráficos, voz, 
voz interativa, vídeo e vídeo em tempo real, podem coexistir em uma mesma rede (MESTRIC; SIF; FESTRAETS, 2005).

Além da largura de banda, para garantir a vazão destes tráfegos, existe um outro aspecto que deve ser equacionado, e que aparece devido a este novo comportamento. Este aspecto é o aumento da sua complexidade, devido ao fato do surgimento de requisitos específicos para cada tipo de tráfego. Requisitos estes que podem ser caracterizados como baixo atraso de transmissão, variação mínima do atraso de transmissão, baixa taxa de erro e alta disponibilidade. Desta forma um nível de Qualidade de Serviço (QoS - Quality of Service) deve ser aplicado adequadamente a fim de atender, para cada tipo de tráfego, os seus requisitos particulares, porém sem causar prejuízos aos demais (OODAN et al., 2003; MELO, 2001).

De acordo com o cenário apresentado verifica-se a necessidade de que redes cada vez mais eficientes sejam elaboradas e implementadas, para garantir que as características citadas possam ser atendidas, conforme os requisitos de qualidade de serviço necessários para os tráfegos demandados pelos usuários finais. Estas características de QoS das aplicações devem ser traduzidas em características de Qualidade de Transmissão (QoT - Quality of Transmission), com objetivo garantir a qualidade mínima desejada para que uma transmissão seja possível em uma rede.

Além da entrega com a qualidade de serviço solicitada, através da qualidade de transmissão adequada, estas redes devem desempenhar suas funções de forma eficiente e otimizada, ou seja, evitando o desperdício de recursos e aproveitando ao máximo cada um deles, através de uma arquitetura bem elaborada de infra-estrutura de rede.

No cenário atual estão presentes as redes convencionais de pacotes, onde trafegam sinais elétricos e os dados são processados de forma eletrônica, com suas diversas tecnologias e protocolos relacionados, e as redes ópticas, com sua estrutura peculiar de transporte de dados. Importante observar que as redes ópticas vêm evoluindo muito nos últimos anos, sendo capaz de fornecer uma grande capacidade de transmissão para as camadas superiores, ou seja, serviço de transporte de alta 
velocidade e de grande disponibilidade de banda, para as redes convencionais de dados, através de tecnologias como o DWDM (Dense Wavelenght Division Multiplexing) (GORALSKI, 2001). De acordo com o cenário exposto, as grandes empresas do mercado, como as operadoras de telecomunicações, ISPs (Internet Service Providers) ou mesmo outras organizações que possuem redes próprias, estão preocupadas com os custos operacionais destas redes heterogêneas, e como garantir eficiência nas suas configurações, gerenciamento de falhas e segurança, contabilidade e desempenho.

O desafio surge como forma de suprir a necessidade de se utilizar toda a tecnologia atual disponível, de redes heterogêneas, através de um provisionamento a ser realizado de maneira rápida, flexível e econômica, para que seja possível realmente maximizar os benefícios da utilização do transporte óptico transparente, ou seja, independente de protocolo e com a velocidade da comunicação óptica, para trafegar seus dados que têm origem e destino nas aplicações residentes em redes convencionais.

Desta forma as arquiteturas de rede devem ser desenvolvidas considerando-se a integração entre as redes citadas, de tecnologias distintas já existentes, visando sempre a otimização dos recursos disponíveis e o rápido provisionamento dos circuitos. Estas arquiteturas integradas devem ter como principal objetivo aproveitar a melhor característica de cada uma das tecnologias existentes em uso pelo mercado como por exemplo a identificação da melhor rota no mundo IP (Internet Protocol), a engenharia de tráfego do MPLS (Multiprotocol Label Switching) e a velocidade e capacidade de transmissão das redes ópticas.

Para cumprir o objetivo de integrar estas redes há duas abordagens importantes que podem ser consideradas, sendo uma delas através de um provisionamento centralizado e a outra através de um provisionamento distribuído (AMAZONAS; GIOZZA, 2003). O provisionamento centralizado deve integrar as redes através de configurações específicas nas interfaces das redes ópticas, e seu mecanismo possui um controle central, o que traz um ponto negativo quando a rede necessita de boa 
escalabilidade. De outra maneira, o provisionamento distribuído está baseado na implementação de um plano de controle único e distribuído por todos os elementos das redes como os roteadores IP (Internet Protoco), switches MPLS, OXCs (Optical Cross Connects), OADMS (Optical Add Drop Multiplexers), PXCs (Photonic Cross Connects) e sistemas SDH (Synchronous Digital Hierarchy) e DWDM, integrando todas as redes desta forma, com a utilização de protocolos padronizados neste plano de controle.

Verifica-se então que para se obter a integração destas redes os planos de controle têm um papel muito importante nesta tarefa. Torna-se fundamental que seja desenvolvido um plano de controle robusto e automático que seja capaz de lidar com as diferentes características de cada tecnologia de rede envolvida no processo, tendo como principal objetivo comandar de forma eficiente o funcionamento e as tarefas das redes que estão interligadas, ou seja, das redes convencionais de pacotes conectadas às redes ópticas, e tudo isto de forma padronizada, para que seja alcançada redução de custos operacionais e a melhoria da qualidade da rede.

Os planos de controle possuem como estrutura básica três blocos fundamentais sendo eles a sinalização, o gerenciamento de recursos e o roteamento. As características de cada um deles serão abordadas mais adiante no capítulo 3 deste trabalho. Importante salientar que as funções de roteamento nos planos de controle atuais estão divididas em duas principais áreas, onde uma delas se preocupa com o roteamento intra-domínios e a outra com o roteamento inter-domínios.

As duas abordagens de roteamento, apesar de distintas, possuem características em comum sendo a principal delas o esforço para a utilização dos recursos de maneira eficiente através da relevância que deve ser dada às restrições intrínsecas impostas pelas redes ópticas, dadas pelas suas características particulares, como a quantidade de comprimentos de onda disponível, a disponibilidade de conversão de comprimento de onda nos elementos da rede, a banda disponível, entre outras. 
O roteamento intra-domínios tem sido a preocupação de entidades de estudos e organismos de padronização, e como resultado há trabalhos e padrões desenvolvidos sobre este assunto (YIN; KUO, 2005; CUGINI; ANDRIOLLI; CASTOLDI, 2004; MIYAMURA; KURIMOTO; AOKI, 2003; KOMPELLA, K.; REKHTER, 2005a; KOMPELLA, K.; REKHTER, 2005b; KOMPELLA, K.; REKHTER, 2005c), em contrapartida as investigações e o desenvolvimento dos padrões para o roteamento inter-domínios se encontram em outro estágio de desenvolvimento, como por exemplo, a padronização da Arquitetura GMPLS (MANNIE, 2004) cita que, para este ambiente, o protocolo BGP (Border Gateway Protocol), poderia ser utilizado, porém com devidas extensões, mas estas extensões, neste momento, ainda são apenas propostas, e não estão divulgadas como padrão estabelecido. Uma alternativa padronizada recentemente para lidar com o cenário inter-domínios, bem como inter-camadas e inter-áreas, no sentido de proporcionar uma solução possível para o mecanismo de roteamento nas redes integradas é o PCE - Path Computation Element (FARREL; VASSEUR; ASH, 2006).

\subsection{Motivação e Objetivos}

A motivação deste trabalho está baseada no estudo e análise da arquitetura PCE, proposta para o problema de roteamento das redes integradas, as quais exigem cuidados especiais devido aos requisitos de engenharia de tráfego que são introduzidos nestas redes, que não existiam em redes homogêneas. A novidade do assunto, a ausência de documentação abundante disponível, e a falta de estudos abrangentes, devido exatamente ao aspecto de ser uma proposta recente, foram fatores que motivaram a escolha deste tema.

Como objetivo geral deste trabalho, pode-se destacar a realização da análise, através das respectivas definições e estrutura de funcionamento, sobre a viabilidade da adoção da Arquitetura PCE como uma alternativa para ser utilizada como mecanismo de roteamento das redes integradas. Em seguida, de acordo com os resultados obtidos, a apresentação de uma proposta para extensão do seu escopo, 
a fim de incluir a manipulação de certos requisitos de qualidade de transmissão do sinal óptico (QoT - Quality of Transmission)

De forma mais específica este trabalho tem como objetivos:

- Analisar o comportamento das mensagens PCReq e PCRep que fazem parte do protocolo PCE Protocol da arquitetura do PCE;

- Analisar o comportamento do tráfego introduzido pelo mecanismo PCE;

- Discutir problemas específicos das redes ópticas que potencialmente podem causar prejuízos à transmissão;

- Propor uma extensão ao protocolo PCE Protocol de acordo com estas características apontadas;

- Analisar o comportamento das novas mensagens e comparar o mesmo com o comportamento do protocolo original sem a extensão proposta.

\subsection{Organização do Trabalho}

Inicialmente são examinadas as definições e os conceitos relacionados às redes ópticas e a importância dos planos de controle no desenvolvimento da integração destas redes com as redes convencionais eletrônicas, bem como os principais requisitos de engenharia de tráfego exigidos nesta integração e as dificuldades enfrentadas pelos mecanismos de roteamento em lidar com estas questões. $O$ foco é dado ao mecanismo do PCE, seu funcionamento e características, e ao longo do trabalho são apresentadas fundamentações teóricas e análises relacionadas ao seu comportamento, bem como uma proposta de extensão do seu principal protocolo para lidar com questões de QoT.

Este trabalho aborda o cenário atual das redes ópticas no capítulo 2, onde são apresentadas suas principais características e as particularidades que devem ser levadas em consideração para a integração com outras redes. Em seguida, no capítulo 3, é introduzido o conceito de planos de controle, sendo definidos seus 
objetivos e mecanismos de funcionamento, para que possam realizar a tarefa de integração das redes de transporte ópticas às redes convencionais, com o objetivo de construir desta maneira uma rede única. Neste capítulo também são analisadas as principais alternativas de mecanismos de roteamento existentes que podem ser aplicadas aos planos de controle das redes integradas, e as abordagens necessárias para atender os requisitos de engenharia de tráfego exigidos por estas redes. O capítulo 4 define a arquitetura PCE, apresenta suas características e seu funcionamento como mecanismo de roteamento para as redes integradas, bem como a descrição detalhada do seu principal protocolo, o PCE Protocol, o qual será objeto de análise. No capítulo 5 é apresentada uma proposta de extensão para o PCE Protocol, para que o mesmo possa ter a capacidade de lidar com determinados requisitos de QoT, peculiares das redes ópticas. No capítulo 6 são realizadas análises para verificação da influência do PCE, com relação ao tráfego que o mesmo gera. É utilizado o protocolo na sua forma original, e, em seguida, a extensão proposta do mesmo, apresentada nos capítulos anteriores, para que possam ser comparados. O capítulo 7 apresenta as conclusões e considerações finais a respeito do trabalho, incluindo as principais contribuições obtidas e sugestões para trabalhos futuros. 


\section{Definições e Conceitos Relacionados Às Redes Ópticas}

As redes ópticas se baseiam no paradigma dos sistemas de comunicação óptica, onde a transmissão de dados é realizada através de pulsos de luz, e são utilizados comprimentos de onda específicos do espectro eletromagnético, únicos capazes de serem empregados com sucesso para realização da transmissão de informação. Neste sistema o elemento responsável pela emissão da luz é um laser ou um led que, por meio de mecanismos de modulação, emitem os dados como pulsos de luz, através de uma guia de onda chamada fibra óptica, até o elemento receptor, que é um detector óptico como um fotodiodo. Esta guia de onda condutora, a fibra óptica, é formada por uma casca e por um núcleo, normalmente feitos de sílica, onde a casca possui índice de refração menor que o núcleo para que a luz esteja confinada no mesmo através de um fenômeno chamado de reflexão total, que é obtido com a introdução do feixe de luz na fibra a um determinado ângulo denominado ângulo crítico.

Durante o trajeto esta luz perde potência por diversos fatores, que limitam, desta forma, a qualidade do sinal e o alcance da transmissão, ou seja, a distância do enlace, bem como podem aumentar também a taxa de erros no elemento receptor. Estes fatores limitantes são os tipos de dispersão (modal, cromática e por modo de polarização), a atenuação, a absorção e os efeitos não-lineares que aparecem sob certas condições, além de macro-curvaturas e micro-curvaturas que podem ocorrer na fibra ao longo do enlace, por fatores externos diversos, e durante o processo de fabricação respectivamente (GORALSKI, 2001).

Com o objetivo de obter transmissões ópticas alcançando as maiores distâncias possíveis e compensando as perdas devidas aos fatores mencionados, os amplificadores de sinais são utilizados nos enlaces das redes. Estes amplificadores têm a capacidade de regenerar o sinal corrigindo sua amplitude, sua temporização e seu formato, porém os mesmo devem transformar o sinal óptico em elétrico para conseguir operar. Esta conversão não é interessante nas redes ópticas, pois a mesma faz com que a transparência e velocidade da transmissão sejam perdidas. 
Surgem então os amplificadores ópticos, sendo importante observar que os mesmos são elementos essenciais que viabilizam uma transmissão em um enlace óptico como conhecemos hoje, pela sua capacidade de amplificar sinais de forma transparente, ou seja, totalmente no domínio óptico, sem a necessidade de conversão O-E-O (óptico/elétrico/óptico). Permitem desta forma a utilização da velocidade de transporte óptica sem interferir nesta transmissão, o que poderia introduzir um gargalo no sistema (GORALSKI, 2001).

O início dos estudos da propagação da luz em fibras ópticas data da década de 60 e os primeiros sistemas desenvolvidos na prática são da década de 70 (ABELÉM; STANTON, 2002). Sendo assim, até hoje, foi desenvolvida uma quantidade grande de material didático e técnico com o objetivo de explicar o funcionamento destes sistemas, os seus principais problemas e desafios, bem como a solução de muitos deles, e toda a sua evolução ao longo destas décadas. Como este trabalho não se propõe a detalhar os princípios de funcionamento da transmissão óptica, são algumas referências para o aprofundamento no assunto (GOFF, 2002; GORALSKI, 2001; RAMASWAMI; SIVARAJAN, 2002).

\subsection{Transporte de Dados nas Redes Ópticas}

O cenário apresentado na introdução deste trabalho demonstrando a necessidade de alta capacidade de banda e o tratamento diferenciado para tipos distintos de tráfego, com requisitos particulares de qualidade de serviço, fez com que as previsões de alguns anos atrás, onde se esperava que a alta capacidade das fibras ópticas suprissem facilmente a demanda de tráfego atual, não se concretizassem.

Como alternativa a este novo cenário, surgem algumas opções que podem suprir esta demanda crescente, podendo-se destacar o lançamento de novas fibras, o aumento na taxa de transmissão e a utilização de vários comprimentos de onda transportando informações em uma mesma fibra. 
O lançamento de novas fibras se mostra uma alternativa custosa que faz sentido quando se fala em aumentar a malha atual e não em aumentar a capacidade de transmissão da malha já existente lançando fibras pelos mesmos caminhos aonde já existem fibras. Ou seja, as fibras lançadas atualmente possuem capacidade de banda ociosa, visto que cada fibra pode transportar um tráfego da ordem de Tbps e os sistemas de transmissão podem chegar, atualmente, a transmitir em uma velocidade de até 40 Gbps comercialmente. Porém, segundo Alacatel ${ }^{1}$, experimentos muito recentes conseguiram a transmissão de 25,6 Tbps, utilizando 160 canais através de três enlaces de $80 \mathrm{Km}$.

Tabela 2.1 - Hierarquia Sonet/SDH

\begin{tabular}{|l|l|l|l|}
\hline Optical level & SONET level (electrical) & SDH level (electrical) & Data rate (Mbps) \\
\hline OC-1 & STS-1 & - & 51.840 \\
\hline 0C-3 & STS-3 & STM-1 & $\mathbf{1 5 5 . 5 2 0}$ \\
\hline OC-9 & STS-9 & STM-3 & 466.560 \\
\hline 0C-12 & STS-12 & STM-4 & $\mathbf{6 2 2 . 0 8 0}$ \\
\hline OC-18 & STS-18 & STM-6 & 933.120 \\
\hline OC-24 & STS-24 & STM-8 & 1.244 .160 \\
\hline OC-36 & STS-36 & STM-12 & 1.866 .240 \\
\hline 0C-48 & STS-48 & STM-16 & 2.488 .320 \\
\hline OC-96 & STS-96 & STM-32 & 4.976 .640 \\
\hline 0C-192 & STS-192 & STM-64 & $\mathbf{9 . 9 5 3 . 2 8 0}$ \\
\hline OC-768 & STS-768 & STM-256 & $\mathbf{3 9 . 8 1 3 . 1 2 0}$ \\
\hline OC-N & STS-N & STM-N/3 & N551.840 \\
\hline
\end{tabular}

PERROS, G.H. Connection-Oriented Networks: SONET/SDH, ATM, MPLS and Optical Networks. Chichester, England: John Wiley \& Sons Ltd, 2005. 356 p.

As taxas de transmissão apresentadas na Tabela 2.1 podem ser obtidas através da utilização de sistemas de transmissão de alta velocidade sobre uma infra-estrutura de fibras ópticas, como o SDH (Synchronous Digital Hierarchy) e o Sonet (Synchronous Optical Network).

O SDH, padronizado internacionalmente pela ITU-T (International Telecomunications Union - Telecommunications Standardisation Sector), e adotado na Europa, Japão e

\footnotetext{
${ }^{1}$ ALCATEL. Alcatel-Lucent achieves a world record 25.6 Terabit/s optical transmission. Anaheim, USA, 2007. Notícia publicada em: www.alcatel.com. Acessada em: Abril, 2007.
} 
Brasil, e o Sonet, padronizado pela ANSI (American National Standards Institute) e adotado nos Estados Unidos, podem ser descritos, de forma básica, como sistemas síncronos de hierarquia digital que têm como característica a multiplexação de canais de menor velocidade em canais de maior velocidade, apresentando, como resultado final, altas taxas de transmissão através de fibras ópticas. Ambos os sistemas possuem uma taxa básica de transmissão, sendo 51,840 Mbps para o Sonet e 155,52 Mbps para o SDH, e a partir destas taxas ocorre o mecanismo hierárquico de transporte realizando a multiplexação e transportando em taxas cada vez maiores até os limites indicados na Tabela 2.1 (PERROS, 2005; GORALSKI, 2001; GILLESPIE, 2001).

Com o aumento da taxa de transmissão percebe-se problemas que até então não eram percebidos com taxas menores, como o surgimento dos efeitos não lineares nas fibras ópticas, que afetam diretamente a qualidade da forma de onda e também a dispersão por modo de polarização (PMD - Polarization Mode Dispersion), limitando desta forma a distância da transmissão para que o sinal não seja degradado, além de interferir negativamente na máxima taxa de transmissão e no aumento da taxa de erros.

Uma alternativa a esta limitação é a transmissão de mais de um comprimento de onda, ou seja, mais de um canal, de forma simultânea, em uma única fibra óptica. Neste mecanismo, cada canal é capaz de transportar uma determinada taxa de transmissão, e o total de canais possíveis em uma fibra é o total da banda de transmissão disponível. Pode-se citar como exemplo a transmissão de 4 canais de 2,5 Gbps de forma simultânea totalizando uma transmissão de 10 Gbps em uma única fibra óptica. Este mecanismo de transporte é conhecido como WDM (Wavelenght Division Multiplexing) e o mesmo possui variações como o DWDM (Dense Wavelenght Division Multiplexing), e o CWDM (Coarse Wavelenght Division Multiplexing) (GORALSKI, 2001; RAMASWAMI; SIVARAJAN, 2002). A figura 2.1 apresenta a evolução do sistema WDM, descrito a seguir.

Este sistema foi desenvolvido no início da década de 80 utilizando dois comprimentos de onda nas faixas de $850 \mathrm{~nm}$ e $1310 \mathrm{~nm}$, e era chamado de wideband 
WDM. Neste sistema eram utilizados dois pares de fibras onde um deles era para a transmissão e o outro para a recepção. No começo da década de 90 a segunda geração WDM foi desenvolvida com a utilização de 2 a 8 canais distintos, onde estes canais tinham um espaçamento de $400 \mathrm{Ghz}$ na janela de $1550 \mathrm{~nm}$, e era chamado de narrowband WDM.

Na metade desta década surgiu o WDM denso (DWDM) com a utilização de 16 a 40 canais com um espaçamento de 100 a $200 \mathrm{Ghz}$. Esta tecnologia foi evoluindo para o final dos anos 90 com 64 a 160 canais espaçados em intervalos de 50 até $25 \mathrm{Ghz}$. Potencialmente os sistemas DWDM podem possuir até 400 canais em intervalos de até $10 \mathrm{Ghz}(0,1 \mathrm{~nm})$, porém os resultados em laboratório obtidos atualmente (Março, 2007) alcançaram os valores de 25,6 Tbps utilizando 160 canais em apenas uma fibra óptica, conforme citado anteriormente.

O CWDM apareceu como uma alternativa menos custosa em relação ao DWDM onde a principal diferença é a utilização de 8 canais com um espaçamento de $20 \mathrm{~nm}$ entre estes canais, muito diferente do espaçamento de $0,1 \mathrm{~nm}$ do DWDM descrito anteriormente. Desta maneira o sistema CWDM não requer lasers tão precisos quanto o DWDM, pois seus canais não estão tão próximos entre si.

Enquanto os sistemas WDM foram evoluindo em sua capacidade de transmissão de canais de forma simultânea eles também evoluíram em termos de flexibilidade de configuração, com a introdução de funções de manipulação de comprimentos de onda, como a retirada e o acréscimo de comprimentos de onda em uma rede, e também com habilidades de gerenciamento deste sistema. 


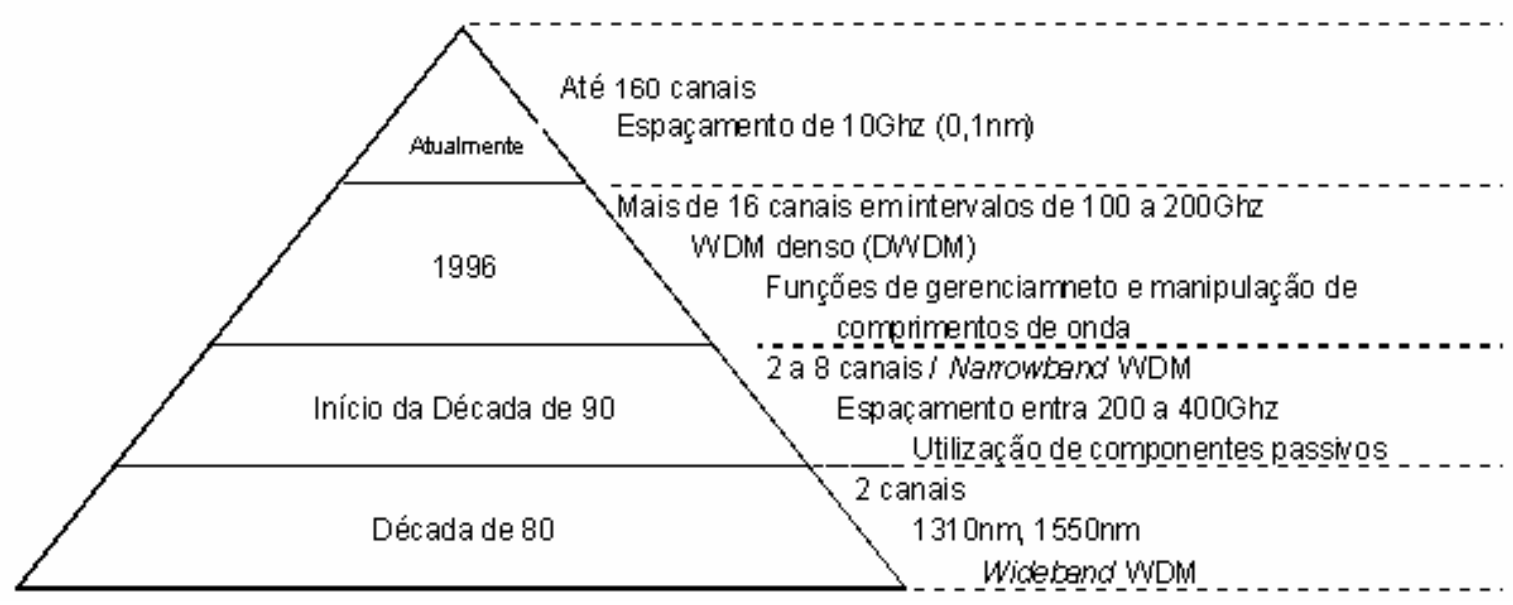

Figura 2.1 - Evolução do WDM

Esta tecnologia trouxe uma evolução para o transporte de dados em redes ópticas, porém ela também apresenta algumas dificuldades inerentes a este mundo de transmissão óptica e que devem ser cuidadosamente equacionadas em cada projeto. As principais dificuldades que devem ser analisadas são a oscilação de determinadas variáveis no transporte do tráfego, como o aumento da taxa de transmissão e o aumento do número de canais, ou comprimentos de onda na mesma fibra, onde o espaço entre estes comprimentos de onda diminuí. Ambas variáveis podem atuar negativamente, em conjunto ou não, com a velocidade de transmissão. Além destas há os limites para a máxima potência de transmissão a ser empregada em cada canal, bem como a característica peculiar do tráfego em rajadas que em determinado momento utiliza pouco o canal e em outro momento inunda este canal com uma quantidade enorme de bits. De acordo com a quantidade de bits injetada nos canais as variáveis de potência, taxa de transmissão e número de canais na fibra sofrem determinadas interferências, sendo que estas são percebidas diretamente na qualidade da transmissão (ZHANG; TANG, 2001).

Estas dificuldades são objeto de estudos contínuos, com o objetivo de maximizar as distâncias cobertas por uma transmissão óptica, com o maior número de canais, e na maior velocidade possível, que possa garantir a qualidade do sinal na recepção do mesmo. 
Apesar dos aspectos negativos citados, a utilização do DWDM ainda oferece a possibilidade de um melhor aproveitamento da capacidade de transmissão disponível em uma fibra óptica, a qual fornece uma banda que alcança a ordem de grandeza de Tbps. Além do acréscimo da capacidade de transmissão em uma mesma fibra óptica, há uma característica muito importante neste sistema de transporte que é a habilidade de carregar cada sinal de forma independente dos demais. Desta maneira um sistema DWDM permite que cada sinal possa ser transmitido com velocidades distintas e também com tipos de transmissão distintos, ou seja, podem ser transmitidos vários protocolos, de forma transparente na fibra, portanto verifica-se outra característica muito importante que é a independência de protocolos (ZHANG; TANG, 2001).

Sendo esta a tecnologia que realmente demonstra o potencial de utilizar a banda passante disponível nas fibras ópticas, e que no momento, apesar de não atingir toda esta capacidade, é a que pode alcançar a maior taxa de transmissão, ao mesmo tempo que permite transparência com relação ao tráfego transportado, verifica-se que ela se torna uma boa alternativa para ser implantada como infraestrutura para as redes de transporte ópticas.

Porém todas as redes implementadas anteriormente, principalmente aquelas com tecnologia Sonet/SDH, ainda estão em plena produção em muitas empresas responsáveis pelo transporte de dados, como as grande operadoras. Estas redes ainda atendem bem a uma determinada parte do tráfego existente atualmente, como o tráfego de voz, e possuem a confiabilidade de serem redes estruturadas e experimentadas ao longo do tempo, sendo assim são redes ainda eficientes para muitas aplicações. Esta característica faz com que a substituição imediata por outra tecnologia não ocorra, e seja muito bem estudada, sendo que muitas vezes tecnologias distintas deverão coexistir operando através da integração entre elas. 


\subsection{Elementos Habilitadores nas Redes Ópticas}

As tecnologias de transporte de dados nas redes ópticas citadas possuem elementos habilitadores que viabilizam a sua implementação, permitindo desta forma o funcionamento destas redes. Estes elementos foram criados e desenvolvidos ao longo do tempo, sendo que as tecnologias empregadas nas primeiras implantações de redes ópticas evoluíram bastante até este momento. Uma breve apresentação dos principais elementos utilizados nestas redes é realizada a seguir, e maiores detalhes sobre o funcionamento destes elementos são descritos em (MUKHERJEE, 1997).

Os acopladores, como o PSC (Passive Star Coupler), têm a função de combinar comprimentos de onda em uma única fibra óptica e também de dividir os comprimentos de onda desta fibra. É um dispositivo de broadcast onde todas as saídas apresentam o comprimento de onda que foi injetado na sua entrada, com a potência igualmente dividida entre estas saídas, e é utilizado em redes broadcast and select. Uma estrela passiva com $\mathrm{N}$ entradas e $\mathrm{N}$ saídas ( $\mathrm{NxN}$ ) tem a capacidade de rotear $\mathrm{N}$ conexões simultâneas, contando que haja tantos comprimentos de onda disponíveis para a transmissão quanto o número de portas.

O roteador passivo, como o Latin Router, WGR (Waveguide Grating Router) e o WR (Wavelenght Router), possui uma tabela de roteamento fixa e tem a capacidade de enviar para saídas distintas um comprimento de onda que incide em uma única entrada, permitindo que um único comprimento de onda possa transmitir várias conexões através do roteador, ou seja, reutilizando um determinado comprimento de onda na transmissão.

Existem os comutadores ativos, como o WRS (Wavelenght-routing switch) e o WSXC (Wavelenght-selective crossconnect), com a mesma capacidade de conexões do roteador passivo, porém com a vantagem de não operar com uma matriz de roteamento fixa, ou seja, permitindo a reconfiguração sob demanda. Pode oferecer 
uma vantagem adicional que é a capacidade de conversão de comprimento de onda, onde um comprimento de onda é transformado em outro na saída para evitar a contenção e otimizar recursos da rede. Esta capacidade de conversão de comprimento de onda pode ser obtida através de comportamentos muitas vezes indesejados em uma fibra óptica como o FWM (Four Wave Mixing), e há vários estudos neste sentido a fim de se obter conversões cada vez mais eficientes (LACEY; MADDEN, 1998; OBERMANN et al., 1998; HUDGINGS; LAU, 1998; BOFFI; MARAZZI; MARTINELLI, 1999; LEUTHOLD et al., 1999).

Nestas redes também existem os elementos básicos de construção onde a estrutura macro depende deles para garantir o desempenho do sistema como um todo. Podem ser citadas as tecnologias de lasers fixos e sintonizáveis, onde os fixos permitem a emissão de apenas um valor de comprimento de onda e os sintonizáveis permitem que seja escolhido o comprimento de onda através da sintonia realizada por meio mecânico, elétrico-óptico, acústico-óptico ou por injeção de corrente, cada qual com suas características de tempo de sintonia e intervalo de comprimentos de onda sintonizáveis.

Outro elemento importante que deve ser utilizado de acordo com os requisitos de projeto por possuir diferentes características é o filtro óptico que atua como receptor óptico sintonizável, podendo-se citar Fabry-Perot, acústico-óptico, eletro-óptico e Fabry-Perot de cristal líquido. Há os filtros ópticos fixos como os filtros de grade de Bragg a fibra e os de interferência em filme fino.

Os amplificadores ópticos, conforme descrito brevemente, são dispositivos fundamentais na implantação das redes ópticas, de forma que os mesmos minimizam a necessidade de repetidores ao longo da fibra permitindo a transmissão a longas distâncias antes da regeneração do sinal, diminuindo também a necessidade da conversão O-E-O (óptico/elétrico/óptico). Um tipo de amplificador importante é aquele que utiliza fibras ativas, ou fibras dopadas e um laser de bombeamento, como o EDFA (Erbium Dopped Fiber Amplifier). Este amplificador possui uma característica muito interessante e fundamental, que é operar na mesma 
região de comprimentos de onda utilizados pelos sistemas DWDM, e poder amplificar todos os sinais simultâneamente, de forma idêntica, permitindo o uso de apenas um amplificador em uma estação intermediária do enlace para reforço do sinal. Outro amplificador óptico relevante é o amplificador a laser semicondutor.

\subsection{Disponibilidade de Comprimentos de Onda}

Nas redes ópticas os equipamentos de comutação possuem dispositivos específicos, os transmissores, que são os transceivers ou transponders, para enviar o sinal necessário à comunicação que é o comprimento de onda, ou lambda.

Verifica-se que em um LSP (Label Switch Path) qualquer, o qual utiliza o domínio óptico para conectar dois nós da rede, os canais dentro deste domínio óptico são constituídos por comprimentos de onda. Em uma rede onde existem muitos nós que requisitam conexões de forma dinâmica surge a necessidade de que sejam configurados tantos LSPs quanto for o número de conexões requisitadas, e desta maneira o domínio óptico deve atender a estas requisições através da realização de conexões entre seus nós utilizando os comprimentos de onda que estão disponíveis nos equipamentos de comutação desta rede óptica.

Percebe-se que para se estabelecer tantos LSPs conforme as requisições geradas deve haver uma quantidade de comprimentos de onda disponível que seja suficiente para atender todas as requisições, ou seja, deve existir um número suficiente de transmissores em cada elemento da rede óptica, cada um capaz de transmitir um comprimento de onda, que seja o mesmo que o número de nós da rede menos um, conforme apresentado na figura 2.2. Considerando uma rede com $\mathrm{N}$ nós, deve-se ter $\mathrm{N}-1$ comprimentos de onda disponíveis para atender todas as requisições de LSPs entre todos os nós desta rede (MUKHERJEE, 1997). 


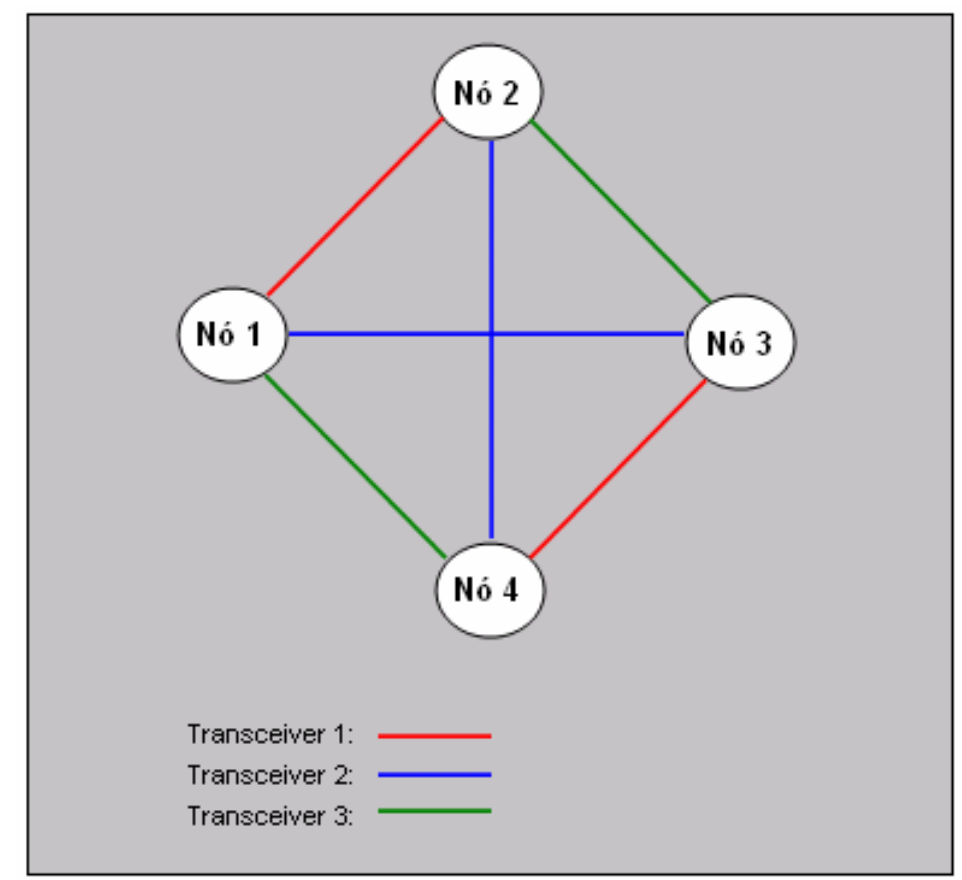

Figura 2.2 - Rede com 04 nós e 03 comprimentos de onda disponíveis

Porém existem certas dificuldades de configuração que aparecem na prática devido a fatores como os descritos a seguir.

O número de nós de uma rede pode aumentar a qualquer instante devido a característica de escalabilidade das redes, e neste caso surge a necessidade de se aumentar a quantidade de transmissores nos elementos de rede, de acordo com o número de nós, para possibilitar que novas conexões possam ser realizadas através de novos comprimentos de onda que serão inseridos na rede. A dificuldade de configuração destes comprimentos de onda através da inserção de novos transmissores é um indicador abstrato, porém esta dificuldade existe na prática, além do alto custo destes transmissores, o qual é um indicador concreto. Verifica-se portanto que a inserção de novos transmissores é uma alternativa possível porém que não é viável no caso de redes muito grandes, pois existem estes aspectos negativos neste tipo de solução para conectar os elementos do domínio óptico.

A própria tecnologia de transmissão óptica apresenta fatores limitantes ao uso de uma quantidade ilimitada de comprimentos de onda nas conexões, ou seja, há um limite para o número de comprimentos de onda que podem ser multiplexados em 
uma única fibra óptica, onde a mesma é capaz de transportar uma quantidade limitada de canais, sendo atualmente algumas dezenas, conforme descrito anteriormente, devido a características desta fibra, como as dispersões e os efeitos não lineares, entre outros.

Uma alternativa à inserção de novos transmissores para aumentar a quantidade de comprimentos de onda, e consequentemente diminuir a probabilidade de bloqueio de estabelecimento de caminhos ópticos, é a utilização de elementos capazes de converter o comprimento de onda ao longo do caminho. No caso de recursos de rede escassos, ou seja, um número limitado de comprimentos de onda disponíveis, estes elementos podem realizar a conversão da freqüência do sinal em determinados nós da rede, que possuírem esta capacidade. Este elemento recebe o sinal de um determinado enlace na sua entrada e, caso não seja possível a continuidade do trajeto com este sinal, ele converte o mesmo para uma freqüência que não esteja sendo utilizada no enlace seguinte, conforme apresentado na figura 2.3 a seguir, onde o nó 3 converte o sinal azul para vermelho, garantindo desta forma a continuidade do caminho e o estabelecimento da rota fim-a-fim, evitando o bloqueio.

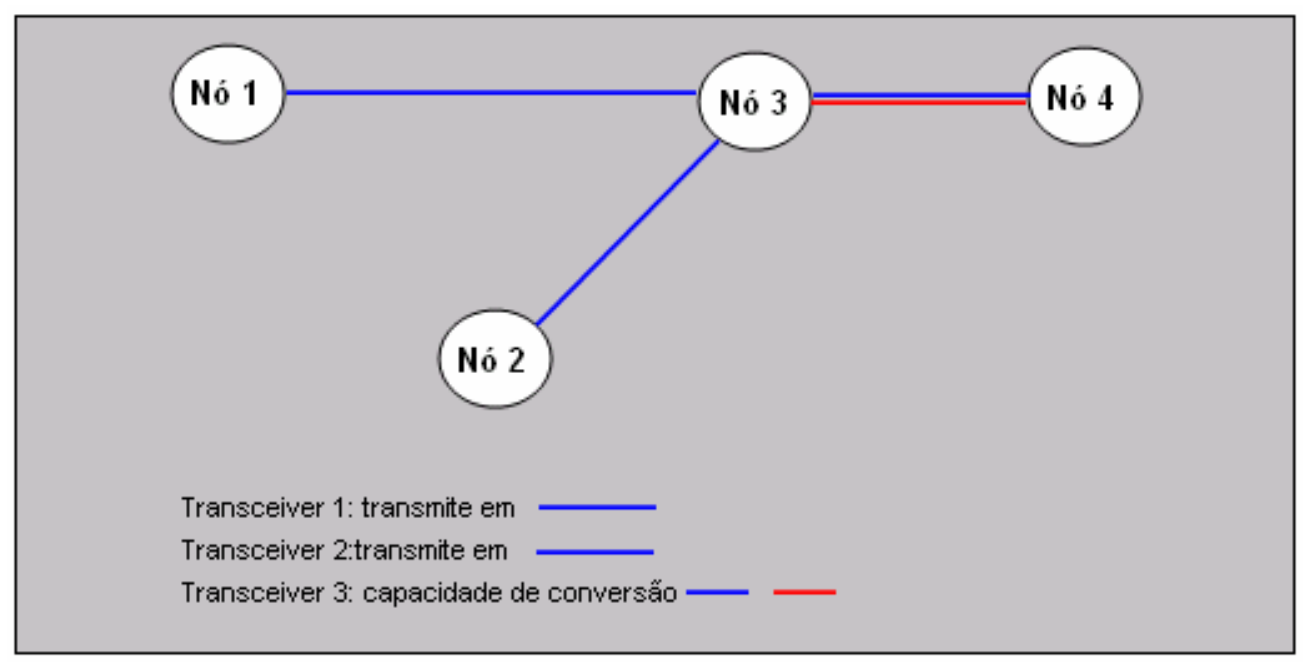

Figura 2.3 - Rede com capacidade de conversão de comprimento de onda

A utilização desta alternativa pode apresentar certa dificuldade com relação à quantidade de conversões de comprimento de onda realizadas ao longo do caminho óptico. Esta dificuldade está diretamente relacionada ao fator de degradação óptica 
que limita a quantidade de conversões de comprimento de onda através dos enlaces, e desta forma, está diretamente relacionado com a quantidade total de enlaces que podem ser utilizados em uma transmissão limitando a distância alcançada pelo caminho óptico.

O tipo de tráfego também aparece como uma dificuldade visto que a diferença de comportamento que pode ocorrer entre os canais devido à característica distinta dos tráfegos em rajadas por exemplo, cria determinadas situações onde se tornam muito relevantes questões como o dimensionamento do comprimento total de um enlace óptico, a quantidade de comprimentos de onda a ser transmitida de forma simultânea em uma fibra e a potência a ser utilizada nos canais (ZHANG; TANG, 2001).

Dadas as possíveis dificuldades apresentadas, verifica-se que dentro do domínio óptico, um dos problemas é a descoberta de uma forma de se obter conexões para LSPs que são requisitados através de um número limitado de comprimentos de onda disponíveis nos elementos da rede óptica. Os LSPs devem ser estabelecidos através de rotas determinadas pelos comprimentos de onda disponíveis, além do que estas rotas devem ser configuradas com o objetivo de otimizar os recursos de rede, ou seja, maximizando a quantidade de LSPs possíveis.

Conforme apresentado, o objetivo é evitar a qualquer custo o bloqueio, ou negação, de uma conexão, que pode se dar pela falta de comprimento de onda disponível em um determinado enlace, visto que em uma fibra podem trafegar apenas determinados valores de comprimentos de onda.

Como ilustração, a seguir são apresentadas as configurações mais comuns utilizadas dentro do domínio óptico e os principais algoritmos de roteamento utilizados especificamente com estas configurações (MUKHERJEE, 1997). Importante verificar que o objetivo destas configurações e seus algoritmos é 
conseguir a conectividade através dos comprimentos de onda disponíveis para que o bloqueio seja evitado.

- Singlehop Networks: as redes de um lance único têm como característica possuir todos os nós conectados, através de uma estrela passiva (ver item 2.2), sem que haja nós intermediários para realizar a comunicação entre qualquer par de nós nesta rede, conforme apresentado na figura 2.4.

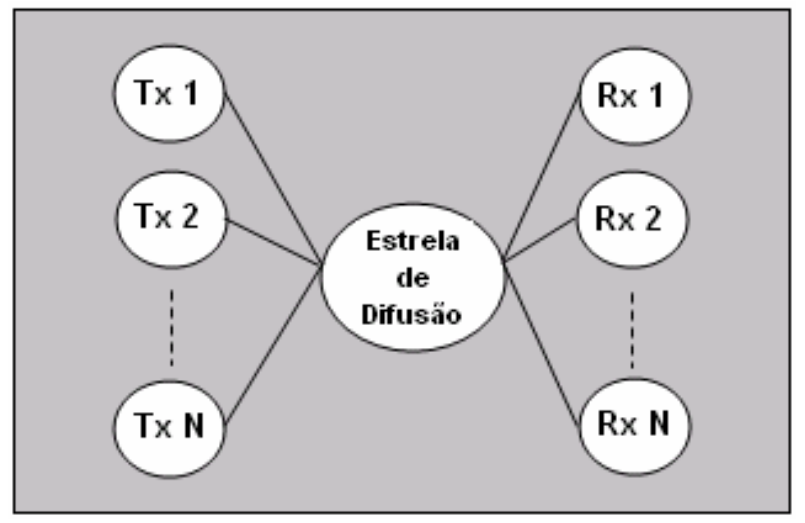

Figura 2.4 - Rede Singlehop

Neste tipo de configuração os transmissores e receptores devem ser capazes de sintonizar de forma rápida os diferentes comprimentos de onda, ou canais, para que os pacotes possam ser enviados e recebidos de forma satisfatória, porém normalmente a velocidade dos pacotes é maior que a velocidade de chaveamento dos comprimentos de onda executado pelos elementos da rede. Esta questão faz surgir a necessidade de que sejam desenvolvidos protocolos que sejam capazes de coordenar de forma eficiente todo o mecanismo de transmissão dos dados. Estes protocolos atuam no domínio óptico e podem ser classificados conforme a figura 2.5 a seguir: 


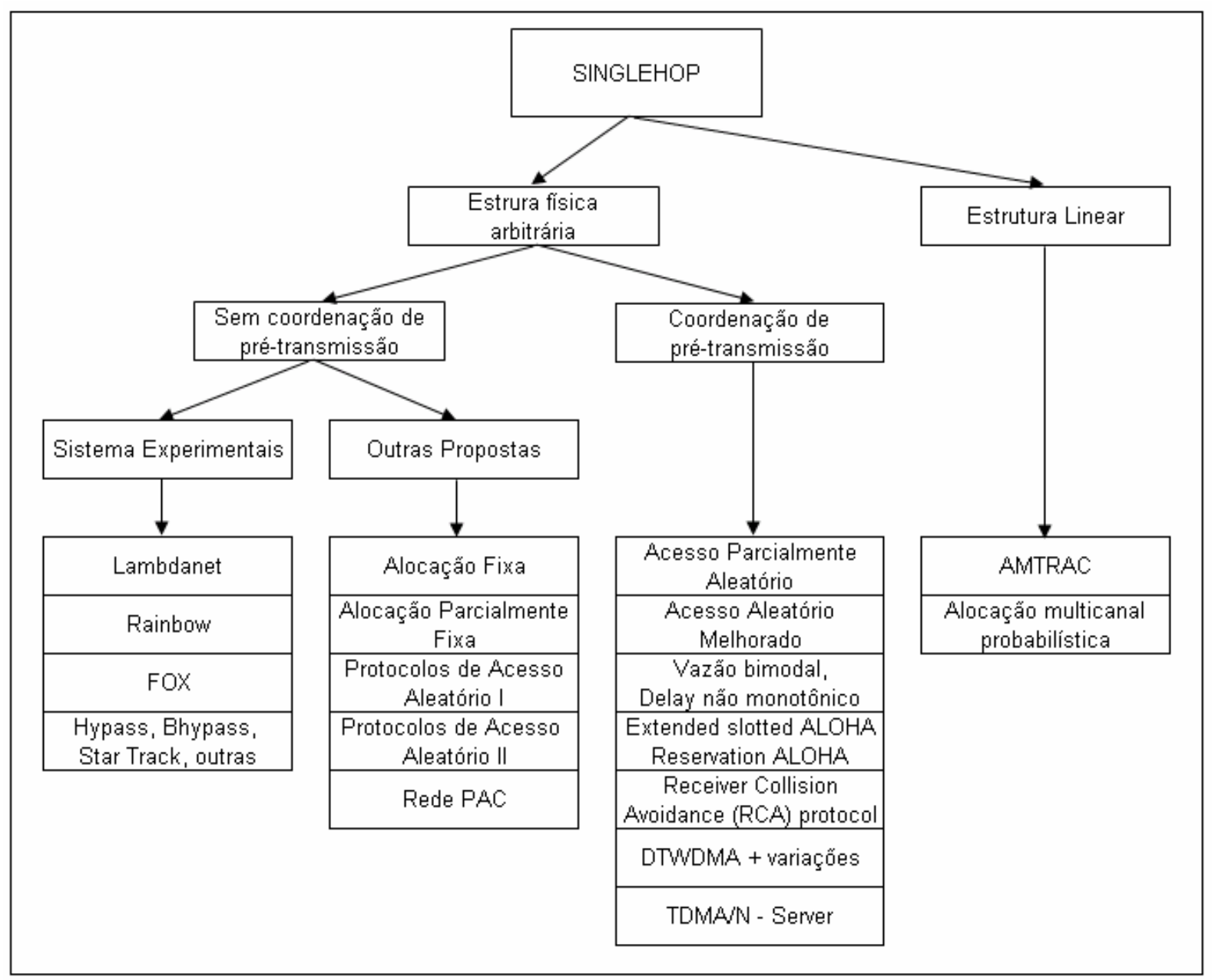

Figura 2.5 - Protocolos singlehop do domínio óptico

MUKHERJEE, B. Optical Communications Networks. Ontario, Canada: McGraw-Hill, 1997. 576 p.

- Multihop Networks: as redes de múltiplos lances têm como característica principal o aspecto que os comprimentos de onda, ou canais, são relativamente estáticos na rede, e desta forma não é muito provável que cada um destes nós possua um caminho direto para a comunicação com todos os demais. O que ocorre é a configuração de uma topologia virtual onde um mecanismo de roteamento faz com que cada nó da rede possa encaminhar os dados para outro nó, e assim por diante até alcançar o destino final. Neste sistema a alocação de um comprimento de onda, ou canal, como é relativamente estático, e os tempos de sintonia, de forma diferente das redes singlehop, não têm um impacto muito grande. O que surge agora são várias alternativas de caminhos entres dois nós que desejam se comunicar, conforme apresentado na figura 2.6 a seguir. Esta configuração traz consigo o problema de roteamento, ou seja, através das métricas da rede como o número de 
lances, a taxa de transmissão, o atraso médio, entre outras, serão definidos os melhores caminhos.

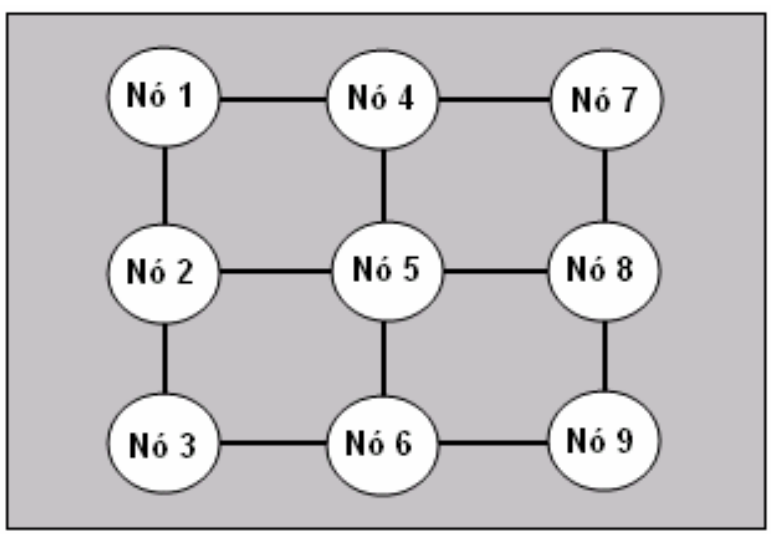

Figura 2.6 - Rede Multihop

Estas redes podem variar em suas estruturas e a forma de roteamento em cada uma delas. A figura 2.7 a seguir apresenta a classificação das redes multihops.

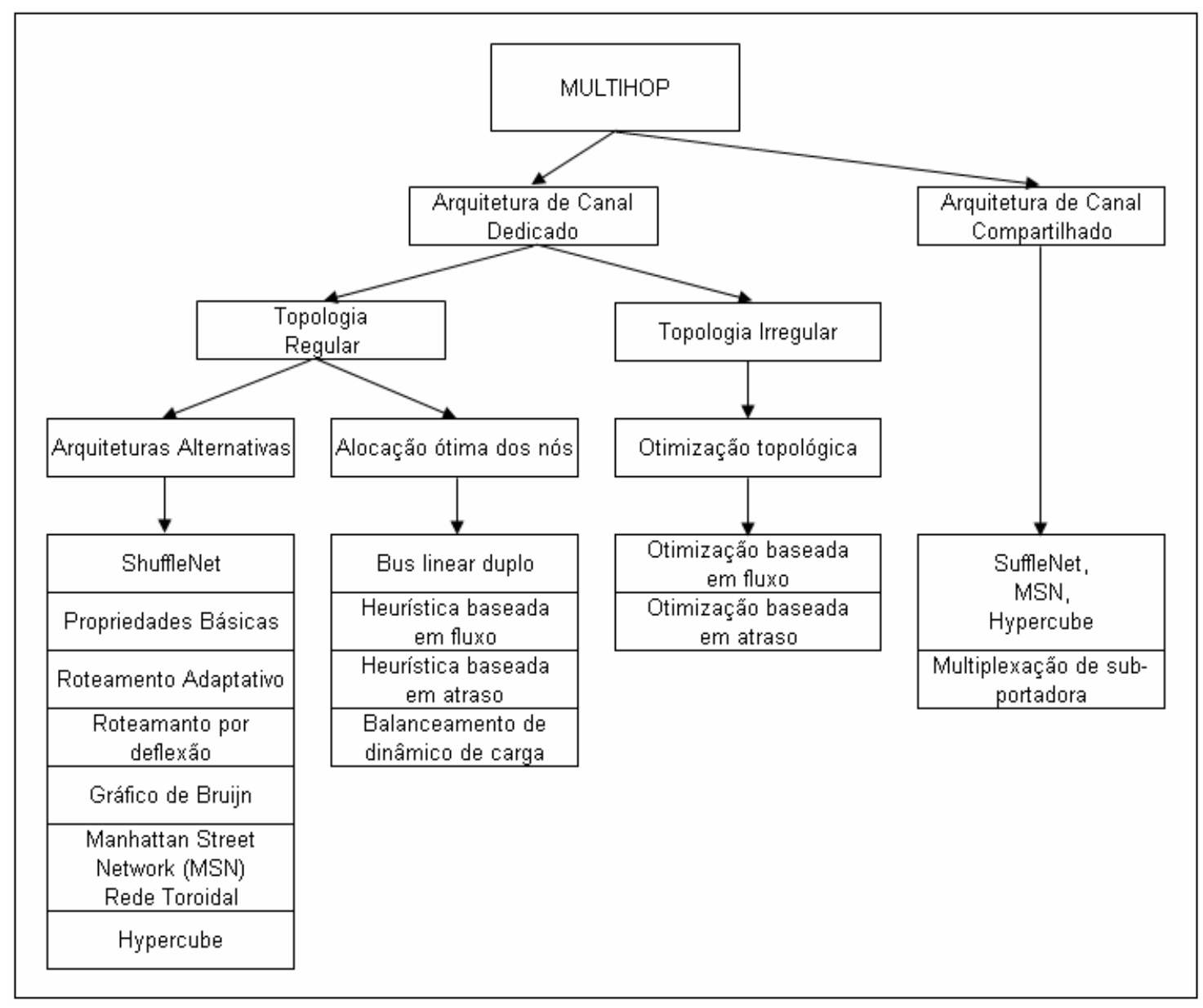

Figura 2.7 - Protocolos multihop do domínio óptico

MUKHERJEE, B. Optical Communications Networks. Ontario, Canada: McGraw-Hill, 1997. 576 p. 


\subsection{Qualidade do Sinal Óptico}

A qualidade do sinal óptico está relacionada à qualidade de transmissão (QoT) e conforme o objetivo definido neste trabalho, deve ser considerada como um parâmetro importante para o mecanismo de roteamento de uma rede integrada.

\subsubsection{Qualidade do Sinal Óptico e Qualidade de Serviço}

Espera-se que as atividades de planejamento e de implantação das redes ópticas tenham a responsabilidade, e sejam competentes o suficiente, para equacionar e prover as soluções necessárias para os problemas físicos que podem ocorrer em uma transmissão óptica, no sentido de oferecer uma topologia de rede adequada e funcional. Este planejamento deve lidar com todas as situações de degradação óptica no sentido de oferecer disponibilidade total, de todos os trajetos selecionáveis pelo processo de roteamento, ou seja, para que todos eles possam realmente ser utilizados caso sejam selecionados, com a qualidade esperada, sem problemas de degradação de sinal, que podem resultar em aumento das taxas de erro e até da impossibilidade em utilizar certo caminho.

Esta situação pode variar muito de acordo com o objetivo de determinado domínio, dentro de cada rede de óptica. Pode-se verificar que para redes que não têm a intenção de crescer mais do que uma transmissão de 2,5 Gbps, não há muita dificuldade no seu planejamento com o objetivo de oferecer canais utilizáveis e disponíveis, porém no caso de redes maiores, de grandes troncos internacionais por exemplo, há a necessidade de um planejamento muito cuidadoso dos domínios ópticos dentro desta rede, para que os canais disponíveis sejam realmente executáveis na prática, levando-se em consideração todos os fatores de degradação descritos a seguir.

Porém esta situação pode ser válida para a implantação de novas redes, mas quando se trata das redes já existentes em operação, verifica-se que o fator tempo 
causa um impacto negativo nestas redes, como o envelhecimento das fibras e o aumento das emendas ao longo dos enlaces. Além disso, a interconexão entre elas, com a presença de uma diversidade de equipamentos de transmissão, a utilização de tecnologias distintas, vários fabricantes, e fibras ópticas com parâmetros de fabricação distintos, percebe-se que a discussão sobre a qualidade do sinal óptico que deverá trafegar pelos enlaces destas redes se torna um aspecto relevante, e deve ser levado em consideração, para garantir que os caminhos ópticos escolhidos sejam realmente executáveis com taxas de erro aceitáveis.

De uma forma geral, tanto em redes novas quanto em redes que já estão em operação, verificam-se, no mínimo, dois fatores em comum, e importantes no resultado da qualidade da transmissão, sendo um deles a demanda por aumento de banda ao longo do tempo, principalmente devido aos novos perfis das novas aplicações, e o outro a necessidade de aumentar o tamanho dos domínios de transparência do domínio óptico, para aproveitar as vantagens da velocidade da transmissão óptica na fibra sem conversão O-E-O, além de possibilitar a diminuição de custos com a utilização dos amplificadores ópticos. Estes requisitos vão resultar, no final, em acréscimo da potência de transmissão dos nós, em aumento do número de canais na mesma fibra (WDM), e em aumento da quantidade de amplificadores ópticos ao longo dos enlaces. Este processo faz com que apareçam determinados fenômenos na transmissão que inicialmente não existiam como o crosstalk, efeitos não-lineares, e dispersões, entre outros. Devido às suas características, os amplificadores ópticos, em particular, vão eliminar a possibilidade de regeneração do tempo e da forma do sinal, além de introduzir ruído em amplitude no sinal óptico e, consequentemente, levando a uma degradação da relação sinal/ruído (OSNR Optical Signal Noise Rate).

Desta forma, a qualidade da transmissão é ameaçada, fato que anteriormente não ocorria, sem as novas condições impostas com o surgimento das novas variáveis.

Esta discussão é importante no cenário atual onde as aplicações requerem níveis de qualidade de serviço distintos, ou seja, agora não só a questão do bloqueio devido à 
falta de comprimento de onda disponível é relevante, mas a qualidade de serviço entregue para cada aplicação também se torna relevante. De acordo com a taxa de erros, ou do atraso que um determinado caminho apresenta, a aplicação pode sofrer severas conseqüências negativas, e até se tornar não executável, dependendo do nível de qualidade de serviço entregue pela rede e do mínimo exigido pela aplicação.

Em redes ópticas, normalmente os valores das taxas de erro, ou BER (Bit Error Rate), que podem ocorrer nas transmissões estão entre $10^{-9}$ a $10^{-15}$ erros por segundo, sendo tipicamente $10^{-12}$ (RAMASWAMI, R.; SIVARAJAN, 2002).

Estes valores estão diretamente ligados à qualidade do sinal nos enlaces, a qual depende da quantidade de ruído que podem ocorrer nos mesmos, bem como de outros fenômenos que podem degradar o sinal e que estão presentes no sistema de uma forma geral.

\subsubsection{Fatores Relevantes à Qualidade do Sinal Óptico}

A seguir serão apresentados alguns fatores que podem influenciar negativamente a transmissão do sinal óptico e levar à degradação este sinal. Mais adiante, neste trabalho, será abordado o aspecto de como estes fatores deveriam ser tratados pelos mecanismos de roteamento nas redes integradas, a fim de que seus efeitos possam ser considerados na escolha do melhor caminho óptico, visto que eles podem realmente influenciar na transmissão de acordo com os argumentos apresentados nos parágrafos anteriores.

Os fenômenos mais importantes são, basicamente, a atenuação, a dispersão e os efeitos não lineares que podem ocorrer com as transmissões nas fibras ópticas. 


\section{i) Atenuação}

A atenuação consiste na perda de energia do sinal óptico ao longo do caminho, enfraquecendo-o até o ponto em que ele não pode ser reconhecido pelo receptor ou simplesmente este sinal não chega até ele.

As principais causas da atenuação são:

- Absorção: ocorre quando o sinal de luz encontra impurezas no núcleo da fibra e perde parte de sua energia, pois uma parcela deste sinal é absorvida. Os fótons também são absorvidos por elétrons dos átomos constituintes da fibra.

- Espalhamento: devido a pequenas mudanças que podem ocorrer na densidade do material no núcleo da fibra, nas próprias moléculas do vidro, o sinal de luz ao passar por estas regiões sofre um espalhamento para todas as direções, perdendo parte de sua energia.

- Macro curvaturas: qualquer alteração de origem externa como dobras na fibra, pressão, ou nós causam uma alteração no ângulo de incidência do sinal dentro do núcleo que vai desrespeitar o valor do ângulo crítico, fazendo com que este sinal possa escapar do núcleo sendo refratado para a casca, portanto perdendo parte de sua energia.

- Micro curvaturas: são distorções microscópicas, originadas no processo de fabricação, que fazem com que o sinal escape do núcleo para a casca, da mesma forma que ocorre com as macro curvaturas.

A figura 2.8 a seguir, apresenta as curvas das principais causas de atenuação em uma fibra óptica com relação ao comprimento de onda envolvido na transmissão. 


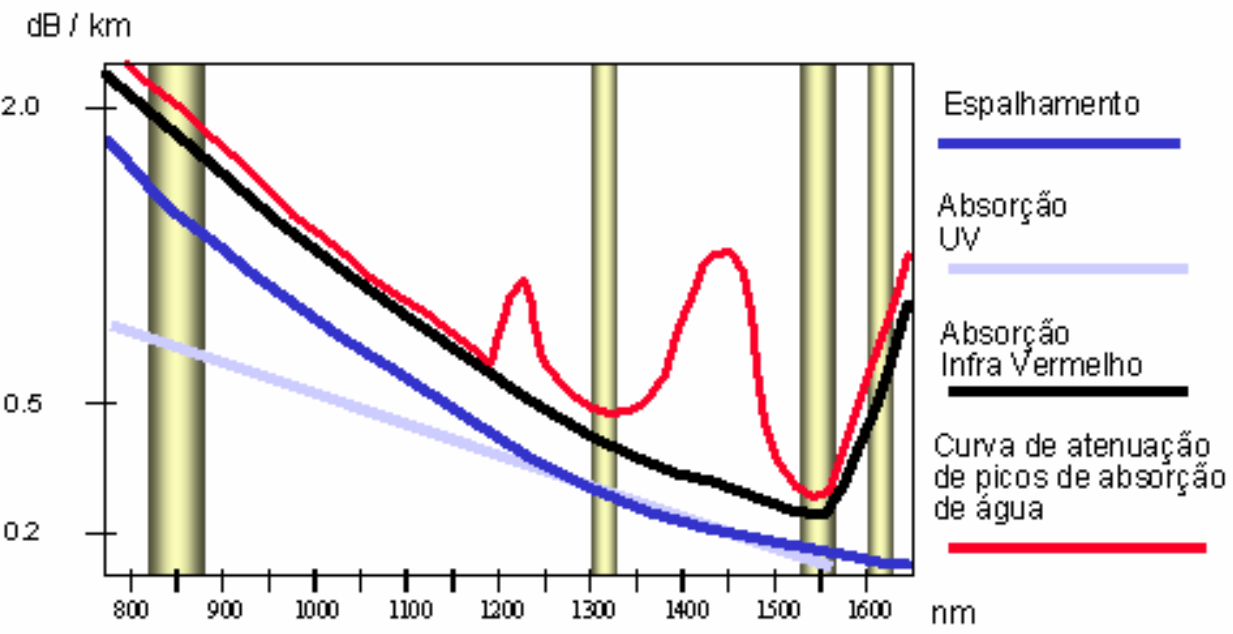

Figura 2.8 - Representação das curvas dos fenômenos ópticos que ocorrem nas janelas de transmissão utilizadas na comunicação óptica

\section{ii) Dispersão}

Dispersão é o nome dado à expansão ou alargamento do pulso de luz do sinal transmitido na fibra óptica devido a determinadas propriedades desta. A figura 2.9 ilustra um sinal deteriorado após passar por um enlace de fibra com problemas de dispersão. O maior impacto negativo causado pela dispersão é a limitação da largura de banda que ela impõe à transmissão.

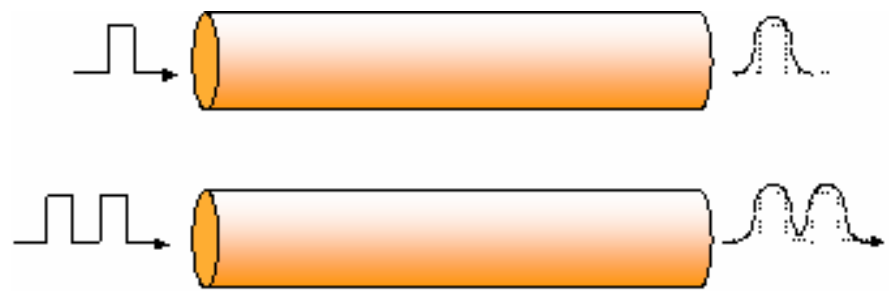

Figura 2.9 - Sinal deteriorado após a passagem por um enlace de fibra óptica

Basicamente, se os pulsos de dados são enviados muito próximos uns dos outros, como acontece em altas taxas de transmissão, e ocorrer dispersão, eles podem se misturar e atrapalhar o receptor na identificação de quando um pulso termina e o outro se inicia, conforme apresentado na figura 2.10. Esta desordem é chamada de interferência inter-simbólica, e causa degradação no desempenho da transmissão. 


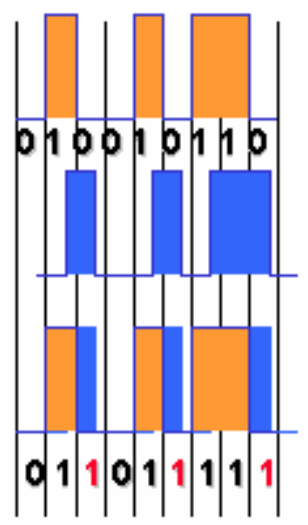

Figura 2.10 - Interpretação incorreta do receptor ao receber um sinal por uma fibra óptica onde ocorreu a dispersão

Existem três tipos principais de dispersão sendo elas a Dispersão Intermodal que pode ocorrer em fibras multímodo e a Dispersão Cromática (CD) e Dispersão por Modo de Polarização (PMD) que podem ocorrer nas fibras monomodo.

- Dispersão Intermodal: A Dispersão Intermodal resulta dos diferentes modos de propagação que um pulso de luz pode ter em uma fibra multímodo, conforme pode ser observado na figura 2.11. Como cada componente do pulso pode pegar um caminho diferente dentro da fibra eles não chegarão no final ao mesmo tempo causando desta forma o alargamento do pulso.

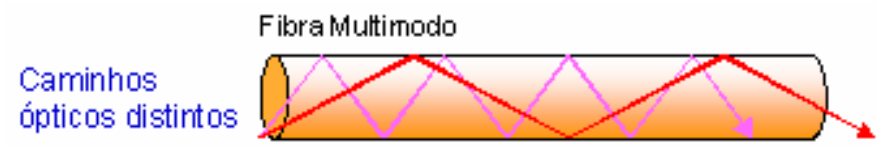

Figura 2.11 - Representação da dispersão intermodal em um enlace de fibra óptica

- Dispersão Cromática: A Dispersão Cromática é resultante das diferentes velocidades que diferentes comprimentos de onda de um pulso de luz trafegam dentro de uma fibra óptica, conforme apresentado na figura 2.12.

Apesar de atualmente os transmissores possuírem espectros de luz muito estreitos, em uma transmissão ainda existem inevitavelmente um pequeno range de 
comprimentos de onda. Devido a estes diferentes comprimentos de onda do sinal transmitido, trafegarem com velocidades distintas, ocorrerá no final o alargamento do pulso.

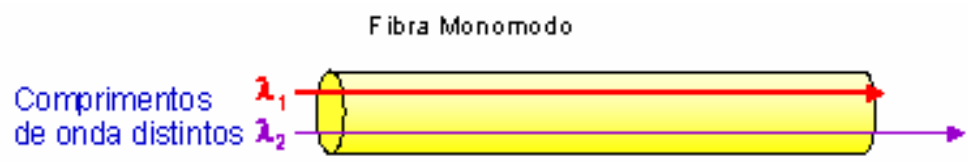

Figura 2.12 - Representação da dispersão cromática em um enlace de fibra óptica

Uma vez que estas propriedades são conhecidas, seus efeitos negativos podem ser removidos ou compensados através de Módulos de Compensação de Dispersão. Para sistemas WDM onde múltiplos comprimentos de onda são transmitidos simultâneamente com altas potências ópticas e altas taxas de transmissão este fenômeno deve ser corretamente controlado para garantir um desempenho da transmissão adequado.

- Dispersão por Modo de Polarização (PMD): Esta dispersão é importante em redes de longa distância e com altas taxas de transmissão, incluindo sistemas WDM e DWDM. As fibras monomodo transmitem a luz através de eixos internos de propagação, que representam modos de polarização distintos sendo eles horizontal, vertical e linear.

A figura 2.13 ilustra a transmissão da luz com diferentes modos de propagação e tempos de chegada distintos no destino.

Uma fibra perfeitamente circular ao longo de toda sua extensão vai manter estes modos de polarização constante, porém devido a processos de fabricação ou a fatores externos, a fibra não é perfeitamente circular por toda sua extensão. Como resultado desta imperfeição ocorre a dispersão por modo de polarização, que vai influenciar uma interação nos pulsos de luz resultando na degradação do sinal.

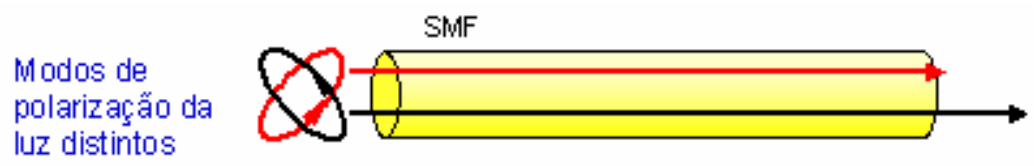

Figura 2.13 - Representação da dispersão por modo de polarização em um enlace de fibra óptica 
Esta dispersão é particularmente muito prejudicial para as transmissões devido a sua característica não estática e portanto não previsível, como ocorre com a dispersão cromática. Ela varia de acordo com as condições externas como movimentação da fibra e a variação da temperatura, podendo ter seus valores alterados a qualquer momento.

\section{iii) Efeitos Não-Lineares}

Estes efeitos começam a aparecer e se tornar relevantes em redes que utilizam alta potência óptica e percorrem longas distâncias.

São efeitos cumulativos devido a interação do sinal de luz com o material no qual ele trafega, resultando em mudanças deste sinal, e em interações entre os sinais, no caso da transmissão de vários deles de forma simultânea, como nos sistemas WDM e DWDM.

Podem ser caracterizados principalmente pela ação de dois processos, sendo que um deles pode ser descrito como um espalhamento onde ocorrem interações entre o sinal óptico e as vibrações moleculares na fibra, como por exemplo o Espalhamento de Raman e Espalhamento Brillouin, que caracterizam uma atenuação do sinal onde há uma conversão de parte da luz para outros comprimentos de onda.

O efeito Raman ocorre na mesma direção do sentido de propagação da transmissão e o efeito Brillouin ocorre no sentido oposto da propagação.

No outro processo ocorre a variação do índice de refração não linear da fibra, dependente da intensidade do sinal óptico, podendo-se citar como exemplos:

- Auto Modulação de Fase (SPM): onde o espectro do sinal se alarga tornando os efeitos da dispersão problemáticos;

- Modulação de Fase Cruzada (XPM): em sistemas WDM, o espectro do sinal sofre um alargamento devido à alta intensidade do sinal de um canal adjacente; 
- Mistura de Quatro Ondas (FWM): ocorre a interação entre sinais de vários comprimentos de onda no WDM, os quais se misturam e geram sinais com comprimentos de onda adicionais que vão retirar potência da transmissão dos canais. 


\section{Planos de Controle e Roteamento em Redes ópticas}

Este capítulo apresenta a importância dos planos de controle, com foco no seu mecanismo de roteamento de forma particular.

\subsection{Serviços sobre Redes Ópticas e as Arquiteturas Multi-camadas}

As aplicações oriundas das camadas superiores, atualmente a grande maioria baseado em tráfego IP, podem utilizar a infra-estrutura de transporte das redes ópticas para realizar a transmissão de dados com o objetivo de obter vantagem dos benefícios que estas redes apresentam, conforme descrição anterior. Com a finalidade de que esta estrutura de comunicação seja possível, foram definidos mecanismos, como determinados conjuntos de protocolos e interfaces, para que sejam implementados sobre a camada óptica, e através da utilização dos mesmos, a coordenação da transmissão pode ser realizada, permitindo tirar proveito da infraestrutura oferecida pelas redes ópticas.

O objetivo destas implementações, bem como seu maior desafio, é disponibilizar para as empresas operadoras de telecomunicações e provedores de serviços, um meio para que elas possam oferecer seus serviços, utilizando suas redes de forma otimizada, com eficiência e garantindo qualidade na entrega, ou seja, estas implementações devem possibilitar o transporte de um grande volume de tráfego de maneira eficiente, em termos de custo e desempenho. Além destes requisitos o provisionamento dos serviços deve ser flexível e deve ser executado de maneira rápida. Estas características deverão ser alcançadas através da arquitetura implantada em suas redes, com as pilhas de protocolo e as interfaces adequadas disponíveis para esta tarefa.

Existem algumas arquiteturas desenvolvidas para suprir estas necessidades (GORALSKI, 2001), sendo as mais relevantes apresentadas na figura 3.1 a seguir: 


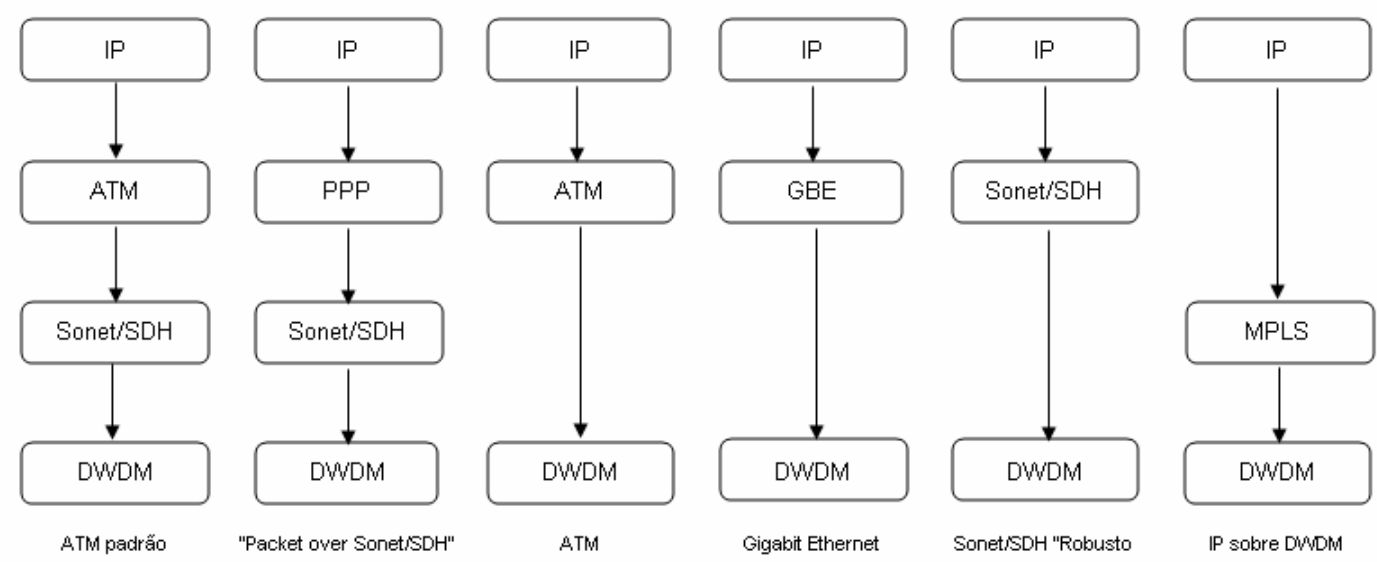

Figura 3.1 - Arquiteturas de Redes IP sobre Redes Ópticas

As arquiteturas com mais camadas apresentam tipicamente um desempenho abaixo do ideal devido à sobreposição das tecnologias. As principais dificuldades, que são inerentes a este tipo de sistema multicamadas, podem ser citadas como o surgimento de redundância em determinadas tarefas devido à sobreposição de serviços existentes nas tecnologias, a limitação da escalabilidade da rede, a dificuldade de se obter um rápido provisionamento dos serviços, bem como custos elevados de operação e manutenção, pois percebe-se que cada camada possui seu próprio gerenciamento e normalmente cada uma delas opera com seus equipamentos específicos.

A flexibilidade da rede no que se refere à entrega do tráfego requisitado pelo usuário também pode ser citada como um exemplo importante de falta de eficiência. Observa-se que em um sistema SDH/Sonet é definida uma hierarquia de transporte onde a mesma possui taxas de tráfego fixas como $155 \mathrm{Mbps}, 622 \mathrm{Mbps}, 2,5 \mathrm{Gbps}$ e 10 Gbps. Neste caso, se um cliente deseja trafegar um fluxo de dados de 100 Mbps através da tecnologia FastEthernet por exemplo, deverá ser utilizado um canal de 155 Mbps e o mesmo terá uma banda ociosa de $33 \%$, e se a necessidade for trafegar GigabitEthernet através de um enlace de 2,5 Gbps a banda ociosa será de $50 \%$. Para tornar as coisas mais complicadas, caso haja a necessidade de um acréscimo de banda de um fluxo original de 1 Gbps para 3 Gbps, o cliente deverá descartar seu enlace de 2,5 Gbps para obter um de 10 Gbps, que é o próximo na hierarquia. 
O trabalho realizado por (ALOIA, 2003), também demonstra a ineficiência dos sistemas multicamadas onde o mesmo apresenta o overhead introduzido devido à sobreposição de camadas. Neste trabalho é demonstrado que nas arquiteturas IP/ATM o overhead médio, pois analisa vários tamanhos de pacotes trafegando em um tronco Internet, alcança aproximadamente o valor de $24 \%$, sendo que principalmente os pacotes menores, com aproximadamente 40 bytes, e que significam uma porcentagem representativa do tráfego, são os que apresentam maior deficiência com relação ao overhead introduzido. Nas arquiteturas SDH/Sonet o overhead médio chega a $4,6 \%$.

Desta forma, ao se implantar uma solução com arquitetura IP/ATM/SDH-Sonet, deve-se levar em consideração o overhead médio de 24\% (IP/ATM) adicionados a 4,6\% (SDH/Sonet), e nas arquiteturas IP/PPP-HDLC/SDH-Sonet o overhead médio a ser considerado é de $2 \%$ adicionados a $4,6 \%$.

Através das evidências apresentadas pode-se verificar, de uma forma básica, um cenário qualitativo e quantitativo a respeito das dificuldades encontradas com relação à ineficiência das implementações que operam com arquiteturas sobrepostas.

Em contrapartida, espera-se que a arquitetura desenvolvida com apenas duas camadas, ou seja, o IP sobre o DWDM, ofereça um desempenho superior no sentido de responder melhor às dificuldades encontradas nas arquiteturas multicamadas.

Este desempenho mais atraente refere-se à possibilidade da obtenção de uma melhor escalabilidade da rede, maior flexibilidade e mais eficiência na operação e manutenção, eliminando tarefas redundantes e facilitando o provisionamento dos serviços de maneira mais rápida.

Importante mencionar a relevância do overhead introduzido pelas arquiteturas que utilizam as camadas sobrepostas, quando analisadas de forma individual. Por exemplo, tomando-se apenas o overhead dos sistemas $\mathrm{SDH} /$ Sonet, verifica-se que 
as funções possíveis através de sua utilização são muito importantes para estas tecnologias, pois as mesmas viabilizam a operação através de um gerenciamento apropriado obtido a partir dos bits de controle presentes neste overhead. Em contrapartida um sistema DWDM, sendo uma tecnologia de transporte óptico puro, não possui esta mesma capacidade de gerenciamento, neste mesmo nível, pelo menos até este momento. Verifica-se então que o desafio que surge ao eliminar as camadas sobrepostas, com seus overheads de controle, é justamente desenvolver um mecanismo que possa suprir com eficiência as mesmas funções que eles executam no sentido de gerenciar a rede como um todo.

Desta maneira, com o objetivo final de se obter a integração entre as redes convencionais de pacotes e as redes ópticas para a arquitetura IP/WDM, com a eficiência e qualidade desejadas, conforme apresentado, deverá existir um elemento robusto e bem elaborado que possa garantir o gerenciamento das tarefas e interações entre estas redes. Este elemento é conhecido como plano de controle e será descrito a seguir.

\subsection{Planos de Controle}

Nos itens anteriores verificou-se a preocupação com relação aos custos e dificuldades operacionais, entre outras questões, das redes heterogêneas. Devido a este fato surgiu a necessidade da integração destas redes de forma robusta e otimizada, e com este objetivo os planos de controle realizam uma tarefa fundamental neste cenário.

Os planos de controle nas arquiteturas de redes são os elementos responsáveis por operações essenciais das mesmas, podendo ser destacadas a alocação correta de banda, o estabelecimento de caminhos, a reserva de recursos, o mecanismo de roteamento e a recuperação de erros, entre outras. De acordo com estas tarefas pode-se definir que o plano de controle estabelece as condições fundamentais e necessárias para viabilizar o plano de encaminhamento de dados. 
Os planos de controle podem ser operados de forma manual ou de forma automática, sendo que esta segunda maneira de operação normalmente possui vantagens como uma melhor escalabilidade no caso do crescimento das redes. Outro aspecto importante é a maior flexibilidade e agilidade na manutenção e operação no caso de alterações, programadas ou não, na topologia da rede devido à introdução de novos dispositivos, ou da retirada destes por motivo de falha. A adaptação da rede às novas condições operacionais, que normalmente ocorrem em redes dinâmicas, se torna mais atraente, principalmente com relação à utilização mais racional dos recursos envolvidos. Em contrapartida, este mecanismo que habilita o plano de controle a operar automaticamente deve ser bem elaborado e implementado, para que não ocorra negação de serviços indevidamente, evitar loops desnecessários na rede, auxiliar na resolução de eventuais problemas que possam surgir ao longo do tempo e principalmente para não desperdiçar recursos importantes de rede.

Além da forma de configuração e manutenção de um plano de controle, existe outro aspecto importante a ser comentado sobre o seu funcionamento, que é a maneira com que as informações deste mecanismo fluem pela rede. Basicamente estas informações poderão ser transportadas no mesmo meio físico que trafegam outros dados da rede, como os dados das aplicações dos usuários, também chamado de plano de encaminhamento de dados, ou em outro meio físico completamente separado do primeiro (CHOI; LONG, 2002). Pode-se citar como exemplo a utilização de fibras ópticas distintas para carregar informações do plano de controle e do plano de dados, ou a utilização de uma mesma fibra óptica transportando os dois planos em conjunto. No caso do transporte em meios físicos distintos há a vantagem de separar o plano de controle do plano de dados através de caminhos físicos distintos, e desta maneira uma eventual falha em um deles não interfere no outro, porém esta solução requer a utilização de mais recursos da rede.

Com a utilização do mesmo meio físico ainda surgem duas alternativas, sendo uma delas a possibilidade de transportar os dois planos através do mesmo canal e a outra através de canais separados. Tomando-se o exemplo do enlace de fibra, verifica-se que nesta configuração as informações transportadas em uma única fibra óptica podem utilizar comprimentos de ondas distintos, sendo um para cada plano, 
ou no mesmo comprimento de onda, sendo diferenciados, desta forma, através do tipo de protocolo utilizado.

Existem diversos planos de controle em funcionamento, com seus próprios protocolos que fornecem sua capacidade de operação, com características específicas para cada aplicação de rede, podendo ser citados o SS7 com seus protocolos ISUP (Integrated Services Digital Network User Part) e IS41, o GSM (Global System for Mobile Communication), o ATM, o TCP/IP e o MPLS com seus protocolos de sinalização e roteamento como RSVP (Resource Reservation Protocol), BGP (Border Gateway Protocol), OSPF (Open Shortest Path First), IS-IS (Intermediate System to Intermediate System), entre outros.

Após esta breve introdução, e segundo (SOLE-PARETA, 2003), pode-se definir que basicamente os principais aspectos de um plano de controle são:

- Um esquema de endereçamento definido, onde cada elemento da rede pode ser identificado;

- Um protocolo de roteamento para a distribuição da informação sobre a topologia e recursos da rede, sendo estas informações utilizadas por um algoritmo de roteamento que vai calcular as melhores alternativas de rotas entre os elementos da rede;

- Uma rede de sinalização que proporciona um canal de comunicação entre os elementos da rede para a requisição de serviços e o atendimento a estas requisições;

- Um protocolo de sinalização para controlar esta comunicação, utilizado para o estabelecimento, manutenção, recuperação e liberação dos circuitos de comunicação, canais virtuais ou caminhos ópticos.

De uma forma geral este quadro demonstra as responsabilidades e os blocos construtivos básicos que formam um plano de controle. Importante notar que até este ponto as redes são tratadas de maneira indistinta, ou seja, não há diferenciação entre as redes convencionais de circuitos e pacotes e as rede ópticas. Porém estas 
redes possuem operações distintas e, portanto, possuem requisitos de funcionamento distintos. Devido a este fato a integração de redes convencionais com redes ópticas requer análise adicional de como as características se comportam quando estas redes são conectadas.

\subsection{Planos de Controle e as Redes Ópticas}

Uma breve demonstração dos problemas encontrados pelos planos de controle, na tarefa de lidar com as redes ópticas, pode ser verificada claramente através da dificuldade em gerenciar as diferentes camadas, com tecnologias distintas e um número grande de variáveis para realizar o transporte dos dados, através do plano de encaminhamento das mesmas.

Os mecanismos utilizados pelo plano de controle devem suportar grandes redes, com probabilidade alta de expansão de tamanho, contendo um elevado número de nós (OXCs, OADMs, etc), com uma grande quantidade de portas e comprimentos de onda por nó, centenas de fibras em paralelo conectando fisicamente estes dispositivos e de canais de comprimento de onda sendo transmitidos nestas fibras.

Com o objetivo de lidar com estes desafios, os planos de controle das redes convencionais interconectadas com as redes ópticas podem ser integrados ou não, e estes planos de controle, com o objetivo de atender os requisitos do domínio óptico, possui como principais funções, entre outras:

- A determinação do comprimento de onda a ser utilizado na comunicação entre dois nós;

- A determinação do time slot utilizado;

- A determinação de uma ou mais fibras ou da porta física da interface do equipamento em questão;

- A determinação das tabelas de comutação nos elementos de rede como os OXCs e os OADMs; 
- O estabelecimento dos caminhos ópticos entre dois nós da rede para possibilitar a comunicação entre eles;

- A execução do sincronismo;

- A efetuação da troca de mensagens de alarmes e gerenciamento;

- A negociação do tipo de tráfego suportado pelo caminho óptico;

- A negociação do volume ou largura de banda.

Conforme descrito, um aspecto importante que deve ser destacado é a diferença de natureza entre as redes convencionais que comutam pacotes no domínio elétrico e as redes ópticas que comutam circuitos no domínio óptico. De acordo com esta definição verifica-se que os mecanismos desenvolvidos e utilizados nas redes de pacotes, como os protocolos destas redes, normalmente não poderão ser utilizados diretamente no plano de controle das redes ópticas, sem algum tipo de adaptação, como extensões nos mesmos, a fim de atender necessidades exclusivas destas redes.

O trabalho realizado no sentido de elaborar e padronizar adaptações dos atuais protocolos já existentes, bem como eventuais propostas para o desenvolvimento de novos protocolos, também padronizados, é muito importante. Seu objetivo é a redução de custos operacionais e de implantação destas redes integradas, através da possibilidade da utilização de equipamentos de diversos fabricantes distintos, que terão que aplicar regras amplamente conhecidas, para estar em conformidade com os padrões adotados.

Estes trabalhos são conduzidos atualmente por dois organismos internacionais de padronização, sendo eles o IETF (Internet Engineering Task Force) com o desenvolvimento do GMPLS (Generalized Multiprotocol Label Switching) e o ITU-T (International Telecommunications Union - Telecommunications Standardisation Sector) com o desenvolvimento do ASON (Automatically Switched Optical Networks). 
Este trabalho tem o objetivo de apresentar uma análise do PCE conforme descrito anteriormente no capítulo 1. Sendo assim, como esta arquitetura é definida pelo IETF para redes MPLS e GMPLS, o foco é dado particularmente para as padronizações deste organismo, e portanto as definições do ITU-T não são apresentadas.

\subsection{IETF e o GMPLS}

Dentro do IETF existe um grupo designado para o desenvolvimento dos padrões para o GMPLS, que é o CCAMP Working Group (Common Control and Management Plane). Estes padrões incluem o desenvolvimento e adaptações dos protocolos, bem como a visão geral da arquitetura GMPLS. O IETF preocupa-se com os requisitos do mercado em geral, e seu objetivo é o desenvolvimento do GMPLS como plano de controle para as redes ópticas através da extensão do MPLS, e de seus protocolos.

O MPLS é uma tecnologia de rede que permite a comutação de pacotes através da introdução de rótulos nos mesmos, eliminando desta forma o trabalho da camada de rede, dentro dos seus domínios. Este mecanismo de comutação de pacotes possibilita a criação de circuitos virtuais, através da introdução de rótulos, os quais substituem as funções de roteamento da camada de rede (ROSEN; VISWANATHAN; CALLON, 2001).

Uma das motivações para o desenvolvimento desta tecnologia está baseada no fato de se alcançar uma velocidade de transmissão um pouco mais elevada através da utilização do paradigma de comutação de pacotes através de rótulos, porém esta vantagem não se mostra a mais atraente do MPLS, pois a velocidade de processamento de um cabeçalho IP de 32 bits não é muito inferior ao processamento de um rótulo MPLS de 20 bits, ambos realizados por circuitos integrados dedicados disponíveis atualmente (ASIC - Application-specific integrated circuit), (OSBORNE; SIMHA, 2003). Os maiores benefícios alcançados com a utilização da tecnologia MPLS é a capacidade de construir VPNs (Virtual Private 
Networks), a possibilidade de implantação de QoS na rede, e principalmente a possibilidade da implementação de engenharia de tráfego onde a origem de um fluxo pode controlar o caminho por onde este fluxo trafega até o destino final, permitindo maior flexibilidade de encaminhamento comparado ao esquema baseado apenas no endereço de destino.

O funcionamento básico do MPLS está baseado na criação dos circuitos virtuais através de rótulos, sendo que estes circuitos vão existir em uma parte da rede formada por um domínio de equipamentos que podem interpretar estes rótulos, e através deles podem encaminhar as informações sem ter que interpretar o cabeçalho IP.

Os principais elementos de rede em uma arquitetura MPLS são os roteadores que estão dentro do domínio MPLS e implementam as funções de encaminhamento neste domínio. Estes roteadores são denominados LSR (Label Switched Router). Os roteadores que fazem a interface do domínio de rótulos com o domínio IP são denominados LSR de ingresso (Ingress LSR) e LSR de egresso (Egress LSR). Eles têm a função de receber os pacotes da rede IP e atribuir um rótulo na entrada do domínio de rótulos e retirar este rótulo na saída deste domínio, respectivamente.

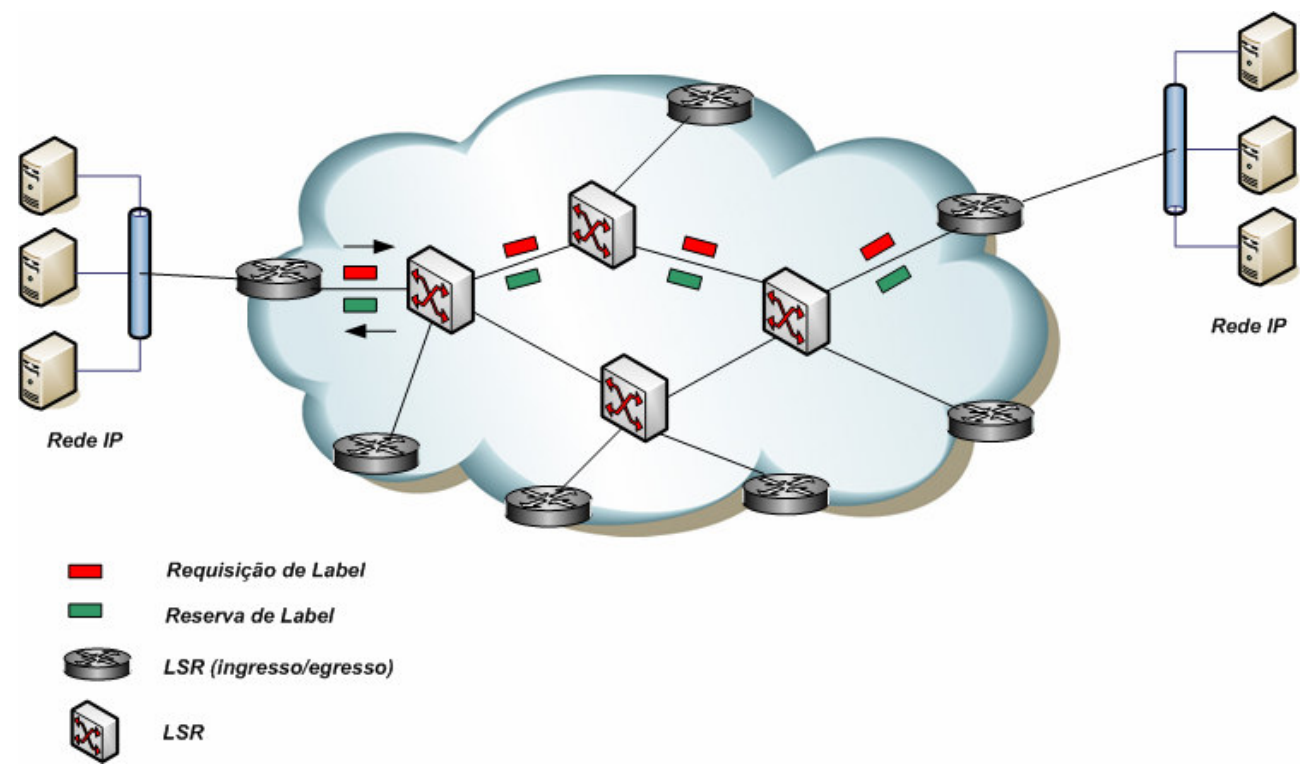

Figura 3.2 - Rede MPLS 
$\mathrm{Na}$ arquitetura MPLS existem os protocolos de roteamento como o OSPF e o ISIS, que vão estabelecer a alcançabilidade da rede em um primeiro momento. Em seguida o protocolo de distribuição de rótulos, como o RSVP, determina o mapeamento entre o rótulo e a rede de destino, alocando os recursos necessários neste caminho para satisfazer os requisitos mínimos para estabelecer esta conexão. Com a conexão realizada, o LSR de ingresso recebe o pacote da rede IP, realiza uma busca na sua tabela de rótulos e insere o rótulo apropriado no pacote. Os LSRs da rede encaminham o pacote rapidamente através da comutação baseada nos rótulos. Finalmente, o LSR de egresso recebe o pacote, verifica o rótulo, remove o mesmo e entrega o pacote novamente à rede IP de destino. A figura 3.2 apresenta uma rede MPLS básica, com seus principais elementos. A arquitetura MPLS á apresentada com detalhes em (ROSEN; VISWANATHAN; CALLON, 2001; OSBORNE; SIMHA, 2003).

Neste ponto percebe-se que a tecnologia MPLS opera apenas no mundo eletrônico, sendo que as redes ópticas não são consideradas nos seus domínios. Desta forma, o mecanismo apresentado no MPLS não é suficiente para acrescentar as redes ópticas dentro da sua arquitetura. Então, modificações tornaram-se necessárias e o resultado final foi a evolução do MPLS para o GMPLS, onde o domínio óptico é tratado de forma integrada com a rede de pacotes, com diferentes níveis de integração, através da elaboração dos planos de controle competentes para este fim.

O GMPLS adiciona mecanismos para e estender o paradigma do chaveamento de rótulos para atender requisitos de outras tecnologias de transmissão, diferentes daquelas que são comutadas por pacotes, como as interfaces TDM (Time Division Multiplex) (SDH/Sonet), a comutação por comprimentos de onda e a comutação espacial (fibras e portas físicas dos equipamentos). Então novos formatos de rótulos foram introduzidos para suportar estes diferentes domínios, onde na realidade estes rótulos são entradas nas tabelas de comutação destes domínios. 
As seguintes interfaces foram definidas no GMPLS para atender os diferentes domínios propostos (MANNIE, 2004).

a) Interface PSC - Packet Switch Capable: reconhece as fronteiras dos pacotes e pode encaminhar dados baseadas no conteúdo do cabeçalho do pacote;

b) Interface L2SC - Layer-2 Switch Capable: reconhece as fronteiras de quadro/célula e pode encaminhar dados baseadas no conteúdo do cabeçalho do quadro/célula;

c) Interface TDM - Time-Division Multiplex Capable: encaminha dados baseados em janelas de tempo (time slot);

d) Interface LSC - Lambda Switch Capable: encaminha os dados baseadas no comprimento de onda no qual estes dados são recebidos;

e) Interface FSC - Fiber Switch Capable: encaminha os dados baseadas em sua posição no espaço físico;

A arquitetura GMPLS é desenvolvida com o objetivo de ser uma tecnologia fim-a-fim, com elementos GMPLS espalhados por toda a rede integrada. A flexibilidade é um fator importante a ser destacado no seu desenvolvimento, onde a possibilidade de um ambiente onde múltiplos fabricantes possam se conectar é sempre um objetivo a ser alcançado. A figura 3.3 ilustra um exemplo de rede integrada, onde elementos dos domínios óptico e eletrônico são conectados.

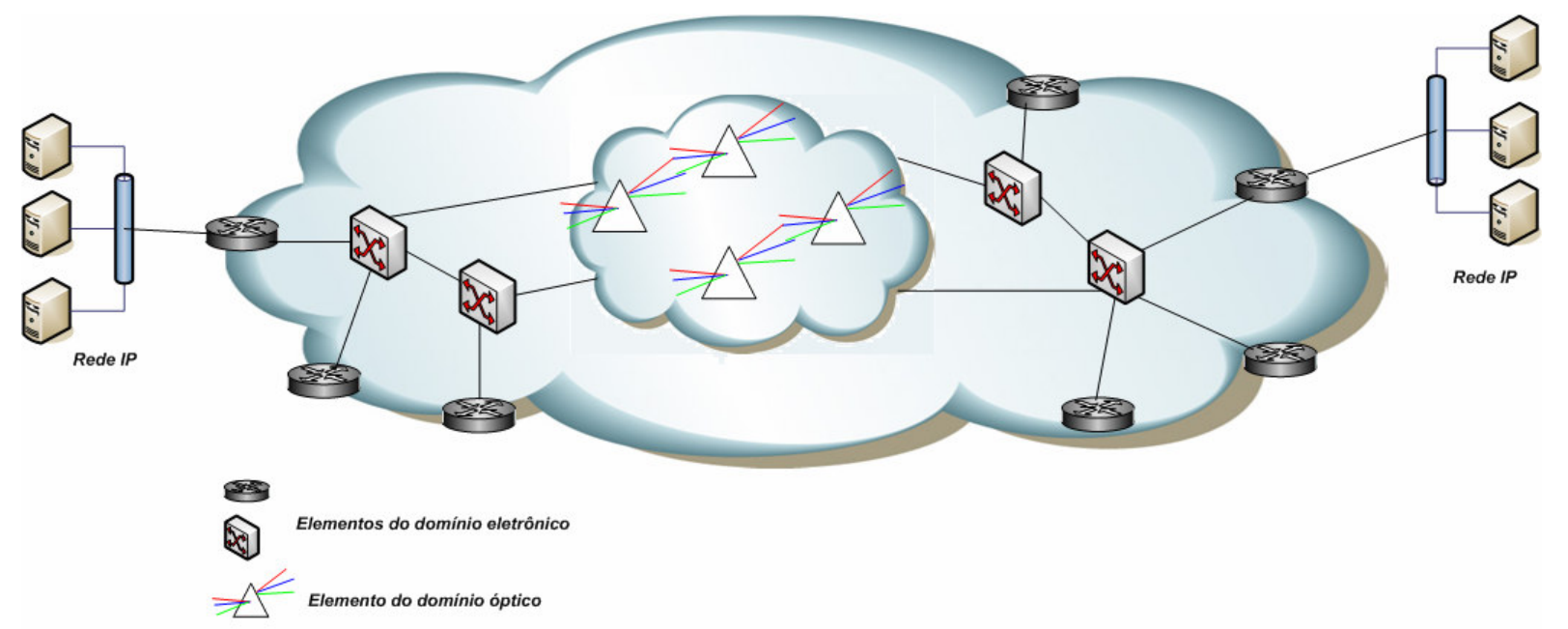

Figura 3.3 - Rede GMPLS 


\subsubsection{Extensões para o GMPLS}

Verifica-se a introdução de variáveis que não existiam anteriormente, onde as mesmas acrescentam uma nova complexidade na rede, devido ao tratamento exigido nas novas interfaces dos novos domínios introduzidos. Este cenário requer novas soluções para que sejam solucionados problemas de roteamento e de sinalização que não ocorriam com o MPLS.

O plano de controle para o GMPLS adquire agora uma característica particular sendo estendido para operar com camadas que não reconhecem limites de células e pacotes, mas devem trabalhar de alguma forma em conjunto com estas, para proporcionar a integração.

$\mathrm{Na}$ arquitetura GMPLS são introduzidas extensões dos protocolos de roteamento utilizados pelo MPLS como o OSPF-TE (Open Shortest Path First - Traffic Engineering) e o ISIS-TE (Intermediate System to Intermediate System - Traffic Engineering), que têm o objetivo de propagar informações da topologia, alcançabilidade, recursos e capacidade da rede através do plano de controle. Estes protocolos são considerados para o roteamento intra-domínios, sendo que para o roteamento inter-domínios não há muitos detalhes das definições a serem adotadas de acordo com a padronização da arquitetura (MANNIE, 2004).

Da mesma forma, extensões do protocolo de sinalização RSVP-TE (Resource Reservation Protocol - Traffic Engineering), são utilizados para determinar a maneira como os rótulos são requeridos e distribuídos, para trocar informações de sincronização, para a alocação de rótulos entre outras funções. Novamente, 0 objetivo das extensões é atender os novos requisitos exigidos pela introdução dos elementos da rede óptica no cenário (KOMPELLA; REKHTER 2005a; KOMPELLA; REKHTER, 2005b; KATZ; KOMPELLA; YEUNG, 2004; BERGER, 2003b). 
Além das extensões dos protocolos de roteamento e de sinalização, um novo protocolo foi introduzido para realizar o gerenciamento dos enlaces. Este protocolo chamado LMP (Link Management Protoco) tem a função de gerenciar o canal de controle, estabelecendo, configurando e mantendo a conectividade entre os nós adjacentes através da topologia de rede de controle (LANG, 2005).

\subsubsection{Modelos de Implementação dos Planos de Controle no GMPLS}

O plano de controle na arquitetura GMPLS é separado do plano de dados, e este plano de controle pode suportar mais de um tipo de modelo de interconexão entre as camadas das redes ópticas e as camadas que não pertencem ao domínio óptico, sendo eles o overlay, o peer e o augmented (MANNIE, 2004).

No modelo overlay, os detalhes da implementação do roteamento e da sinalização, bem como os protocolos utilizados dentro do domínio da rede óptica são distintos da implementação do roteamento, da sinalização e dos protocolos utilizados fora dos domínios da rede óptica, e são executados separadamente, cada qual dentro do seu domínio. Neste modelo o domínio óptico funciona como um provedor de serviços fornecendo conectividade e transporte para as redes ligadas a ele.

O modelo peer, ou modelo integrado, apresenta um único plano de controle para os domínios sendo que todos os elementos que formam a rede são submetidos ao gerenciamento deste plano de controle. Desta forma todos os elementos têm uma visão completa da topologia e operam de forma integrada da rede podendo ser acessados diretamente.

O modelo augmented possui instâncias de roteamento separadas para os domínios ópticos e de comutação de pacotes, porém algumas informações de roteamento podem ser passadas através dos domínios para estender a alcançabilidade da informação. Por exemplo, um endereço IP poderia ser transportado através de 
protocolos da rede óptica permitindo que outros elementos IP pudessem obter esta informação de como alcançá-lo.

\subsection{Algoritmos e Protocolos de Roteamento e as Redes Integradas}

Os planos de controle, conforme apresentado no item 3.2, possuem blocos fundamentais de construção, sendo que um deles, o que cumpre as funções de roteamento, que é o foco deste trabalho através da arquitetura PCE, será apresentado neste capítulo sob a ótica das redes integradas.

Basicamente um mecanismo de roteamento em redes pode ser definido como um processo que tem como objetivo possibilitar a tranferência de informações entre sistemas finais, mascarando as diferenças existentes entre as sub-redes e os meios de comunicação utilizados durante estas transferências (CARVALHO, 1994).

De acordo com este conceito, o processo de roteamento avalia a origem e o destino do tráfego de informações baseado no seu conhecimento com relação às condições da rede. Este processo deverá identificar o melhor caminho a ser utilizado para transportar o tráfego até o seu destino final, sendo que a escolha deste caminho, ou seja, a decisão de roteamento poderá se basear em uma variedade de critérios como a capacidade dos enlaces, a distância entre os nós e o atraso nos enlaces, entre outras métricas que podem ser adotadas para a escolha deste caminho, dependendo do mecanismo e do protocolo de roteamento adotado, de acordo com cada necessidade.

Um mecanismo de roteamento deve executar, no mínimo, duas funções básicas para cumprir seu objetivo:

- Criação e manutenção de tabelas de roteamento;

- Seleção dos caminhos através da consulta a estas tabelas previamente elaboradas. 
As tabelas de roteamento indicam o caminho pelo qual a informação deverá seguir e podem ser atualizadas de forma estática por um administrador a cada mudança na topologia da rede ou de forma dinâmica através de protocolos e algoritmos de roteamento distribuídos pelos nós da rede. Esta segunda abordagem se mostra interessante e é a mais adotada, pois oferece melhor escalabilidade, além de ser uma forma automática de atualização.

Os algoritmos têm a função de construir e manter estas tabelas de roteamento enquanto que os protocolos desempenham o papel de trocar as informações de rotas para que os algoritmos tenham a informação necessária para montar as tabelas.

Os principais algoritmos de roteamento são o Distance Vector que é baseado em uma métrica simples de contagem de saltos onde o melhor caminho é determinado pela menor distância entre os nós, e o Link State, mais elaborado onde o mesmo leva em consideração o estado dos enlaces através de várias métricas associadas a estes enlaces.

O algoritmo que utiliza a distância como métrica tem a vantagem de ser mais simples e de utilizar menos processamento, porém sua convergência pode ser lenta, pode ter dificuldades em encontrar nós com defeitos e o tráfego gerado pelo mesmo pode ser alto.

O algoritmo que utiliza informações de estado dos enlaces, como por exemplo o Djikstra ou SPF (Shortest Path First), efetua o cálculo de toda a topologia da rede para que, em seguida, possa escolher o melhor caminho. Ao montar esta topologia seus cálculos de rotas levam em consideração as métricas dos enlaces para que possa ter uma visão geral da rede com relação aos parâmetros destes enlaces como velocidade, atraso ou outros parâmetros definidos. Este algoritmo exige mais recursos de processamento, porém apresenta convergência mais rápida e as 
informações de rotas mais inteligentes considerando mais parâmetros no momento da escolha da melhor alternativa.

Um algoritmo muito importante no cenário relacionado às redes integradas é o CSPF (Constrained Shortest Path First) (DAVIE; REKHTER, 2000; OSBORNE; SIMHA, 2003). Este algoritmo basicamente é uma modificação do SPF descrito anteriormente onde existe uma tarefa adicional que é a seleção prévia dos enlaces capazes de satisfazer determinada condição requerida, como por exemplo, certa largura de banda mínima. No CSPF as entradas para o cálculo são as informações das métricas dos enlaces, como no SPF, em conjunto com as restrições para o caminho pretendido, como uma largura de banda mínima aceitável, por exemplo.

De uma forma geral, os algoritmos que possuem a capacidade de manipular informações dos estados dos enlaces, como as métricas para elaboração das rotas, deverão ser utilizados nos planos de controle das redes integradas. O objetivo é atender os requisitos destas redes, as quais exigem diversas informações conforme abordado anteriormente no capítulo 2 .

Com relação aos protocolos de roteamento, os mais comuns são o RIP (Routing Information Protoco), o OSPF, o BGP, o IGRP (Interior Gateway Routing Protocol, proprietário) e o ISIS no mundo da arquitetura TCP/IP (KOZIEROK, 2005). Conforme descrito, cada um destes protocolos possui seu mecanismo particular para carregar as informações de roteamento e utilizam um determinado algoritmo de roteamento, como os descritos acima.

A abordagem deste trabalho será feita considerando a utilização de algoritmos e protocolos de roteamento com a capacidade de trabalhar com os estados dos enlaces e com as métricas dos mesmos, pois estas informações são fundamentais no desempenho do mecanismo de roteamento nas redes integradas. Nestes tipos de rede, o sucesso da configuração de uma rota está diretamente ligado à quantidade $e$ qualidade de informações disponíveis a respeito da topologia da rede e dos enlaces 
que fazem parte da mesma. Um aspecto importante a ser observado é o alto custo associado a este mecanismo mais abrangente, pois o mesmo está diretamente relacionado ao tráfego da rede, aos recursos de processamento bem como à escalabilidade da solução.

\subsubsection{Cenários Intra-domínios e Inter-domínios}

As redes podem trabalhar com uma instância de um determinado protocolo de roteamento, que neste caso são denominados intra-domínios. Conforme ocorre o crescimento das redes, os protocolos de roteamento podem apresentar problemas de escalabilidade. A disseminação de informações dos parâmetros dos enlaces pode se tornar não gerenciável para os mecanismos que trabalham com Link State, ou a convergência pode ser inatingível no caso dos mecanismos Distance Vector. A divisão destas redes em sub-redes, conforme ilustrado pela figura 3.4, contorna este problema, fazendo com que em cada área exista uma instância do protocolo de roteamento, sendo chamado de roteamento inter-áreas Este procedimento visa otimizar a utilização dos recursos de rede.

As informações das rotas passadas entre as áreas são normalmente informações de alcançabilidade, e para melhorar o desempenho do mecanismo, podem ser sumarizadas. (KOZIEROK, 2005; KENYON, 2002; PADJEN; LAMMLE, 2000).

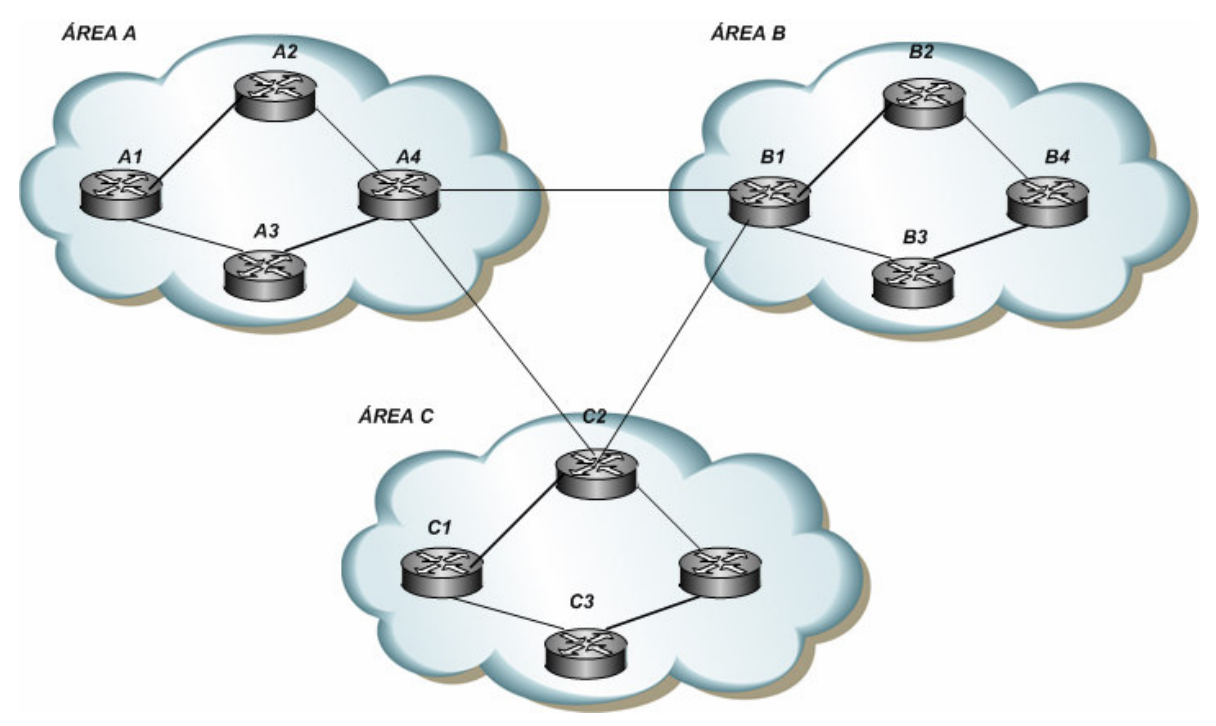

Figura 3.4 - Rede dividida em diversas áreas 
Outros motivos importantes que levam ao particionamento das redes em áreas distintas podem ser classificados como:

- Questões administrativas: com o objetivo de facilitar o gerenciamento da rede como um todo, dividindo também as ferramentas de gerenciamento e as responsabilidades dos responsáveis;

- Estrutura de negócio: ocorrem fusões entre organizações distintas porém, por motivos estratégicos, as redes devem permanecer separadas;

- Compatibilidade: podem existir redes distintas que possuem diferentes protocolos de roteamento, e desta forma, a conexão imediata não é possível sem que ocorra uma modificação em pelo menos uma delas.

Existe também um outro aspecto importante relacionado à divisão das redes, e que aparece quando se trata de redes de organizações distintas, que é o conceito de Sistemas Autônomos.

Um Sistema Autônomo (AS - Autonomous System), pode ser definido como um conjunto de elementos de rede que possuem a mesma política de roteamento e está sob uma única administração, sendo que para o mundo exterior o AS é visto como um única entidade (WRIGHT, 2003; DIMITROPOULOS et al., 2006).

Percebe-se, através deste conceito, que a Internet só é possível com a conexão das redes desta forma, sendo ASs distintos conectados entre si, conforme a figura 3.5. Estas conexões devem ser realizadas para que os elementos das redes dentro de cada AS possam se comunicar, e esta função é realizada por protocolos de roteamento inter-domínios, como o BGP. Estes protocolos possuem a tarefa de esconder os detalhes internos de cada AS e possibilitar o roteamento através da troca de informação de rotas sumarizadas entre os elementos que estão na divisa de cada AS, e através de políticas de roteamento. 


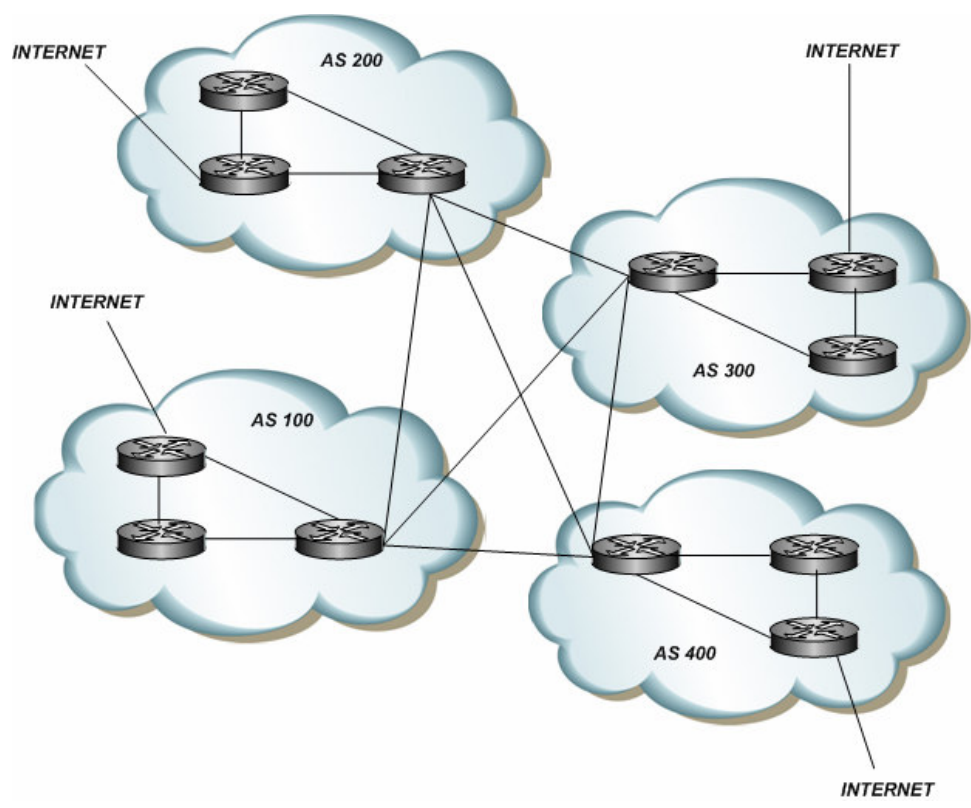

Figura 3.5 - Rede Inter-AS

Existe também um terceiro cenário onde as redes são divididas, o qual abrange as redes com tecnologias de transporte distintas, ou seja, as redes onde as áreas do domínio óptico se conectam ao domínio eletrônico. São denominadas inter-camadas, onde cada domínio é definido como uma camada na arquitetura da rede, conforme apresentado na figura 3.6.

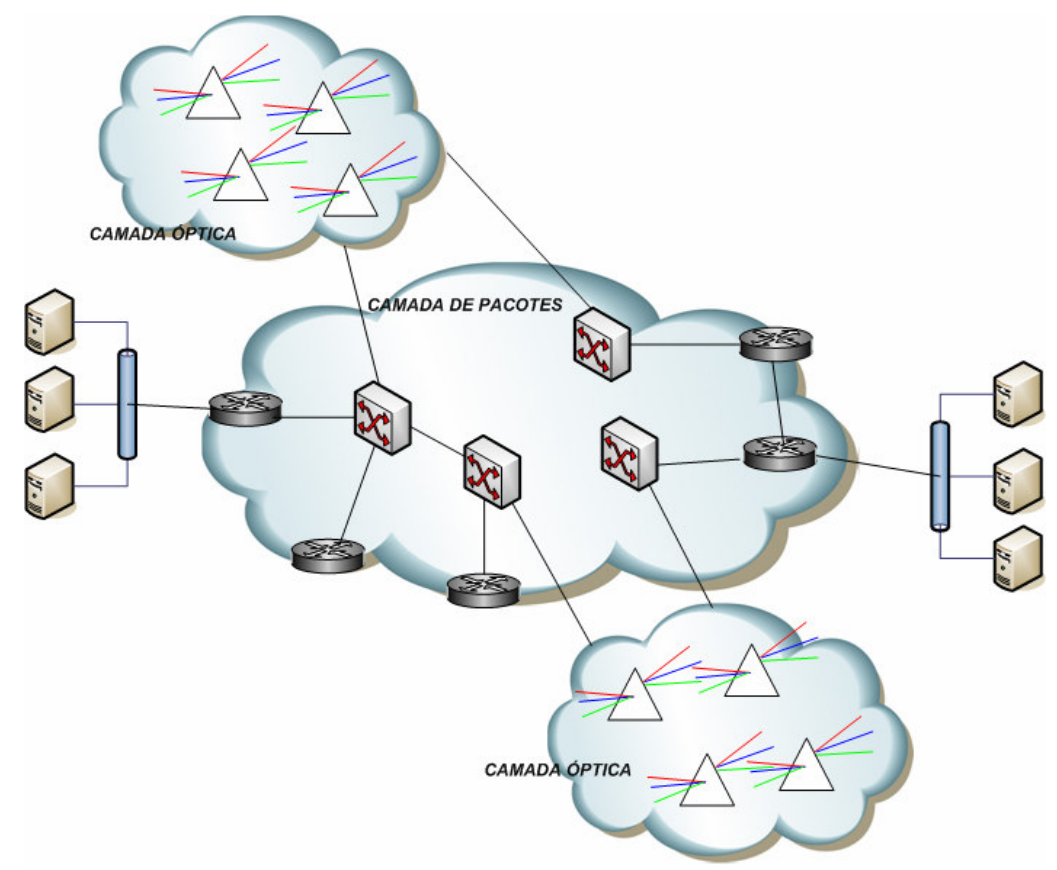

Figura 3.6 - Rede Inter-camadas 
Neste cenário há grupos de estudo desenvolvendo padronizações, e seguindo o escopo deste trabalho, é importante citar o IETF com a arquitetura GMPLS, que menciona o BGP como alternativa a ser utilizada. Porém os estudos e trabalhos realizados com este protocolo para desempenhar esta função ainda devem ser mais consistentes. Uma outra alternativa proposta é a utilização da arquitetura do PCE para lidar com os parâmetros das diferentes camadas quando estas redes devem se interconectar (FARREL, 2006).

Para todos os cenários mencionados, as informações das características dos enlaces das redes normalmente não são repassadas entre domínios distintos, devido aos aspectos citados como escalabilidade, otimização de recursos e políticas, causando, desta forma, um prejuízo na escolha da melhor alternativa de caminho entre estes domínios. Bloqueio, ou negação de rota, também são resultados indesejados devido à falta de informação dos detalhes dos enlaces.

Adiante, no capítulo 4 deste trabalho, o mecanismo do PCE será abordado e serão apresentadas suas características para a operação com as redes divididas dos modos apresentados acima, sejam elas inter-camadas, inter-ASs ou inter-áreas, com o objetivo de manipular as importantes informações sobre os parâmetros dos enlaces.

\subsubsection{Particularidades da Arquitetura GMPLS}

A Arquitetura GMPLS possui certas características específicas que devem ser tratadas pelos planos de controle. Estas particularidades serão apresentadas sem que detalhes sejam discutidos, pois, conforme estabelecido no objetivo do trabalho, o foco da análise para o mecanismo de roteamento está direcionado para as características de qualidade de transmissão, descritas no item anterior. Os detalhes das características apresentadas abaixo podem ser encontrados em (MANNIE, 2004). 
- Enlaces TE: a arquitetura GMPLS utiliza o conceito de enlace TE para divulgar informações de engenharia de tráfego a outros nós da rede. Um enlace TE pode ser visto como um enlace lógico que possui informações de determinados recursos da rede e suas propriedades, para o estabelecimento de um LSP, os quais são utilizados pelo protocolo CSPF para determinar a descoberta de caminhos na rede.

- Espaço de endereçamento: a introdução das interfaces que não operam com pacotes (PSC) apresenta uma nova realidade ao cenário do espaço de endereçamento atual, a qual demanda um número muito grande de endereços IP. Esta característica dificulta a escalabilidade da rede pois exige um espaço grande de endereçamento e consome recursos valiosos do sistema como memória para as tabelas de roteamento, capacidade de processamento e largura de banda para a troca de informações de roteamento entre os nós. Com o objetivo de contornar este problema foram definidos dois mecanismos denominados Enlaces não Numerados e Enfeixamento de Enlaces.

- Proteção de LSPs: a informação de estado de enlace tem a finalidade de definir a capacidade de proteção suportada por determinado enlace, ou seja, os caminhos podem ser escolhidos levando em consideração requisitos de proteção.

- Interfaces: o GMPLS e sua proposta de arquitetura multicamadas, apresenta um requisito fundamental para o mecanismo de roteamento para que as conexões na rede possam ser estabelecidas, que é a divulgação da capacidade de comutação dos nós, ou seja, a forma que as interfaces de cada nó aceita conexões e faz o transporte dos dados. Além desta informação existe o tipo de codificação utilizada pelo LSP que também é relevante para a escolha da rota (BERGER, 2003a).

Os tipos de interfaces suportadas são PSC, L2SC, TDM, LSC, FSC, apresentadas no item 3.4 deste trabalho e definidas em (MANNIE, 2004).

Além da informação da capacidade de comutação da interface, informações adicionais podem ser utilizadas especificando características particulares dentro 
destas interfaces, através de descritores de capacidade da interface, como por exemplo, na camada PSC podem ser utilizados os valores máximo e mínimo da largura de banda para um determinado LSP, e na camada LSC a informação sobre a taxa de transmissão e o tipo de codificação utilizada, entre outras (KOMPELLA; REKHTER, 2005c).

Importante notar que uma interface que conecta um enlace a um LSR pode possuir mais de uma capacidade de comutação descrita acima e, desta forma, esta informação deve ser divulgada na rede. A figura 3.7 apresenta um exemplo de um nó transportando um conjunto de lambdas entre dois LSRs que têm capacidade LSC, e também obtendo um sinal TDM destes lambdas e encaminhando este sinal para outro LSR com capacidade TDM.

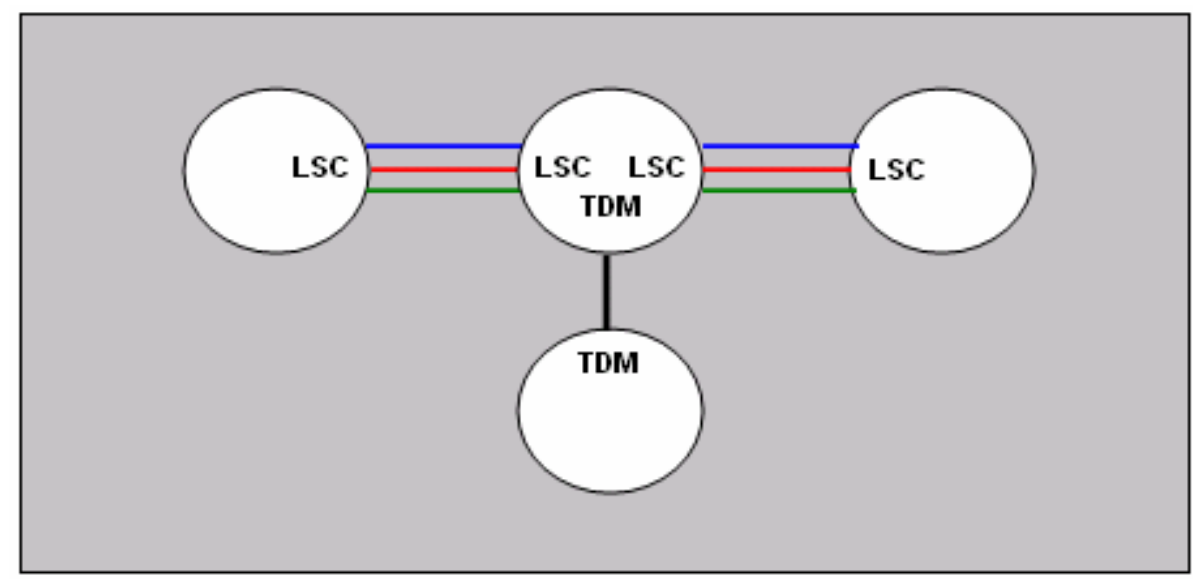

Figura 3.7 - Nós da rede com capacidades de comutação distintas

\subsection{Abrangência do Mecanismo de Roteamento para as Redes Integradas}

Verificou-se no capítulo 2, diversas características exclusivas do domínio óptico que devem ser lavadas em consideração no momento de integrar estas redes com as redes convencionais. Percebe-se de forma clara que os mecanismos de roteamento elaborados para as redes convencionais não conseguem lidar com estas novas características, e desta forma, necessitam de adaptações e extensões para atender os novos parâmetros introduzidos com o novo cenário.

Esta necessidade vem sendo abordada por diversos grupos de trabalho em universidades, empresas de mercado e outros órgãos como o IETF e o IEEE, por 
exemplo. Vários estudos, artigos e alguns padrões foram divulgados no sentido de atender os requisitos descritos no item 2.3 , no sentido de obter a integração das redes da melhor maneira, otimizando os recursos envolvidos e aproveitando ao máximo as capacidades disponíveis.

Pode-se dizer que os trabalhos envolvendo o mecanismo de roteamento foram, informalmente, divididos em duas partes sendo elas os que envolvem soluções para questões de roteamento em pequenas áreas, ou em um domínio, chamado de roteamento intra-domínio, e aqueles que envolvem áreas maiores, ou domínios distintos como ASs distintos, chamado roteamento inter-domínio (ver também item 3.5.1). A seguir serão apresentadas algumas considerações a respeito dos trabalhos envolvendo estes cenários.

\subsubsection{Extensões dos Protocolos Intra-domínios para Redes Ópticas}

\section{i) OSPF}

O protocolo OSPF possui extensões definidas para operar na arquitetura GMPLS através de (KOMPELLA; REKHTER, 2005b), onde algumas das especificações apresentadas no item 2.3 deste trabalho são tratadas no sentido de se obter a padronização de como as mesmas devem ser atendidas.

São definidos TLVs (Type/Length/Value) específicos, para os LSAs (Link State Advertisment) do OSPF, com os valores e conteúdo de cada campo que devem ser utilizados, no sentido de estender este protocolo, com os seguintes objetivos:

- Representar identificadores locais e remotos dos enlaces não numerados;

- Determinar o tipo de proteção dos enlaces;

- Especificar a informação de grupo compartilhado de risco;

- Identificar a capacidade de comutação da interface. 
Definições simples também são formalizadas para definir o procedimento a ser executado no caso de uma reinicialização de um nó qualquer da rede no sentido de informar os demais sobre os recursos já alocados neste nó que e não podem ser utilizados, e aqueles disponíveis para o eventual estabelecimento de um novo LSP, caso seja solicitado.

\section{ii) IS-IS}

O protocolo de roteamento IS-IS foi estendido para operar na arquitetura GMPLS através de (KOMPELLA; REKHTER, 2005a), onde algumas das especificações apresentadas no item 2.3 deste trabalho são tratadas no sentido de se obter a padronização de como as mesmas devem ser atendidas.

Para este protocolo, as extensões aplicáveis foram muito semelhantes àquelas introduzidas no protocolo OSPF descrito anteriormente, podendo-se destacar alguns TLVs utilizados para informar o estado de alguns parâmetros importantes ao GMPLS como:

- Identificadores locais e remotos dos enlaces não numerados;

- Tipo de proteção dos enlaces;

- Capacidade de comutação da interface;

- Informação de grupo compartilhado de risco (novo TLV introduzido ao protocolo).

\section{iii) Comentários}

Os protocolos de roteamento internos padronizados pelo IETF através das RFCs para serem utilizados na arquitetura GMPLS foram descritos de forma básica nos itens anteriores. 
Pode-se observar que estes protocolos tiveram extensões muito semelhantes entre si, sendo definidas nas RFCs:

- RFC 4203 - OSPF Extensions in Support of Generalized Multi-Protocol Label Switching (GMPLS);

- RFC 4205 - Intermediate System to Intermediate System (IS-IS) Extensions in Support of Generalized Multi-Protocol Label Switching (GMPLS).

As extensões desenvolvidas nestes documentos seguem de forma lógica e coerente a mesma linha abordada e sugerida pela padronização descrita em (KOMPELLA; REKHTER, 2005c), a qual apresenta extensões para o roteamento nas arquiteturas GMPLS de forma geral. Este documento aborda com mais detalhes as questões descritas nas RFCs dos protocolos OSPF e IS-IS além das várias possibilidades de interfaces para a arquitetura GMPLS com suas características de largura de banda e codificação.

Em contrapartida as extensões definidas nos documentos citados não abordam nenhuma questão apresentada nos itens 2.3 e 2.4 no que diz respeito às particularidades das redes ópticas com relação aos cuidados que devem ser tomados para a escolha dos caminhos nestas redes. $O$ aspecto mais próximo que é definido, conforme observado, trata das capacidades de comutação das interfaces, bem como a largura de banda e tipo de codificação disponibilizada pelas mesmas.

Porém questões importantes como a divulgação da disponibilidade dos comprimentos de onda disponíveis nos enlaces, ou outras informações sobre a qualidade do sinal nos mesmos (QoT), e sua capacidade de transportar este sinal pelos caminhos escolhidos, sem degradação óptica relevante, não são citadas. Estas informações são importantes para o estabelecimento dos LSPs, mas geram um alto consumo de recursos da rede, como processamento e banda, e desta forma, fica claro que, para estas padronizações, o requisito de planejamento e implantação da rede de transporte óptica é um fator essencial para o sucesso da utilização destes protocolos, pois os mesmos, por não tratarem explicitamente destas 
questões, pressupõe que a arquitetura e tecnologia de rede óptica disponível é competente para a transmissão dos dados através do melhor caminho escolhido por eles. Porém, de acordo com os argumentos apresentados em 2.4, verifica-se que esta hipótese inicial não pode ser assumida como verdadeira na prática devido a uma série de fatores já discutidos.

Em contrapartida, para preencher esta lacuna e possibilitar uma melhora no processo de escolha de rotas, há trabalhos publicados que descrevem outras extensões para o OSPF, bem como a forma que deveria ser o processo de divulgação das informações entre os nós (processo de flooding do OSPF) com a intenção de melhorar a utilização de recursos da rede para esta tarefa, e com o objetivo de que a divulgação de informações sobre os comprimentos de onda disponíveis seja possível. Estes trabalhos demonstram que com a divulgação deste tipo de informação a probabilidade de bloqueio, ou negação, de uma determinada requisição de LSP diminui, verificando-se desta forma a importância deste tipo de informação para os nós da rede que realizam a tarefa de calcular o melhor caminho dentro do mecanismo de roteamento quando se trata de redes integradas (YIN; KUO, 2005; CUGINI; ANDRIOLLI; CASTOLDI, 2004; MIYAMURA; KURIMOTO; AOKI, 2003; KOMPELLA; REKHTER, 2005b).

Um aspecto importante a ser ressaltado é a importância relativa de um protocolo em relação ao outro neste cenário, ou seja, qual dos dois protocolos possui a maior oportunidade de ser realmente utilizado na prática.

Em (ADEEL, 2005) pode-se observar, através da apresentação de algumas argumentações analíticas sem que se tenha executado nenhum teste de desempenho, o que até este momento é uma lacuna a ser preenchida na literatura, pois ainda não há avaliações deste tipo disponíveis comparando os dois protocolos intra-domínios, que o protocolo OSPF é o que possui as melhores características disponíveis para que seja o mais provável a ser utilizado. Além disto, pode-se facilmente encontrar uma série de trabalhos divulgados propondo extensões ao 
OSPF enquanto que esta mesma disponibilidade de trabalhos não é encontrada para o ISIS.

\subsubsection{Extensões dos Protocolos Inter-domínios para Redes Ópticas}

Atualmente os mecanismos de roteamento inter-domínios para as redes integradas não se encontram no mesmo estágio de evolução dos mecanismos de roteamento intra-domínios no que se refere aos trabalhos de pesquisa, produção de artigos e divulgação de padronizações.

Alguns fatores aparecem como urgentes para que o trabalho com os mecanismos inter-domínios seja acelerado, sendo que o mais importante reside no fato de que os grandes troncos de transporte de dados são formados por operadoras de telecomunicações distintas, as quais se interconectam para oferecer um serviço global de transporte, bem como o crescimento das redes comuns, a sua integração com as redes ópticas e sua divisão em áreas, conforme descrito anteriormente em 3.5.1.

\section{i) BGP - Border Gateway Protocol}

Verifica-se a possibilidade da utilização do BGP como mecanismo de roteamento inter-domínios nas redes integradas, pois o mesmo é um mecanismo amplamente utilizado neste cenário com as redes convencionais, e também pelo fato da padronização do GMPLS (MANNIE, 2004), indicar o mesmo como uma possibilidade para resolver as questões relacionadas a esta arquitetura.

O protocolo BGP é utilizado amplamente nas conexões de redes onde a extensão das mesmas se torna grande o suficiente para que um mecanismo de roteamento intra-domínios não possa suportar. Este fato normalmente ocorre devido a quantidade de informações sobre os estado dos enlaces (LSAs), que se torna 
volumosa conforme o tamanho das redes e o número de elementos nestas redes aumenta. Existe também a dificuldade de se obter informações de estado dos enlaces de outros domínios quando as redes são divididas e, desta forma, o mecanismo troca estas informações apenas dentro das áreas e, entre as áreas, normalmente apenas informação de alcançabilidade é trocada. Estas grandes divisões geram os chamados sistemas autônomos, onde dentro dos mesmos ocorre uma política de roteamento, e estão sob uma única administração.

A escalabilidade do BGP neste cenário é boa, suprindo as necessidades expostas devido à incompetência dos mecanismos intra-domínios neste ambiente. Esta escalabilidade pode ser alcançada através da possibilidade de manipulação de fluxos de tráfego e da utilização de endereçamento hierárquico, desta maneira o BGP possibilita que seja encontrado um determinado sistema autônomo de interesse, porém uma rede específica dentro deste sistema deverá ser encontrada por um protocolo de roteamento interno. Além da escalabilidade uma característica importante a ser lavada em consideração é a privacidade das informações trocadas entre os domínios, ou ASs, que em determinadas situações é um fator desejável, principalmente quando se trata de conectar duas organizações distintas, por exemplo (REKHTER; LI; HARES, 2006).

Em redes convencionais a utilização do BGP permite a alcançabilidade dos elementos de bordas das redes que pretendem se conectar, e esta alcançabilidade garante o acesso a determinados ASs ou domínios. Porém, nos cenários onde as redes convencionais estão integradas com as redes ópticas este fato não é possível devido à falta de informações adicionais, como os comprimentos de onda disponíveis para as conexões ou a largura de banda disponível. A figura 3.8 a seguir apresenta a falta de informação TE nos enlaces que conectam as redes entre um nó de origem e um nó de destino que desejam estabelecer uma rota. 


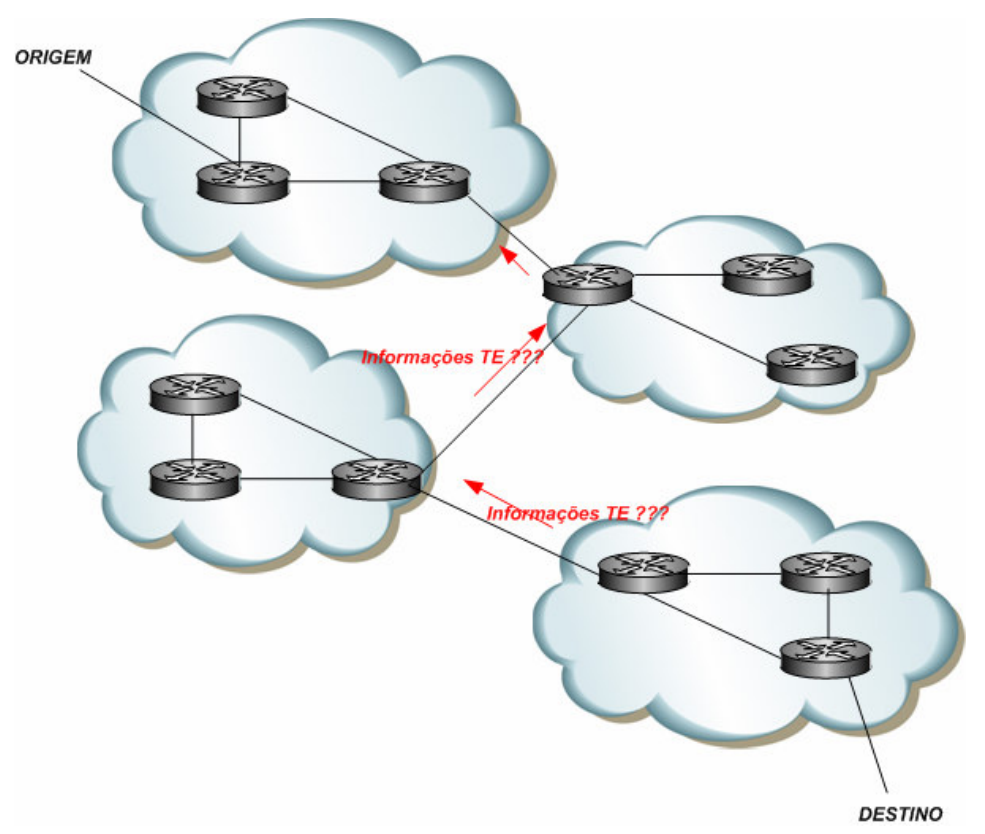

Figura 3.8 - Rede BGP e a falta de informações sobre as características dos enlaces

No caso da largura de banda há uma padronização em estudo (OULD-BRAHIM; FEDYK; REKHTER, 2006), para suprir esta necessidade. Sendo assim, existe a possibilidade de que um LSP não possa ser completado devido à falta de recursos não conhecida previamente. Do mesmo modo que ocorre com os mecanismos de roteamento intra-domínios sem informações dos enlaces, como o comprimento de onda disponível, a probabilidade de bloqueio para solicitações de estabelecimento de LSP aumenta (KHAIR, 2004). Como resultado, ocorrerão solicitações seguidas de configuração de LSP, em uma seqüência de tentativa e erro, até que uma das rotas escolhidas, em um determinado momento, possa realmente atender os requisitos desejados.

Em arquiteturas que utilizam a reserva de recursos de rede previamente para garantir que determinadas condições inicias possam ser satisfeitas para determinado tipo de tráfego, como a utilização do protocolo RSVP nas arquiteturas MPLS e GMPLS, este bloqueio na configuração do LSP é prejudicial ao desempenho da rede. Recursos alocados previamente e depois liberados, por não ter sido possível o estabelecimento de um LSP, podem fazer falta a outras solicitações que eventualmente tenham necessidade do mesmo recurso naquele momento em que 
estava reservado. $O$ ideal é que um recurso reservado seja realmente utilizado pelo elemento que realizou a requisição.

Há trabalhos que abordam o BGP como alternativa para conectar as redes ópticas com as redes convencionais, onde são apresentadas propostas de extensão ao mesmo através da inclusão de novas mensagens, por exemplo a criação da quinta mensagem no BGP, ou da extensão de mensagens já existentes como a inclusão de um novo atributo de caminho na mensagem Update, para que o BGP possa tratar de determinados parâmetros, como os comprimentos de onda disponíveis na rede (FRANCISCO; SIMPSON; PEZOULAS, 2001; FRANCISCO, 2002). Apesar destes estudos divulgados ainda não há realmente um padrão definido a ser seguido para que este mecanismo possa ser utilizado no cenário proposto das redes integradas.

\section{ii) PCE como Alternativa}

Uma padronização divulgada recentemente denominada PCE (FARREL; VASSEUR; ASH, 2006), se apresenta como alternativa viável para ser utilizada no mecanismo de roteamento inter-domínios das redes integradas.

Basicamente, a arquitetura proposta funciona com um ou mais elementos introduzidos na rede com a responsabilidade de computar as rotas e atender às solicitações dos outros elementos destas redes que desejarem estabelecer os LSPs para iniciar uma determinada transmissão.

Com este mecanismo, o problema anteriormente apresentado pelo BGP, de reservar recursos de forma desnecessária pelo caminho, sem saber que o LSP não poderá ser estabelecido devido à falta de recurso suficiente em algum ponto da rede, não existe. Não haverá desta forma uma seqüência de solicitações através de tentativa e erro, para que um LSP possa ser estabelecido, com os recursos desejados. Este mecanismo vai liberar a reserva de recursos apenas em rotas que ele tem certeza que possuí a capacidade suficiente, como largura de banda por exemplo, de atender 
as necessidades requeridas em todos os nós que atravessar. Desta maneira o bloqueio ocorre apenas quando realmente não houver recurso disponível para atender uma requisição, ou seja, os recursos estão realmente esgotados por estarem sendo utilizados, porém a diferença é que não serão reservados recursos previamente, deixando os mesmos disponíveis para outras eventuais requisições.

O próximo capítulo apresenta a arquitetura do PCE e discute sua utilização em redes integradas. 


\section{Arquitetura PCE (Path Computation Element)}

A arquitetura PCE, padronizada pelo IETF (FARREL; VASSEUR; ASH, 2006), pode ser definida como um mecanismo de roteamento com o objetivo de prover rotas executáveis aos elementos solicitantes, para que os mesmos possam estabelecer LSPs, que possuam os recursos necessários, para proporcionar a transmissão de dados desejada.

A motivação para o desenvolvimento desta arquitetura teve o intuito de aumentar o desempenho e a simplicidade de gerência, considerando os seguintes aspectos:

- Diminuição da alta utilização de processamento: os mecanismos de roteamento descritos anteriormente neste trabalho, normalmente requerem alta utilização de recursos, como processamento e memória, para lidar com informações dos estados dos enlaces. Principalmente nas redes integradas, onde devem ser levados em consideração muitos parâmetros como o atraso e a taxa de utilização de um enlace, a capacidade de comutação, características de adaptação, tipos de codificação, e outras informações do domínio óptico, conforme descrito nos capítulos 2 e 3 . A introdução do PCE como elemento responsável pelas rotas alivia esta demanda dos nós intermediários, muitas vezes com baixo poder de processamento.

- Melhor visibilidade da rede: em domínios separados um elemento de ingresso, como um roteador de borda em uma rede, pode não ter uma visão completa da topologia da rede, no caso em que o destino final de uma transmissão esteja em outro domínio. Conforme discutido, devido à falta de troca de informações de característica dos enlaces não serem realizadas entre diferentes domínios, ou ASs, pois apenas informações de alcançabilidade são trocadas, a rota estabelecida pode não ser a melhor alternativa, com as melhores métricas, ou até mesmo, esta rota pode ser negada e nem ser estabelecida. Neste caso o PCE cobre esta deficiência através do conhecimento completo da topologia. 
- Lidar com redes sem planos de controle: redes do domínio óptico podem não possuir planos de controle, ou seja, podem apresentar em sua configuração um plano de encaminhamento e um plano de gerenciamento. Neste cenário o PCE faria o papel do plano de controle para estas redes quando forem integradas e seria um elemento do seu plano de gerenciamento.

- Abranger redes sem capacidade TE: redes que não suportam algum tipo de base de dados de engenharia de tráfego, contendo as características dos seus enlaces ou redes que rodam protocolos de roteamento que não possuem capacidade, ou extensões, para manipular informações dos seus enlaces referentes à engenharia de tráfego.

A arquitetura PCE é descrita de forma detalhada a seguir.

\subsection{Elementos da Arquitetura}

Uma ou mais entidades, denominadas PCE (Path Computaion Element), são designadas para executar os cálculos das rotas através das informações obtidas sobre a topologia da rede e sobre os parâmetros dos enlaces desta rede, que vão além de informações de alcançabilidade. A padronização não define como estas informações são obtidas pelo PCE, porém indica a utilização de protocolos de roteamento com extensões TE, como o OSPF, por exemplo, ou qualquer outro tipo de disseminação dinâmica, ou até mesmo manual, executada pelo administrador da rede. Esta entidade pode se localizar em um elemento da própria rede, como um roteador, ou em um elemento independente como um servidor dedicado para esta tarefa.

Os clientes que fazem as requisições dos caminhos disponíveis pela rede, para o estabelecimento de futuros LSPs, são denominados PCC (Path Computation Clients). 
As comunicações, como a requisição de rotas e respectivas respostas, realizadas entre PCC e PCE ou PCE e PCE, são executadas através do protocolo PCE Protocol (ASH, LE ROUX, 2006; VASSEUR; LE ROUX, 2007; LE ROUX, 2006; BITAR; ZHANG; KUMAKI, 2006).

Podem existir topologias com mais de um PCE disponível para a resolução das requisições de rotas e, desta forma, existe um protocolo de descoberta de PCE, pelo PCC, de acordo com suas características, que é o PCE Discovery Protocol (LE ROUX, 2006).

A figura 4.1 apresenta uma topologia típica da arquitetura PCE onde existem vários domínios conectados, sendo que os domínios 1 e 3 possuem seus PCEs exclusivos, enquanto que os domínios 2 e 4 possuem o mesmo PCE para computar suas requisições de rotas.

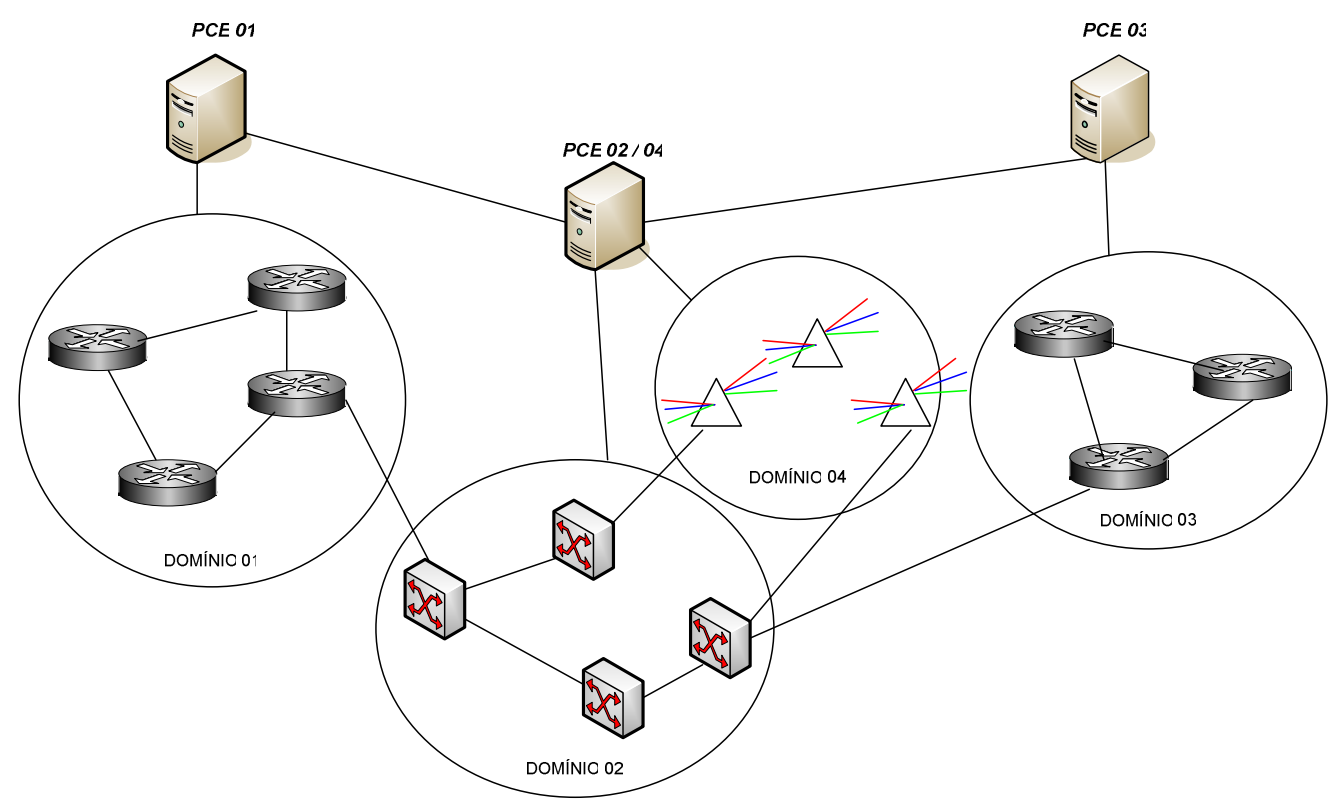

Figura 4.1 - Arquitetura PCE

O elemento PCE deve manter uma base de dados atualizada sobre os enlaces e recursos disponíveis na rede para que a computação das rotas possa ser realizada de acordo com a requisição dos PCCs. Segundo a definição da arquitetura, esta base de dados deve ser mantida por algum protocolo de roteamento interno com 
extensões TE, ou, de forma alternativa, outro tipo de mecanismo poderá ser utilizado como a transferência periódica da base completa, a inserção dos dados de forma manual, ou qualquer outro mecanismo que possa alimentar esta base, pois quanto maior a sincronização desta base de dados com a rede, e quanto maior for o detalhamento dos enlaces e recursos desta rede, melhores caminhos serão configurados.

\subsection{Configurações}

A seguir são apresentadas as formas de configuração para a arquitetura PCE, com relação à distribuição do seu elemento de computação de rotas pela rede.

\subsubsection{Computação Centralizada (Single PCE Computation)}

Existe apenas um elemento PCE com responsabilidade de computar as rotas de modo centralizado. Este elemento é o único a obter informações e detalhes sobre os enlaces e deve receber as requisições dos clientes que necessitam conhecer as rotas para sua transmissão. A figura 4.2 apresenta um único PCE conectado a vários domínios, seno responsável pela resolução das rotas relacionadas a estes domínios.

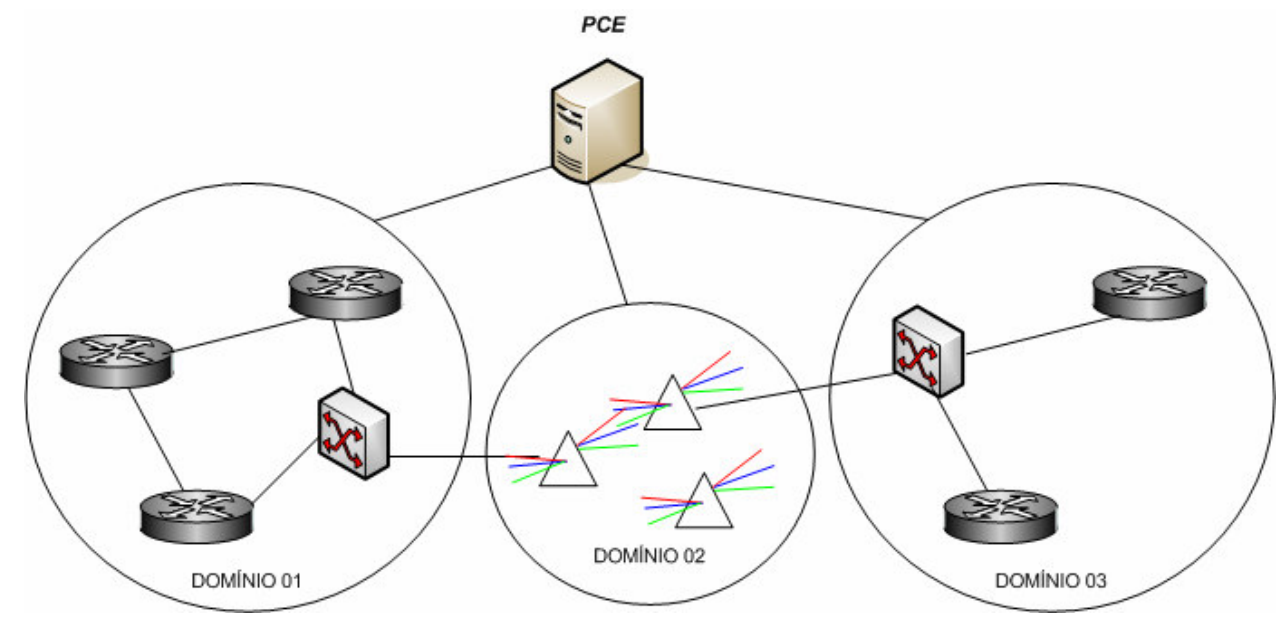

Figura 4.2 - Arquitetura com um único PCE 
Nesta configuração o tempo de estabelecimento do LSP pode ser menor do que na configuração apresentada a seguir, pois não há necessidade de consulta a outros PCEs na rede. Porém no caso de um aumento na quantidade de requisições além da capacidade de processamento do PCE, pode ocorrer um aumento na fila de requisições, e consequentemente um aumento no tempo de resposta às requisições.

\subsubsection{Computação Distribuída (Multiple PCE Computation)}

Existem PCEs em cada domínio ou camada da rede e através da cooperação entre os mesmos a rota requisitada pelo elemento solicitante pode ser estabelecida. Nesta configuração o tempo de estabelecimento do LSP pode ser maior comparando com a configuração anterior devido ao fato de que a rota final pode depender da solicitação de informações de outros PCEs espalhados pela rede. Em contrapartida, a utilização dos recursos computacionais nos PCEs pode ser menor, devido à distribuição das tarefas para o cálculo da rota final. Pode-se citar como exemplo PCEs Inter-domínios, Inter-camadas e Inter-AS, conforme ilustrado na figura 4.1.

\subsection{Comunicação entre os Elementos}

Neste item são descritos os principais protocolos que compõe a arquitetura PCE, com ênfase ao protocolo de requisição e resposta de rotas, o PCE Protocol.

\subsubsection{PCE Discovery Protocol (LE ROUX, 2006)}

A definição da arquitetura permite que vários elementos PCE possam atuar em uma rede. Estes elementos podem ser diferentes entre si, ou seja, cada um deles pode ter uma característica de processamento, políticas de acesso ou conhecimento da rede distintos. Por este motivo um PCC deve conhecer os PCEs disponíveis, e suas características, para que este PCC tenha condições de enviar sua requisição de rota para o PCE mais apropriado a responder de forma adequada sua solicitação. 
As principais características que um PCE pode divulgar são informações gerais sobre o mesmo, como seu endereço na rede, a visibilidade que o mesmo possui dos domínios, bem como informações mais específicas como a quantidade de requisições por segundo suportada, congestionamento, tamanho das mensagens de requisição, quantidade de mensagens de requisição na fila, camadas GMPLS suportadas, entre outras.

Para que o PCC conheça os PCEs disponíveis e suas características, a arquitetura possui o protocolo PCE Discovery Protocol. Além de permitir a escolha do PCE mais adequado em determinado momento, este protocolo também permite a detecção de qualquer modificação em um PCE bem como novos PCEs que eventualmente sejam adicionados na rede.

A arquitetura também deixa livre a implantação do mecanismo de descoberta dos PCEs, não amarrando à utilização do protocolo PCE Discovery Protocol, ou seja, esta configuração pode ser manual ou através da utilização de outros protocolos de roteamento internos como o OSPF, porém com as devidas extensões descritas em (LE ROUX et al., 2006a; LE ROUX et al., 2006b).

\subsubsection{PCE Protocol (VASSEUR; LE ROUX, 2007)}

Verificou-se anteriormente que a arquitetura PCE opera com uma base de dados dos enlaces das redes, e as propriedades destes enlaces, no elemento chamado PCE, sendo este elemento o responsável por calcular a melhor rota, consultando esta base de dados, em resposta a uma requisição que chega para o mesmo, originada pelo elemento requisitante chamado PCC. A requisição de rota deve incluir identificações de origem e destino da rota, bem como um conjunto de parâmetros sobre o estado dos enlaces, necessários à transmissão do elemento requisitante, que serão inclusos no cálculo da rota final. A resposta do PCE deverá incluir a rota desejada ou o motivo da falha na computação desta rota, se for o caso. 
Desta forma, percebe-se que a comunicação entre os elementos PCC e PCE, e entre PCEs, é uma peça fundamental para o funcionamento da arquitetura. Esta comunicação é realizada através de um protocolo de comunicação desenvolvido para esta tarefa, denominado PCE Protocol, ou simplesmente PCEP. De uma forma geral este protocolo permite que o PCC possa enviar solicitações de rotas ao PCE, e que este PCE possa devolver uma resposta contendo a rota entre a origem e o destino, com os requisitos TE atendidos, de volta ao PCC. Além disto, permite a comunicação entre os PCEs, da mesma forma, através de solicitações e respostas, para possibilitar cooperação entre eles, caso haja mais de um PCE na topologia, a fim de resolver a rota requisitada e entregar a resposta ao PCC solicitante. Como exemplo pode-se citar o caso de um PCE localizado na borda de uma rede MPLS e um outro PCE localizado na borda de uma rede óptica, onde cada um deles possui o conhecimento das rotas configuradas dentro do seu domínio. Sendo assim, uma rota fim-a-fim que tenha que atravessar estes domínios deverá ser computada a partir da cooperação entre os PCEs, e, neste caso, um deverá solicitar uma rota ao outro através do protocolo PCE Protocol. Importante notar que não há nenhuma modificação no protocolo para operar entre PCC e PCE ou entre PCEs.

O PCE Protocol foi elaborado com a preocupação de ser um protocolo flexível e que proporcione capacidade para permitir extensões, ou seja, novas mensagens e objetos poderão ser incluídos neste protocolo para acomodar futuras necessidades.

O transporte do PCE Protocol é realizado sobre TCP, tornando desta forma a comunicação entre os elementos confiável e permitindo o controle do fluxo, sem que o protocolo tenha que se preocupar, ou seja, tornando o PCE Protocol livre destas funções. 


\section{i) Fluxo Geral do Funcionamento}

A figura 4.3 a seguir, apresenta o fluxograma do mecanismo de requisição de rotas por um elemento PCC a um elemento PCE, na arquitetura PCE, sendo detalhadas, na seqüência, as responsabilidades de cada um.

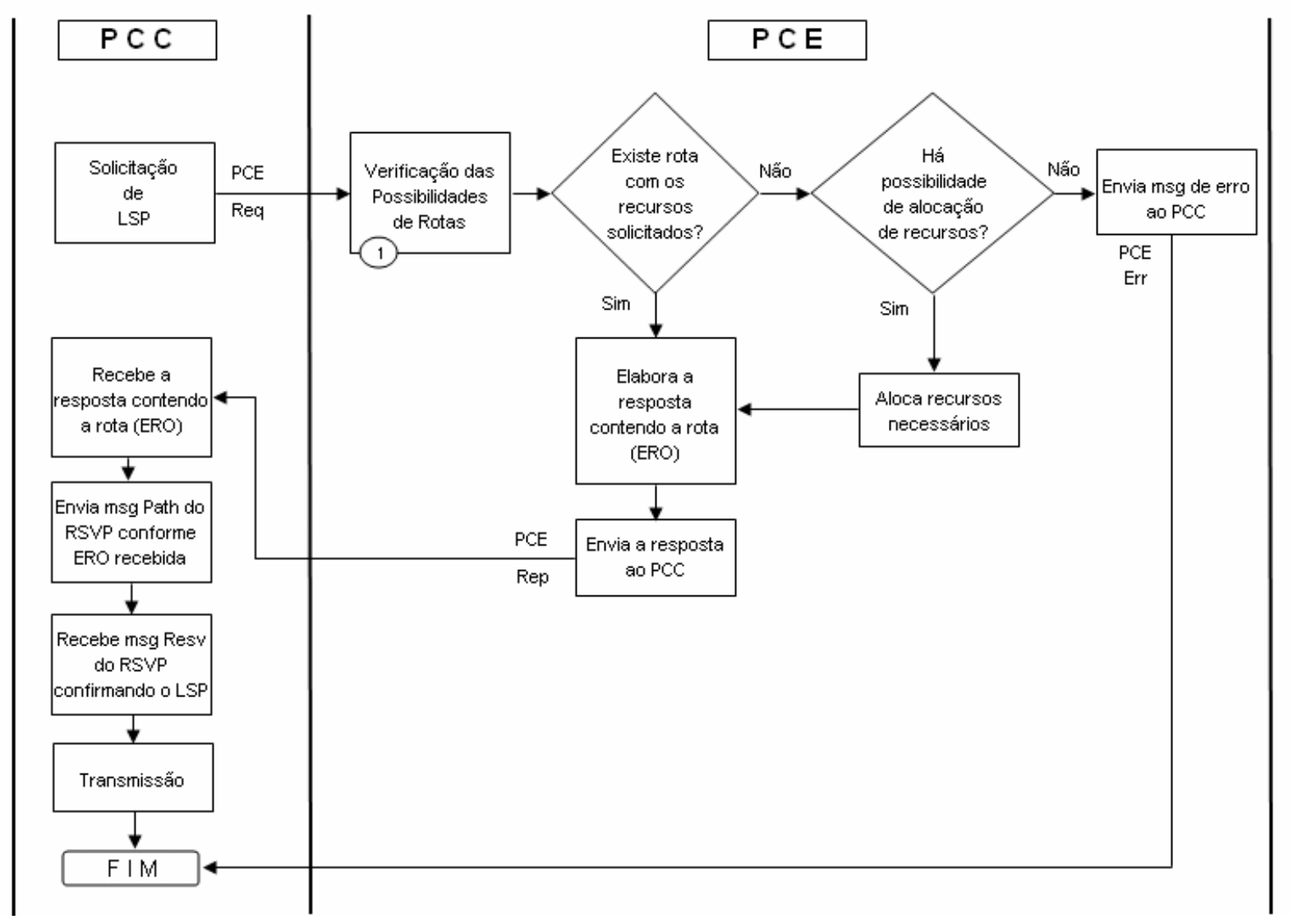

Figura 4.3 - Fluxograma do mecanismo de requisição de rotas e respostas da arquitetura PCE

As solicitações de cálculo de rotas, entre uma origem e um destino, é possível com a utilização da mensagem PCReq. Esta mensagem é enviada, contendo um conjunto de especificações, que deverão ser consideradas para a configuração da rota requisitada. Estas especificações estão contidas em objetos que definem o tipo de rota desejada, ou seja, são parâmetros que podem ser enviados para que sejam levados em consideração no cálculo da rota, como a origem e destino da transmissão, a largura de banda entre outros. A seguir serão apresentados, de forma detalhada, os objetos suportados por esta mensagem, visto que o foco deste 
trabalho é a análise do comportamento do mesmo em determinadas situações e a extensão deste protocolo para lidar com parâmetros de QoT.

Após calcular a rota possível, de acordo com os parâmetros solicitados, a mensagem PCRep é enviada como resposta ao solicitante. Esta mensagem contém objetos definidos que podem ser enviados como um ERO (Explicit Route Object), por exemplo, para ser utilizado posteriormente pelo RSVP na reserva dos recursos da rede para a configuração do LSP desejado. Caso haja indisponibilidade de rota em outra camada naquele instante, como na camada óptica, há a possibilidade de tentativa de alocação da mesma naquele momento. Caso a nova alocação possa ser realizada com sucesso, a rota é passada ao PCC requisitante através do PCRep, caso contrário, uma informação de falha é gerada e passada ao requisitante, através do PCErr juntamente com os parâmetros que não foram atendidos, e como os mesmos deveriam ser relaxados.

A seguir serão detalhados os objetos que esta mensagem pode carregar.

- Observação: A aplicação PCE verifica a rota possível utilizando, por exemplo, o CSPF. Esta rota deverá atender as necessidades da solicitação enviada, pois o PCE possui a informação sobre os parâmetros dos enlaces da rede (informação TE). Neste fluxo apresentado, apenas um PCE elabora a rota, porém vários PCEs podem estar conectados, onde cada um conhece uma parte da rede, e em conjunto, através de perguntas e respostas entre eles, podem elaborar uma rota final ao requisitante. Desta forma, quando a mensagem Path do RSVP é enviada pelo solicitante para a reserva de recursos pela rede, o mesmo tem a certeza de que a rota escolhida possui as características mínimas necessárias para atender os requisitos do seu fluxo.

\section{ii) Detalhes das Mensagens do PCE Protocol}

O PCE Protocol possui um conjunto definido de mensagens para sua operação, sendo estas mensagens descritas abaixo. 
Open: inicializar uma sessão PCEP;

Keepalive: manter uma sessão PCEP;

PCReq: mensagem PCEP enviada pelo PCC ao PCE para requisitar a elaboração de uma determinada rota;

PCRep: mensagem PCEP enviada pelo PCE ao PCC como resposta a uma solicitação de rota. Esta mensagem pode conter a rota solicitada caso tenha sido possível computar a mesma de acordo com os parâmetros solicitados, ou uma resposta negativa caso não tenha sido possível computar a rota desejada;

PCErr: mensagem enviada caso tenha ocorrido uma condição de erro do protocolo, por exemplo no caso do PCE receber qualquer mensagem do PCE Protocol antes de uma mensagem Open;

PCNtf: mensagem de notificação enviada pelo PCC ao PCE, ou ao contrário, para informar um evento específico, como por exemplo uma requisição enviada pelo PCC ao PCE que não necessita mais ser processada, ou uma informação do PCE ao PCC sobre congestionamento que o PCE esteja enfrentando;

Close: utilizada para encerrar uma sessão PCEP.

Após o estabelecimento da sessão TCP entre os elementos PCC e PCE, ou entre PCEs, a mensagem de Open pode ser enviada para inicializar a utilização do $P C E$ Protocol. Além deste procedimento de estabelecimento de sessão, mensagens de keepalive são trocadas entre os elementos para verificação do estado ativo dos mesmos.

Estes procedimentos podem ser verificados através da figura 4.4. 


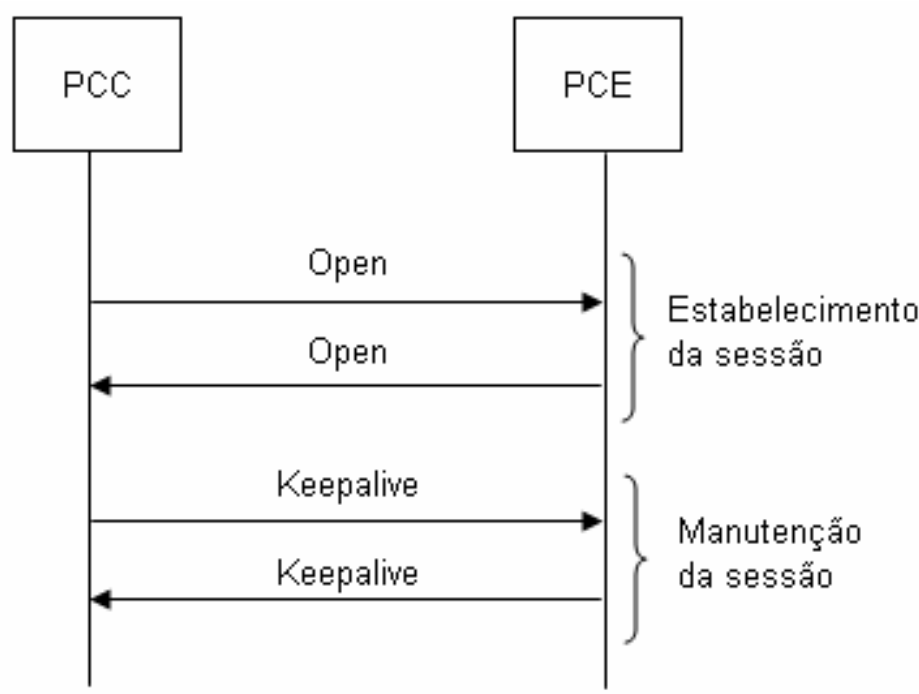

Figura 4.4 - Fluxo das Mensagens Open e Keepalive

Após o estabelecimento da sessão, o PCC está habilitado a enviar uma requisição de rota ao PCE, conforme apresentado na figura 4.5, contendo, por exemplo, os endereços de origem e destino da rota, além de parâmetros dos enlaces como a largura de banda mínima necessária para o LSP.

Eventos no PCC:

1. Ocorre uma necessidade de requisiçẫo de rota; 2. Escolhe o PCE adequado;

3. Envia a mensagem de requisiçẫo de rota ao PCE escolhido

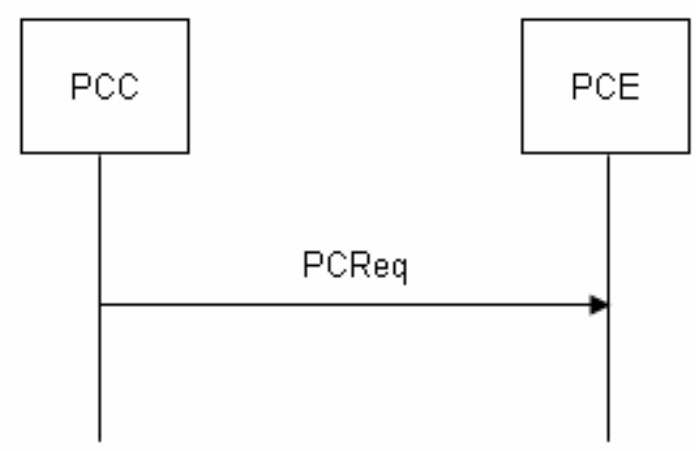

Figura 4.5 - Fluxo da Mensagem PCReq

Quando o PCE recebe a mensagem de requisição de rota, o mesmo efetua os cálculos necessários e escolhe a rota capaz de atender todos os requisitos solicitados, em seguida elabora a mensagem de resposta, PCRep, e a envia ao solicitante. No caso de não conseguir uma rota som os requisitos solicitados, elabora 
uma mensagem de resposta, porém negativa, contendo os parâmetros que não puderam ser atendidos. A figura 4.6 e 4.7 ilustram estes procedimentos.

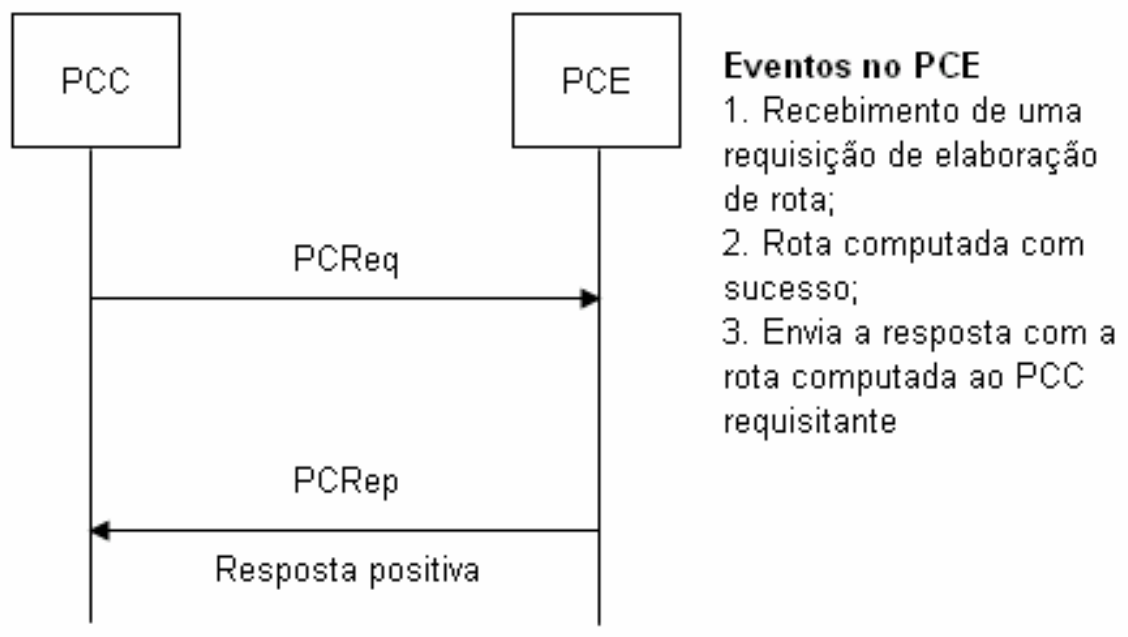

Figura 4.6 - Fluxo da Mensagem PCRep positiva

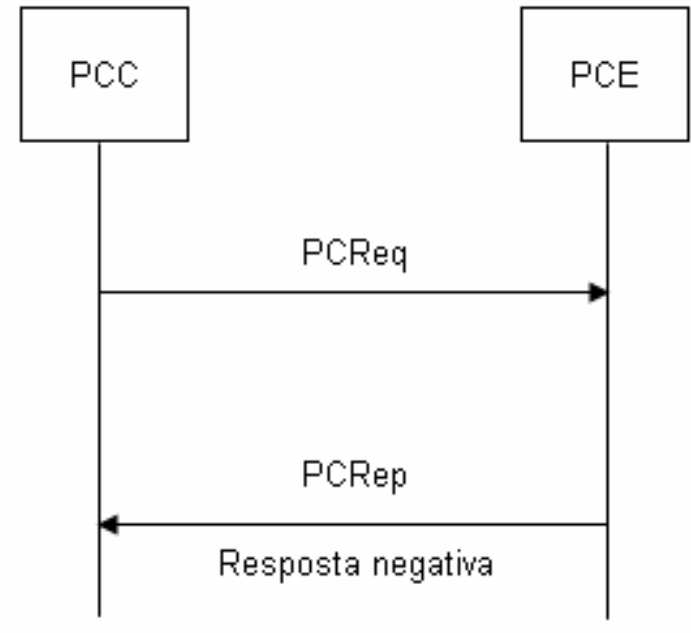

\section{Eventos no PCE}

1. Recebimento de uma requisiçẫo de elaboraçẫo de rota; 2. Nẫo existe rota disponivel que atende todos os parâmetros solicitados;

3. Envia a resposta negativa ao $\mathrm{PCC}$, opcionalmente com informaçỗes sobre os parâmetros nẫo atendidos.

Figura 4.7 - Fluxo de Mensagem PCRep negativa 


\section{iii) Composição das Mensagens do PCE Protocol}

Este item apresenta as estruturas das mensagens utilizadas para a análise de tráfego realizadas neste trabalho. As mensagens analisadas foram PCReq, PCRep, Open e Close. Os detalhes de cada campo das mensagens e dos objetos que constituem estas mensagens estão definidos em (VASSEUR; LE ROUX, 2007).

A princípio as mensagens de interesse são PCReq e PCRep, pois as mesmas carregam todas as informações necessárias para a requisição de rotas e resposta para as mesmas, gerando desta forma um fluxo importante a ser analisado na rede. Porém as mensagens Open e Close também foram incluídas no escopo, pois em uma das formas de implantação da arquitetura PCE estas mensagens são utilizadas em cada requisição de rota. Outra implantação permite que elas sejam utilizadas com menor freqüência, porém com o objetivo de analisar o caso mais severo, foi escolhida a implantação onde as mensagens Open e Close sempre são utilizadas.

\section{- Mensagem Open}

A mensagem Open foi utilizada nas simulações deste trabalho com o tamanho de 160 bits, conforme definido na padronização e apresentado na figura 4.8, a seguir.

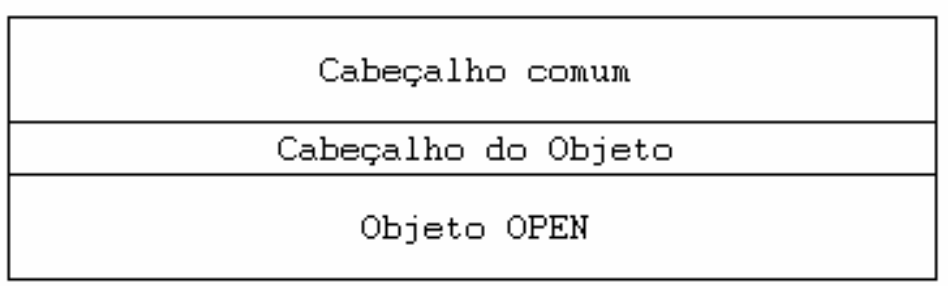

Figura 4.8 - Estrutura da mensagem Open
64 bits

32 bits

64 bits (min.)

Importante notar que esta mensagem possui a função de estabelecer uma sessão entre duas entidades da arquitetura. Porém permite também a troca de informações sobre as características dos elementos como as capacidades do PCE, regras e políticas adotadas. Desta forma o Objeto Open é aberto para que sejam adicionadas 
TLVs conforme a necessidade no estabelecimento da sessão inicial entre as entidades.

\section{- Mensagem Close}

A mensagem Close foi utilizada nas simulações deste trabalho com o tamanho de 160 bits, conforme definido na padronização e apresentado na figura 4.9, a seguir.

\begin{tabular}{|c|}
\hline Cabeçalho oomuJi \\
\hline Cabeçalho do Objeto \\
\hline Objeto CLOSE \\
\hline
\end{tabular}

64 bits

32 bits

64 bits (min.)

Figura 4.9 - Estrutura da mensagem Close

A mensagem Close possui a função de encerrar uma sessão estabelecida entre as entidades da arquitetura e seu objeto prevê algumas situações possíveis para o encerramento da sessão. Da mesma forma que ocorre com a mensagem Open, a mensagem Close também abre possibilidades de incluir novas TLVs em seu objeto para contemplar necessidades futuras.

\section{- Mensagem PCReq}

A mensagem PCReq possui a função de requisitar uma rota a um PCE, de acordo com parâmetros estabelecidos. Esta mensagem possui um tamanho variável devido à característica de possibilitar a inclusão de determinados parâmetros, e pelo fato destes parâmetros poderem assumir diferentes valores para cada requisição.

A seguir, a figura 4.10 apresenta a estrutura da mensagem PCReq, conforme definição da padronização. 


\begin{tabular}{|c|}
\hline Cabecalho Comum \\
\hline Cabeçalho do Objeta \\
\hline Objeta SVEC \\
\hline Cabecalho do Objeto \\
\hline Objeto RP \\
\hline Cabeçalho do Objeto \\
\hline Objeto End-Foints \\
\hline Cabeçalho do Objeta \\
\hline Objeta LSPA \\
\hline Cabeçalho do Objeta \\
\hline Objeta BW \\
\hline Cabecalho do Objeto \\
\hline Objeto MET \\
\hline Cabecalho do Objeto \\
\hline Objeto RRo \\
\hline Cabeçalho do Objeta \\
\hline objeto IRO \\
\hline Cabeçalho do Objeta \\
\hline Objeto Load-Balancing \\
\hline
\end{tabular}

64 bits

32 bits

64 bits (min.)

32 bits

64 bits (min.)

32 bits

64 bits (min.)

32 bits

32 bits (min.)

32 bits

32 ou 64 bits

32 bits

64 bits (mín.)

32 bits

Múltiplos de 64 bits

32 bits

Múltiplos de 64 bits

32 bits

G4 bits

Figura 4.10 - Estrutura da mensagem PCReq

\section{- Mensagem PCRep}

A mensagem PCRep possui a função de responder a uma solicitação de rota recebida pelo PCE e computada pelo mesmo. Esta mensagem contém, fundamentalmente, um objeto ERO que representa a rota calculada pelo PCE, além de outros objetos.

Da mesma forma que a mensagem PCReq, esta mensagem possui um tamanho variável devido à sua flexibilidade que permite a inclusão de determinados 
parâmetros, e também pelo fato destes parâmetros poderem assumir diferentes valores para cada resposta.

A seguir, a figura 4.11 apresenta a estrutura da mensagem PCRep, conforme definição da padronização.

\begin{tabular}{|c|}
\hline Cabegalho comum \\
\hline Caberalho do objeto \\
\hline Objeta SVEC \\
\hline Caberalho do Objeto \\
\hline Objeta RF \\
\hline Cabegalho do Objeta \\
\hline No-Path \\
\hline Cabegalho do objeto \\
\hline Objeto ERO \\
\hline Cabegalho do objeto \\
\hline Objeta LSFA \\
\hline Caberalho da Objeta \\
\hline Objeta $\mathrm{BW}$ \\
\hline Cabegalho do Objeta \\
\hline Objeto MET \\
\hline Cabegalho do Objeto \\
\hline Objeto IFO \\
\hline
\end{tabular}

B4 bits

32 bits

64 bits (min.)

32 bits

64 bits (min.)

32 bits

32 bits (min.)

32 bits

Múltiplos de 64 bits

32 bits

32 bits (min.)

32 bits

32 bits

32 bits

64 bits (min.)

32 bits

Múltiplos de 64 bits

Figura 4.11 - Estrutura da mensagem PCRep

\subsection{Considerações Adicionais com Relação ao PCE em Comparação ao BGP como Alternativa para o Mecanismo de Roteamento Inter-domínios}

De acordo com todas as definições e análises apresentadas nos capítulos anteriores verifica-se que as redes integradas, como as redes GMPLS por exemplo, exigem capacidades especiais dos mecanismos de roteamento, principalmente pelo fato das redes ópticas possuírem certas particularidades que os mecanismos das redes 
convencionais não conseguem atender, a não ser que ocorra modificações e extensões nos mesmos.

Com relação ao roteamento inter-domínios especificamente, seguem algumas considerações sobre qual a alternativa mais interessante a ser adotada entre as duas possibilidades expostas anteriormente que são o BGP e o PCE.

Verifica-se que são conceitos um pouco diferentes visto que o BGP se trata de um protocolo de roteamento e o PCE é uma arquitetura, ou seja, um esquema mais elaborado para solucionar os problemas de roteamento. Porém ambos têm como objetivo final proporcionar um caminho entre dois pontos, e podem ser utilizados em ambientes inter-áreas, sendo que o BGP realiza esta tarefa em cada nó da rede (hop-by-hop), através das tabelas de roteamento em cada um destes nós, e o PCE de uma forma fim-a-fim, ou seja, computando a rota na sua totalidade.

Como o objetivo, ou resultado final, de ambos é o mesmo, ou seja, possibilitar a comunicação entre dois pontos proporcionando uma rota entre estes pontos, a comparação deverá ser feita verificando-se as características de ambos com relação ao atendimento dos requisitos de uma rede multi-camadas e multi-domínios (arquitetura GMPLS) com relação a capacidade de formar um LSP fim-a-fim.

Em um cenário que utiliza o BGP o requisitante deverá enviar a mensagem Path do protocolo RSVP diretamente para o próximo passo da rede, ou seja, o próximo nó segundo a tabela de roteamento. Este procedimento é realizado passo a passo, e enquanto houver recurso disponível pelos nós que vão sendo atravessados, o caminho pode ser estabelecido, até encontrar o destino final. Caso haja recurso suficiente por toda a rota o LSP pode ser estabelecido.

No cenário onde o PCE é utilizado, o requisitante envia a mensagem PCReq solicitando uma rota para o PCE, e caso haja recurso disponível a mensagem de 
resposta PCRep com a rota (ERO) é devolvida, e desta forma o requisitante pode enviar o RSVP para estabelecer o LSP.

Em ambos os casos, se não houver recursos suficientes haverá negação ao estabelecimento do LSP (crankback para o BGP e mensagem PCErr para o PCE).

Porém no caso do PCE há duas alternativas distintas no caso de não haver recurso disponível no momento:

1. Não há recursos porque estão todos realmente ocupados, desta forma haverá negação realmente.

2. Não há recursos, porém por falta de configuração na camada mais baixa (camada óptica por exemplo). Ou seja, não é o caso do recurso estar ocupado mas de não estar configurado naquele momento.

Neste caso o PCE poderá sinalizar esta situação ao responsável pela configuração dos circuitos nas camadas inferiores e o LSP das camadas inferiores poderá ser estabelecido, sendo disponibilizado desta forma o recurso necessário para 0 estabelecimento do LSP fim-a-fim.

Nesta situação o PCE pode informar a possível rota, porém ainda não configurada, de um novo circuito óptico por exemplo, para o requisitante. O processo de sinalização é iniciado pela camada superior e o novo caminho óptico poderá ser configurado, evitando o bloqueio.

Outro aspecto importante é que o fato do cenário onde se utiliza o BGP não conseguir estabelecer a rota em algum ponto da rede devido à falta de recursos apresenta agravantes, como a perda de tempo em tentar uma conexão mal sucedida e a reserva de recursos desnecessários ao longo do caminho impedindo talvez o estabelecimento de outro LSP caso o mesmo seja desejado naquele momento. 
Percebe-se que quanto mais distante da origem ocorrer o bloqueio maior o impacto negativo causado por esta situação.

Através das considerações anteriores, não é difícil perceber que quanto menos recursos a rede possui, maiores serão as dificuldade em se estabelecer um LSP. Porém no caso do PCE não serão alocados recursos desnecessários durante o processo e também não ocorrerá o procedimento de tentativa e erro até que uma rota possível seja estabelecida.

\subsection{Aspectos Negativos}

Apesar das características positivas da arquitetura PCE descritas neste capítulo, podemos observar alguns aspectos negativos de sua implementação, sendo eles:

- Escalabilidade limitada: a escalabilidade é um aspecto questionável para sua utilização como mecanismo de roteamento para a Internet, pois esta arquitetura é considerada aplicável a um conjunto de domínios com relações conhecidas.

- Impacto na operação da rede: a operação da rede pode ser impactada com relação ao tempo de atendimento para estabelecimento de um determinado LSP, pois o mesmo depende de uma consulta a um mecanismo que vai calcular a rota requisitada sob demanda, de forma diferente de um protocolo convencional, onde o que ocorre é uma consulta a tabela de rotas. Efeito a ser analisado através de estudos adicionais, pois no caso dos protocolos convencionais, se o LSP não puder ser estabelecido na primeira tentativa, o seu tempo de estabelecimento já não é apenas o tempo de consulta de uma tabela de rotas, e vai aumentando a cada LSP não estabelecido, ou seja, a cada tentativa e erro.

O tráfego gerado pelas requisições de rotas realizadas pelos elementos solicitantes pode sofrer aumentos inesperados caso ocorram muitas requisições, e gerar 
impacto negativo no funcionamento da rede. Este comportamento é simulado e analisado nos próximos capítulos, e então o impacto deste tráfego em diversos enlaces das redes será apresentado.

- Ausência de tratamento para QoT: os documentos de padronização da arquitetura do PCE, não incluem no seu mecanismo de requisição de rotas, e respectiva resposta para as solicitações, parâmetros específicos sobre a qualidade da transmissão de um sinal óptico, ou Qualidade de Transmissão (QoT). Esta ausência permite que as rotas sejam computadas sem que restrições importantes sejam levadas em consideração, podendo ocasionar o estabelecimento de rotas sem a capacidade de transmissão adequada, devido à falta de QoT. No próximo capítulo, uma extensão ao protocolo de requisição de rotas utilizado pelo PCE é proposta com o objetivo de preencher esta lacuna com relação ao tratamento de QoT, e em seguida, simulações e análises do novo impacto causado nos enlaces da rede são apresentadas. 


\section{Proposta para Extensão do Protocolo PCE Protocol}

As redes ópticas e sua integração com as redes convencionais possuem determinados requisitos que devem ser levados em consideração no momento de sua conexão, e no planejamento do plano de controle que será adotado para gerenciar sua operação integrada. Conforme descrito anteriormente no capítulo 2 , existem vários aspectos importantes que influenciam diretamente na qualidade da transmissão de um sinal óptico. Estes aspectos não devem ser relevados no processo de integração das redes, sob a argumentação de que, no momento do desenho e da implantação da solução do domínio óptico, todos os problemas relacionados à transmissão óptica serão tratados e resolvidos. Este argumento, válido inicialmente, na prática não pode ser sustentado, após uma análise mais ampla, quando são levadas em consideração variáveis como:

- O envelhecimento dos elementos de transmissão como as fibras, transmissores e receptores, entre outros, onde as características iniciais dos mesmos modificam-se ao longo de sua vida útil;

- A interferência do ambiente como temperatura e a acomodação dos cabos de fibra, entre outros;

- A modificação nas taxas de transmissão e na quantidade de canais transmitidos em uma mesma fibra, com conseqüente aumento na potência dos sinais, podendo causar vários efeitos indesejados para a transmissão;

- A conexão de redes distintas, de organizações distintas e tecnologias distintas, onde, em uma parte da rede, determinada característica pode ser mais importante que em outra parte, sendo assim tratadas de forma diferenciada.

Estas variáveis, em conjunto com os fatores relevantes que causam degradação na transmissão do sinal óptico, interferindo diretamente na qualidade da transmissão, são atualmente definidas como QoT (Quality of Transmission) (EZZAHDI et al., 2006; LIVAS, 2005; AL ZAHR et al., 2005; DURRESI et al., 2003) 
Devido a estes fatores de QoT, nota-se que nem todos os caminhos entre dois pontos de uma rede podem garantir capacidade suficiente para suportar os requisitos mínimos exigidos por determinadas aplicações. Nota-se que somente a garantia de conectividade entre dois nós que desejam se comunicar, sendo uma origem e um destino, através de determinados enlaces pela rede, com a capacidade de banda requerida, e os comprimentos de onda, ou lambdas, disponíveis ao longo desta rota, podem não ser suficientes para garantir o sucesso da transmissão, com QoT suficiente, de acordo com as particularidades da aplicação. Em um determinado caminho selecionado podem existir enlaces com parâmetros como o atraso, ou a taxa de erros, inaceitáveis para certas aplicações, ou até mesmo podem apresentar uma qualidade de transmissão do sinal óptico degradada, devido a diversos fatores já descritos neste trabalho, de forma que mesmo uma simples transmissão, sem requisitos especiais de QoT solicitados pela aplicação, pode não ser possível devido ao não discernimento do sinal no destino, ou à alta taxa de erros imposta por este caminho.

Conforme mencionado, existem aplicações que exigem determinados requisitos mínimos para que possam operar de forma satisfatória enquanto outras são menos exigentes para tais requisitos, porém necessitam de outros distintos. Em resumo, há alguns perfis de aplicações distintos entre si, cada um com suas necessidades específicas de recursos de rede para funcionar corretamente. Pode-se citar o caso de aplicações mais comuns, e amplamente utilizadas, como serviços de comércio e banco eletrônico, correio eletrônico, transferência de arquivos, e as aplicações mais específicas como telemedicina, ensino à distância e teleconferência.

Grande parte das aplicações, por exemplo, necessitam de taxas de erro entre $10^{-9} \mathrm{e}$ $10^{-15}$, tipicamente $10^{-12}$ (RAMASWAMI; SIVARAJAN, 2002), porém, podem existir casos extremos, que exigem como requisito mínimo, com relação a taxa de erros, valores mais agressivos, como é o caso do padrão Open Base Station Architecture Initiative (OBSAI), que necessita de um valor de BER melhor que $10^{-15}$ (SUBBIAH, 2006). 
Desta forma, percebe-se facilmente que um mecanismo de roteamento que não leva em consideração a QoT necessária, com determinados parâmetros mínimos de qualidade do sinal, e apenas oferece um caminho entre dois pontos da rede, não é capaz de entregar rotas com a capacidade suficiente de recursos para certas aplicações, e deste modo, estas aplicações podem desempenhar um mau funcionamento, ou até mesmo não funcionar.

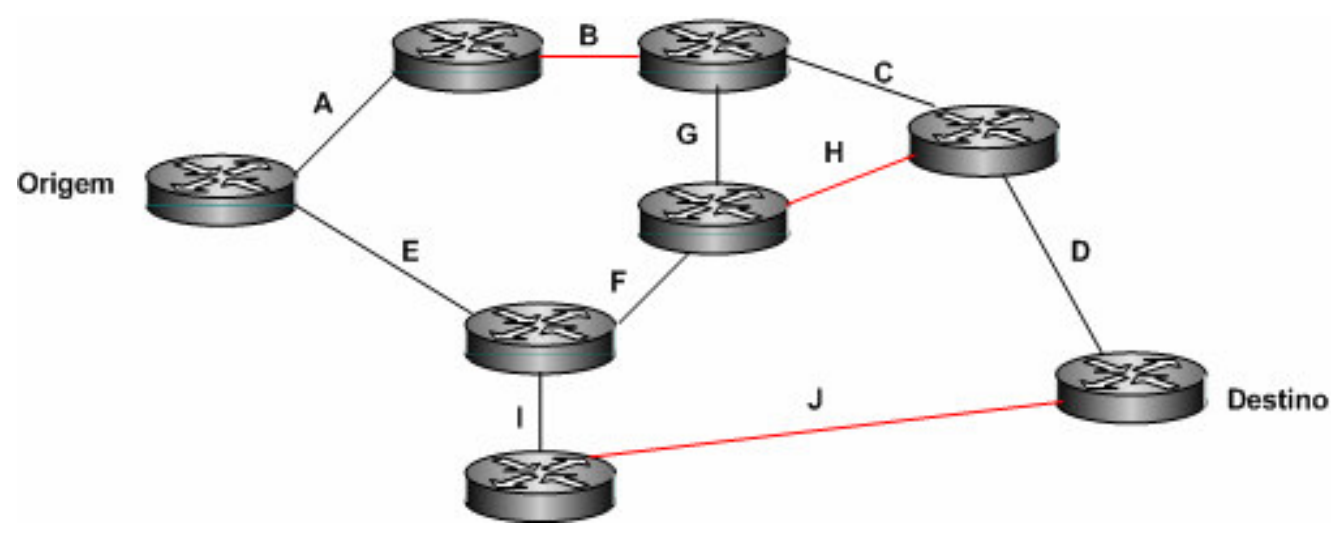

Figura 5.1 - Alternativas de caminhos entre dois nós

A figura 5.1 apresenta uma pequena rede com caminhos alternativos para que o nó identificado como Origem possa se comunicar com o nó identificado como Destino.

Supondo, no cenário ilustrado pela figura 5.1, que o requisito de qualidade QoT, necessário para o sucesso da transmissão é o BER, e que os enlaces $\mathrm{B}, \mathrm{H}$ e $\mathrm{J}$ degradam o sinal óptico devido às características de suas fibras e dispositivos de transmissão, e portanto não conseguem oferecer uma qualidade mínima aceitável. Desta forma a rota a ser escolhida neste caso é aquela que apresenta a maior quantidade de saltos, através dos enlaces E-F-G-C-D.

Se este parâmetro de qualidade não fosse considerado, outra rota mais curta provavelmente seria escolhida, como a rota E-I-J, porém a transmissão seria prejudicada devido à falta de qualidade oferecida pela infra-estrutura desta rede, especificamente pelo enlace J. 
A seguir, na tabela 5.1, são apresentadas as características de determinadas aplicações com relação às suas exigências para determinados parâmetros de rede.

Tabela 5.1 - Requisitos das aplicações com relação a QoS

\begin{tabular}{|c|c|c|c|c|c|c|}
\hline & \multicolumn{6}{|c|}{ Aplicação } \\
\hline Requisitos & Dados & Dados Gráficos & Voz & Voz Interativa & Vídeo & $\begin{array}{c}\text { Video em } \\
\text { Tempo Real }\end{array}$ \\
\hline Largura de Banda & $\mathrm{PE}$ & $E$ & $E$ & $E$ & $\mathrm{ME}$ & $\mathrm{ME}$ \\
\hline Atraso & PE & $\mathrm{PE}$ & $\mathrm{ME}$ & ME & $E$ & ME \\
\hline Variaçäo do Atraso & $\mathrm{PE}$ & PE & ME & ME & $E$ & ME \\
\hline Taxa de Erros & $E$ & $\mathrm{ME}$ & $\mathrm{PE}$ & $\mathrm{PE}$ & $\mathrm{E} /(\mathrm{PE})$ & $\mathrm{ME} /(\mathrm{E})$ \\
\hline
\end{tabular}

PE: Pouco exigente; E: Exigente; ME: Muito exigente

GABOS, D.; CARVALHO, T.C.; BASTOS, V. Curso Tecnologias Convergentes. Larc/PCS/EPUSP, 2004

Conforme detalhamento apresentado acerca da necessidade de informações adicionais sobre a qualidade dos enlaces, com relação à transmissão de um sinal óptico, o QoT, para subsidiar a escolha da melhor alternativa de rota que possa atender aos requisitos das aplicações, o QoS, como aquelas apresentadas na tabela 5.1, é proposta a seguir uma extensão ao protocolo PCE Protocol.

O objetivo da extensão do protocolo PCE Protocol é proporcionar aos PCCs requisitantes de rotas a possibilidade de informar seus requisitos, com limites mínimos aceitáveis, sobre determinados parâmetros de qualidade dos enlaces, de acordo com os requisitos de sua aplicação, para que o PCE possa incluir esta informação no momento da computação da rota solicitada.

Com o intuito de que as extensões propostas possam ser melhor entendidas, é importante apresentar algumas considerações a respeito das informações que serão computadas e disseminadas entre os nós.

Em (DURRESI et al., 2003) pode-se verificar um exemplo de algoritmo que se propõe a utilizar qualidade do sinal óptico para o cálculo de rotas. Este algoritmo propõe a utilização de um valor único e padronizado como um limite aceitável de qualidade de sinal, sendo que este valor é representado por um perfil de sinal (eye diagram) com qualidade mínima aceitável. Os valores dos enlaces que deverão ser 
comparados com este limite devem ser obtidos da rede, através da utilização de dispositivos específicos e dedicados para esta tarefa, denominados coletores.

Outro trabalho que propõe um valor único para medir a qualidade é (AL ZAHR et al. 2005), onde o mesmo sugere que este valor seja uma composição dos valores individuais de outros quatro parâmetros que são a dispersão cromática, PMD, OSNR e o deslocamento de fase não-linear. Esta composição gera um fator global, denominado fator $Q_{g}$, e se relaciona diretamente ao BER.

Outra abordagem, diferente de utilizar um valor único como referência à qualidade do sinal óptico é a utilização de mais de uma informação, considerando os parâmetros de forma individualizada, pois existem vários fatores que degradam 0 sinal óptico em uma transmissão, conforme descrito anteriormente, no item 2.4. Mas, mesmo assim, a disseminação destas informações pode ser difícil, como no caso dos efeitos não lineares que ocorrem nas fibras em determinadas situações. Nesta situação, uma série de características relevantes sobre as fibras utilizadas nos enlaces ao longo das rotas, sobre o tipo de transmissão, entre várias outras, devem ser conhecidas. Neste caso, a recomendação a ser observada é a tradução de efeitos importantes, porém difíceis de serem coletados e/ou disseminados, em parcelas de contribuição na relação sinal/ruído para determinado enlace, o OSNR, e também ser tratado como um limitante de distâncias para os enlaces. Este mecanismo permite que o algoritmo possa utilizar informações importantes na computação das rotas de forma simplificada.

Em contrapartida existem outros parâmetros que podem ser disseminados e computados diretamente. Por exemplo, o PMD e o ruído (ASE - Amplifier Spontaneous Emission) introduzido por amplificadores ópticos que prejudica a importante relação sinal/ruído (OSNR), são considerados como os dois principais ofensores, conforme as taxas de transmissão aumentam em um sistema óptico (CHUNG, 2004; STRAND; CHIU, 2005). Em outro estudo, (STRAND; CHIU; TKACH, 2001) trata de forma particular estes dois fenômenos que ocorrem nas fibras em uma transmissão óptica. 
Considerando a importância destes parâmetros, os mesmos podem ser manipulados de forma particular pelo PCE no momento da computação de uma rota, e, da mesma forma, o mecanismo de distribuição de informações sobre o estado dos enlaces também deve considerar a divulgação destas informações de forma individual. Trabalhos como (STRAND; CHIU; TKACH, 2001; STRAND; CHIU, 2005) abordam propostas sobre como estas informações podem ser disseminadas para os nós de uma rede.

A extensão do PCE Protocol será proposta neste capítulo de forma que possa abranger as características que prejudicam a transmissão de um sinal óptico, conforme descrito ao longo deste trabalho. Porém é necessário levar em consideração dois aspectos importantes que limitam esta abordagem, sendo eles:

- A tradução dos requisitos das aplicações em detalhes das características físicas do sistema de transmissão utilizado, ou seja, como o PCC pode entender as necessidades da aplicação, e transformar estas necessidades, enviando as mesmas ao PCE através de requisitos dos parâmetros físicos do sistema de transmissão;

- A compatibilidade desta extensão com a realidade atual, de acordo com o desenvolvimento dos trabalhos relevantes disponíveis, como os aqui citados, sobre a disseminação e a computação das informações mais importantes, e que representem alternativas viáveis, ou seja, não representem configurações impossíveis na prática.

Desta forma, com o objetivo de atender às premissas apresentadas, a extensão é proposta para contemplar as seguintes características dos enlaces na computação das rotas: atraso, variação do atraso, qualidade do sinal, pontos de falha e custos econômicos.

Estas duas últimas características não são parte de uma necessidade de QoS, como aquelas apontadas na tabela 5.1, e não são traduzidas em especificações de QoT, porém são incluídas nesta proposta de extensão como uma forma de política de direcionamento para influenciar a escolha de determinada rota. 
- Atraso e variação do atraso: são parâmetros que podem ser mapeados diretamente da necessidade da aplicação e enviados ao PCE para computar a rota. Neste caso, de um lado, as aplicações possuem determinadas necessidades de QoS com relação ao atraso e à variação deste atraso, e o PCC tem a responsabilidade de enviar as requisições com estas necessidades ao PCE. Do outro lado, o PCE também deve possuir estas informações relativas aos seus enlaces, como características de QoT, e computar as rotas de acordo com as requisições enviadas pelo PCC.

- Qualidade do sinal: este parâmetro, do lado da aplicação, irá representar a taxa de erros aceitável pela mesma. Do lado do PCE, este deve utilizar as informações mais relevantes sugeridas anteriormente, que são os valores de PMD e OSNR de forma direta. Outros fatores de degradação do sinal podem ser utilizados de forma indireta, que serão representados pelo comprimento total de uma rota, limitado pela ação conjunta destes fatores na degradação do sinal. Os trabalhos citados anteriormente apresentam algumas alternativas para a manipulação e disseminação destes parâmetros, e o aspecto importante para este trabalho é a introdução desta informação como um objeto a mais para ser utilizado na requisição de rotas ao PCE, através da mensagem PCReq, possibilitando o PCE escolher a rota com QoT mais adequado para determinada necessidade.

- Confiabilidade: este parâmetro vai permitir a solicitação de rotas mais confiáveis no sentido de probabilidade de falhas. O PCE deve ter a informação sobre as quantidades de falhas ocorridas nos enlaces ao longo do tempo, e as aplicações poderão, dependendo da criticidade da mesma, solicitar enlaces confiáveis para a transmissão.

- Custos econômicos: este parâmetro vai indicar o tipo de enlace preferencial a ser utilizado pela aplicação com relação ao seu valor econômico, ou seja, o PCE deverá escolher o caminho através de enlaces mais baratos ou mais caros, dependendo da criticidade da aplicação. $O$ valor dos enlaces pode ser ligado diretamente à capacidade de transmissão do mesmo. 
Os parâmetros descritos acima podem ser incorporados ao protocolo existente como um novo objeto para a mensagem PCReq. Este objeto será denominado Quality, e as combinações dos bits deste objeto oferecem alternativas distintas, disponíveis ao PCC, para que o mesmo possa requisitar rotas baseadas na qualidade dos enlaces. O PCE ao receber a mensagem PCReq com este objeto deverá identificar os requisitos exigidos e computar a melhor rota baseada nos mesmos.

O PCC se baseia na tabela 5.1 para classificar as necessidades que devem ser atendidas de acordo com a seguinte lógica adotada. As aplicações que possuem os parâmetros classificados como Exigentes e Muito Exigentes deverão obter sempre os caminhos que apresentarem os melhores valores disponíveis para estes parâmetros, e as aplicações que possuem os parâmetros classificados como Pouco Exigentes, poderão obter os caminhos com qualquer valor disponível. Esta indistinção entre as classificações Exigente e Muito Exigente, no momento de contabilizar a rota, funciona como um simplificador do mecanismo, porém sem que seja perdido o seu objetivo final. Desta forma trabalha-se com o melhor valor disponível e com um valor indiferente, ou seja, que não tem importância se não for o melhor, contando que seja o suficiente para uma qualidade mínima de QoT que possibilite a transmissão.

A composição do objeto Quality é mostrada na figura 5.2 e descrita a seguir.

\begin{tabular}{|c|c}
\hline Cabecalho do Objeto & 32 bits \\
\hline Objeto Quality & 32 bits
\end{tabular}

Figura 5.2 - Objeto Quality

De acordo com a padronização, cada objeto deve possuir um cabeçalho de objeto. Desta forma será utilizado o cabeçalho especificado pela padronização para o objeto Quality proposto.

O objeto Quality possui 9 bits para identificação dos requisitos que podem ser enviados pelo PCC, sendo que os bits restantes são reservados para utilização futura. A divisão dos mesmos é apresentada a seguir: 
- Bits 0, 1 e 2, identificam o parâmetro desejado pelo PCC para a qualidade da rota a ser computada pelo PCE, com relação ao atraso, variação do atraso e taxa de erros (BER). A forma como os mesmos podem ser combinados para identificação destes parâmetros é demonstrada na figura 5.3.

\begin{tabular}{|l|l|l|l|}
\hline $\mathbf{0}$ & $\mathbf{1}$ & $\mathbf{2}$ & Parâmetros requisitados \\
\hline 0 & 0 & 0 & Indiferente \\
\hline 1 & 0 & 0 & BER \\
\hline 0 & 1 & 0 & Atraso \\
\hline 1 & 1 & 0 & BER \& Atraso \\
\hline 0 & 0 & 1 & Variaçẫo do atraso \\
\hline 1 & 0 & 1 & BER \& Variaçẫo do atraso \\
\hline 0 & 1 & 1 & Atraso \& Variaçẫo do atraso \\
\hline 1 & 1 & 1 & Todos os parâmetros \\
\hline
\end{tabular}

Figura 5.3 - Objeto Quality - Definição de parâmetros

- Bits 3, 4 e 5, identificam a prioridade do parâmetro de qualidade, para realizar a computação da rota, no caso de dois ou mais parâmetros serem requisitados juntos, conforme apresentado na figura 5.4 .

\begin{tabular}{|l|l|l|l|}
\hline 3 & $\mathbf{4}$ & $\mathbf{5}$ & Ordem de prioridade \\
\hline 0 & 0 & 0 & $\mathrm{~A}-\mathrm{V}-\mathrm{B}$ \\
\hline 1 & 0 & 0 & $\mathrm{~A}-\mathrm{B}-\mathrm{V}$ \\
\hline 0 & 1 & 0 & V - A - B \\
\hline 1 & 1 & 0 & V - B - A \\
\hline 0 & 0 & 1 & $\mathrm{~B}-\mathrm{A}$ - V \\
\hline 1 & 0 & 1 & $\mathrm{~B}-\mathrm{V}-\mathrm{A}$ \\
\hline 0 & 1 & 1 & Indiferente \\
\hline 1 & 1 & 1 & Năo utilizado \\
\hline
\end{tabular}

A: Atraso; B: BER; V: Variaçẫo do atraso

Figura 5.4 - Objeto Quality - Definição de prioridade de parâmetro

Bits 6 e 7 identificam, de acordo com a figura 5.5, a política a ser adotada para a computação da rota, e a mesma será aplicada após os enlaces com a qualidade desejada forem selecionados.

\begin{tabular}{|l|l|l|}
\hline $\mathbf{6}$ & 7 & Política \\
\hline 0 & 0 & Indiferente \\
\hline 0 & 1 & Confiabilidade \\
\hline 1 & 0 & Custo econômico \\
\hline 1 & 1 & Ambos \\
\hline
\end{tabular}

Figura 5.5 - Objeto Quality - Definição de política 
Bit 8 identifica a prioridade no caso das duas políticas selecionadas juntas, conforme apresentado na figura 5.6.

\begin{tabular}{|c|l|}
\hline 8 & Ordem de prioridade \\
\hline 0 & Confiabilidade - Custo \\
\hline 1 & Custo - Confiabilidade \\
\hline
\end{tabular}

Figura 5.6 - Objeto Quality - Definição de prioridade de política

O objeto proposto possui um total de 64 bits ou 8 bytes, e representa um aumento de 1,4\% em uma mensagem PCReq com tamanho médio de 554 bytes (definido no apêndice A).

Com a extensão proposta, o protocolo PCE poderá garantir que parâmetros importantes relacionados à qualidade de transmissão sejam levados em consideração no momento da computação de uma determinada rota. Desta forma, a rota escolhida para ser enviada ao requisitante possuirá a qualidade mínima necessária para garantir a comunicação fim-a-fim, sem que ocorra bloqueio durante o trajeto, devido à degradação do sinal óptico. Além da garantia de uma rota executável, a inclusão destes parâmetros também possibilita que a mesma tenha capacidade de atender certos requisitos particulares de QoS, necessários para determinadas aplicações, que são sensíveis a estes parâmetros.

Sendo assim, a arquitetura PCE, com esta extensão, proporciona uma alternativa muito importante relacionada ao tratamento da qualidade de transmissão do sinal. 


\section{AnÁlise do Tráfego Gerado Pelo Mecanismo PCE e Seu Impacto na REDE}

Conforme apresentado e discutido nos capítulos anteriores, a conexão das redes convencionais com as redes ópticas requer um mecanismo de roteamento que leve em consideração certos requisitos adicionais. A associação de parâmetros de QoT ao PCE surge como uma alternativa para esta necessidade.

Este capítulo tem o objetivo de realizar uma análise sobre o impacto que a implantação da arquitetura PCE pode causar em determinados enlaces de rede, e como a extensão proposta no capítulo 5 , para lidar com questões de QoT, vai influenciar este comportamento.

Este objetivo é alcançado através da análise das mensagens originais do principal protocolo da arquitetura PCE, que é o PCE Protocol, e seu comportamento em determinadas configurações de enlaces de rede, e da análise posterior incluindo a extensão proposta. Compara-se o comportamento das duas mensagens, a original e a estendida, para que seu impacto na rede seja verificado, com diferentes taxas de requisições.

\subsection{Definição do Cenário para a Análise}

Com o intuito de possibilitar a análise proposta sobre o impacto das mensagens da arquitetura PCE, foi desenvolvido um cenário para a execução de experimentos com as principais mensagens do PCE Protocol, que são a PCReq e PCRep.

Este cenário inclui uma rede integrada, onde existe um domínio contendo os PCCs que geram as requisições ao PCE, e o domínio externo, que pode ser outra área desta rede, outro AS ou outra camada de rede.

Conforme apresentado na figura 6.1, os PCCs estão conectados a um elemento de borda, e do outro lado desta rede se localiza o outro de elemento de borda, remoto, que provê o acesso externo, no qual está conectado o PCE. Entre estes dois 
elementos de borda está o enlace de longa distância, que possibilita a conexão entre ambos. Este enlace pode ser modificado para que o comportamento do tráfego em cada um deles possa ser analisado.

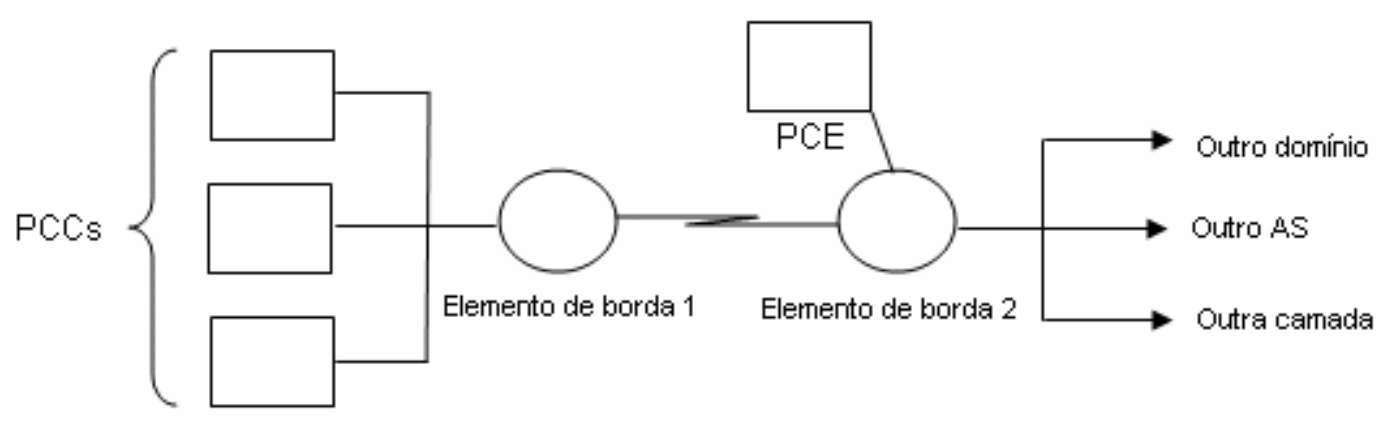

Figura 6.1 - Cenário para análise do comportamento do PCE

É importante apresentar uma hipótese relevante que foi assumida para este experimento, no caso da divulgação das informações ao PCE sobre os enlaces da rede que estão disponíveis, e das características destes enlaces, como os comprimentos de onda disponíveis, a capacidade de comutação, a largura de banda disponível, o atraso de um enlace, entre outros parâmetros. A disseminação destas informações não é um fator relevante para o objetivo da análise deste trabalho, e assume-se que o elemento PCE tem na sua base de dados as informações necessárias para o cálculo das rotas, bem como o mesmo utiliza o algoritmo adequado para esta tarefa. Através desta hipótese, o escopo da sua função, para o cenário deste experimento, fica definido como sendo o elemento responsável pelo recebimento das mensagens de requisição de rotas PCReq, do PCE Protocol, e pelo envio das respostas aos elementos requisitantes.

\subsubsection{Elementos do Cenário}

Neste item serão apresentados de forma específica os elementos do cenário proposto utilizados para os experimentos e a ferramenta escolhida para a realização dos mesmos. 
De acordo com o objetivo deste trabalho, verifica-se a necessidade da utilização de uma ferramenta para prover os dados necessários, a fim de subsidiar a análise sobre o comportamento do mecanismo PCE em relação ao tráfego gerado. Desta forma, o software OPNET IT Guru Academic foi escolhido para ser utilizado neste trabalho devido às suas características que permitem flexibilidade de implementação nas várias camadas de rede, e particularmente, possui uma funcionalidade específica para o ambiente cliente/servidor que se encaixa muito bem ao cenário apresentado. O OPNET IT Guru Academic Edition é uma versão acadêmica do software OPNET Modeler, e se encontra disponível para ser utilizada sem custos.

A seguir serão descritos os elementos utilizados e os detalhes mais relevantes sobre suas configurações para os experimentos.

- PCE - Path Computation Element: o elemento PCE, responsável pela computação das rotas, pode ser inserido na topologia de uma rede com visibilidade ampla de todos os domínios e camadas, ou de forma distribuída utilizando-se mais de um PCE, cada um com visibilidade de um domínio ou camada, conforme detalhado em 4.2. Para esta análise, será utilizado um elemento PCE para responder às solicitações de rota dos clientes PCCs.

Neste cenário o PCE é um elemento específico para a função de computação de rotas, e está diretamente conectado ao roteador de borda, porém, conforme a padronização, esta função poderia ser realizada no próprio roteador de borda, com capacidade computacional suficiente e com a devida aplicação instalada.

Outro aspecto a ser observado é o conceito do domínio no qual o PCE está localizado. Conforme apresentado na figura 6.1, o PCE especificado pode fazer 0 papel de um resolvedor de rotas inter-ASs ou inter-camadas. Porém, para o objetivo deste trabalho esta informação não é relevante, pois o que é necessário ser analisado é o tráfego gerado para o PCE e não o conteúdo das solicitações. 
No Opnet, o PCE é um modelo de servidor padrão, definido previamente pela ferramenta, capaz de responder às requisições que chegam para ele, modeladas pela taxa de transmissão. Uma observação importante a ser considerada no caso da adoção deste servidor é a sua capacidade computacional. Devido ao objetivo desta simulação, que não abrange os tempos de resposta às requisições, nota-se que os parâmetros computacionais deste elemento, bem como os tempos de recepção, desencapsulamento da requisição, cálculo da rota, encapsulamento da resposta e envio da mesma, não são informações relevantes para a análise final.

- PCC - Path Computation Client: neste experimento, são sub-redes configuráveis na ferramenta, contendo os elementos que desempenham o papel dos PCCs Consequentemente são os responsáveis por gerar as mensagens PCReq do protocolo PCE Protocol, para requisição de rotas ao elemento PCE.

- Switches: conectam as sub-redes ao roteador de borda e o elemento PCE ao roteador de borda.

Há um switch inserido entre os PCCs e o roteador para diminuir o tempo de coleta de dados. Um determinado enlace (10 Mbps) é utilizado entre os PCCs e o switch, e outro enlace (100 Mbps), é utilizado entre o switch e o roteador de borda.

- Roteadores: realizam a conexão entre os switches das sub-redes que geram as requisições de rotas ao switch da sub-rede onde se encontra o elemento PCE.

- Enlaces: são os meios de transmissão entre os elementos descritos anteriormente. Foram utilizados vários tipos de enlace, com características de transmissão distintas, para que pudesse ser verificado o comportamento das mensagens do PCE Protocol em cada uma delas.

O enlace de longa distância, que conecta os roteadores de borda, não possui uma capacidade de transmissão única durante os experimentos, e a mesma varia de acordo com a tabela 6.1 , definida a seguir. 
Tabela 6.1 - Enlaces utilizados nos experimentos

\begin{tabular}{|c|c|l|l|}
\hline Função & Enlace & Descrição & Capacidade \\
\hline \multirow{3}{*}{ LAN } & 1 & $10 \mathrm{Mbps}$ & $10 \mathrm{Mbps}$ \\
\cline { 2 - 4 } & 2 & $100 \mathrm{Mbps}$ & $100 \mathrm{Mbps}$ \\
\hline \multirow{6}{*}{ WAN } & 3 & DS0 & $65 \mathrm{Kbps}$ \\
\cline { 2 - 4 } & 4 & $256 \mathrm{Kbps}$ & $256 \mathrm{Kbps}$ \\
\cline { 2 - 4 } & 5 & $512 \mathrm{Kbps}$ & $512 \mathrm{Kbps}$ \\
\cline { 2 - 4 } & 6 & DS1 & $1,544 \mathrm{Mbps}$ \\
\cline { 2 - 4 } & 7 & E1 & 2 Mbps \\
\cline { 2 - 4 } & 8 & DS3 & $44,736 \mathrm{Mbps}$ \\
\cline { 2 - 4 } & 9 & OC1 & $51,84 \mathrm{Mbps}$ \\
\cline { 2 - 4 } & 10 & OC3 & $155,52 \mathrm{Mbps}$ \\
\hline
\end{tabular}

A escolha dos enlaces para a análise abrange um intervalo que contém alguns com baixa capacidade de transmissão. Estes enlaces foram incluídos nos experimentos por dois motivos.

i) Os enlaces com menor capacidade de transmissão podem ser utilizados para a sinalização out-of-band, onde o plano de controle é separado do plano de dados. Para este tipo de utilização é mais provável que não sejam empregados enlaces com grandes capacidades, e mais custosos.

Esta situação pode ocorrer na arquitetura PCE quando se utiliza a configuração com múltiplos PCEs, onde há cooperação entre os mesmos para a computação das rotas, através do envio de mensagens entre eles. Estes canais exclusivos para os PCEs podem ser de menor capacidade, utilizados apenas para este tipo de tráfego de controle.

ii) É mais provável, e esperado, que grandes redes utilizem no seu tronco principal enlaces de alta velocidade e grande capacidade de transporte, como enlaces OC48 de aproximadamente 2,5 Gbps, ou superiores. Para realizar os acessos a estes troncos, ou seja, a conexão dos clientes finais, ou de determinados grupos localizados em filiais remotas, também são esperados enlaces de grandes capacidades, com a finalidade de agregar e dar vazão a todo o tráfego gerado, isto é, atender à demanda imposta pelos usuários destas localidades. Principalmente se o perfil das aplicações destas redes periféricas exigir alta largura de banda. 
Porém, apesar de mais provável, esta situação pode se modificar ligeiramente, pois a mesma depende de algumas variáveis, como a quantidade de usuários, e as aplicações utilizadas nestas redes, ou seja, o perfil da carga de trabalho destes grupos. Em determinadas redes as aplicações podem ser menos exigentes com relação à largura de banda, por exemplo. Desta forma a questão econômica, se torna relevante para a escolha do enlace que irá realizar as conexões de acesso ao tronco principal, e enlaces com menores capacidades de transmissão podem ser utilizados nestes casos. Estas redes, apesar de não terem como requisito principal a largura de banda, também podem estar conectadas à estrutura central do tronco principal, utilizando o mesmo para transportar seus dados.

Para exemplificar este cenário pode ser citada a Rede Nacional de Pesquisas (RNP), que possui pontos de presença em todas as capitais do Brasil. Estes pontos conectam universidades e também podem conectar clientes para prestar determinados serviços como VoIP, videoconferência, transmissão de vídeo e de TV. Em determinadas localidades, ou pontos de presença desta rede, verifica-se a conexão de clientes e outros grupos de usuários, aos principais enlaces de alta velocidade, através de enlaces de acesso com várias capacidades de transmissão como 2 Mbps, 1 Mbps, 512 Kbps e até 256 Kbps, conforme pode ser observado na figura 6.2 .

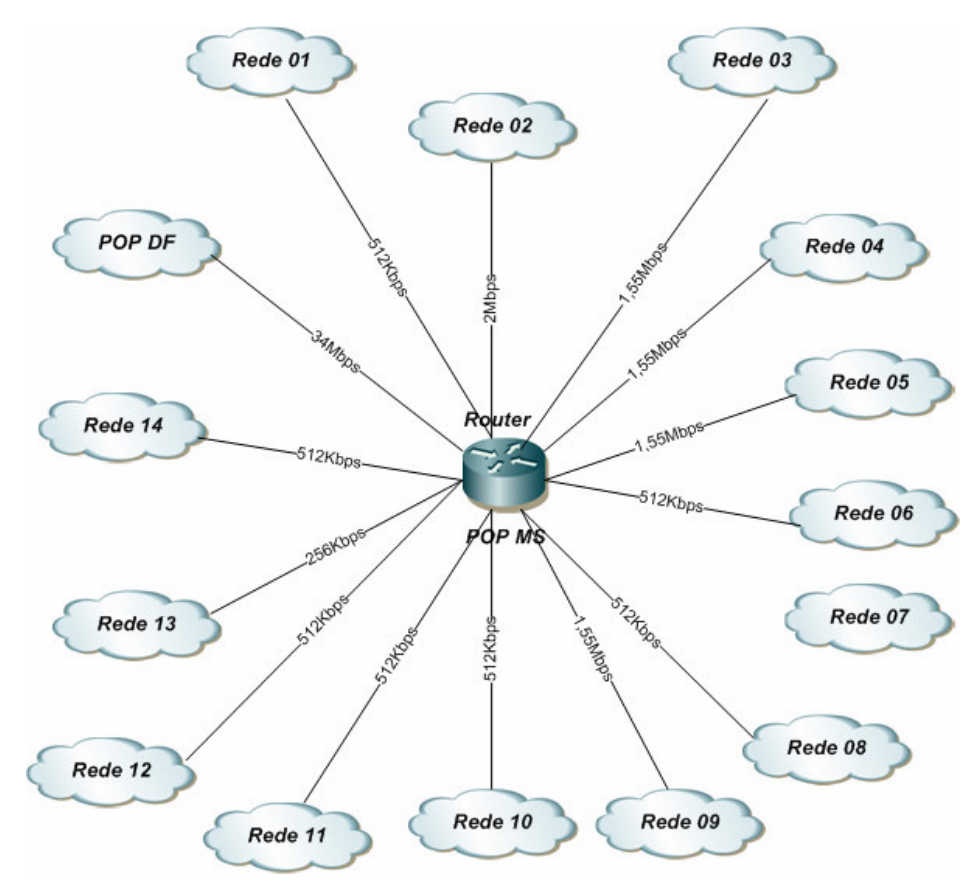

Figura 6.2 - Exemplo de enlaces utilizados no POP MS da RNP 
Outro exemplo é a rede de uma organização privada que também presta determinados serviços de tecnologia da informação a clientes, e para fornecer estes serviços deve conectar as redes de seus clientes com a sua própria rede, através de enlaces de diversas capacidades de transmissão como 2 Mbps, 1 Mbps, 512 Kbps e até $128 \mathrm{Kbps}$, conforme pode ser observado na figura 6.3.

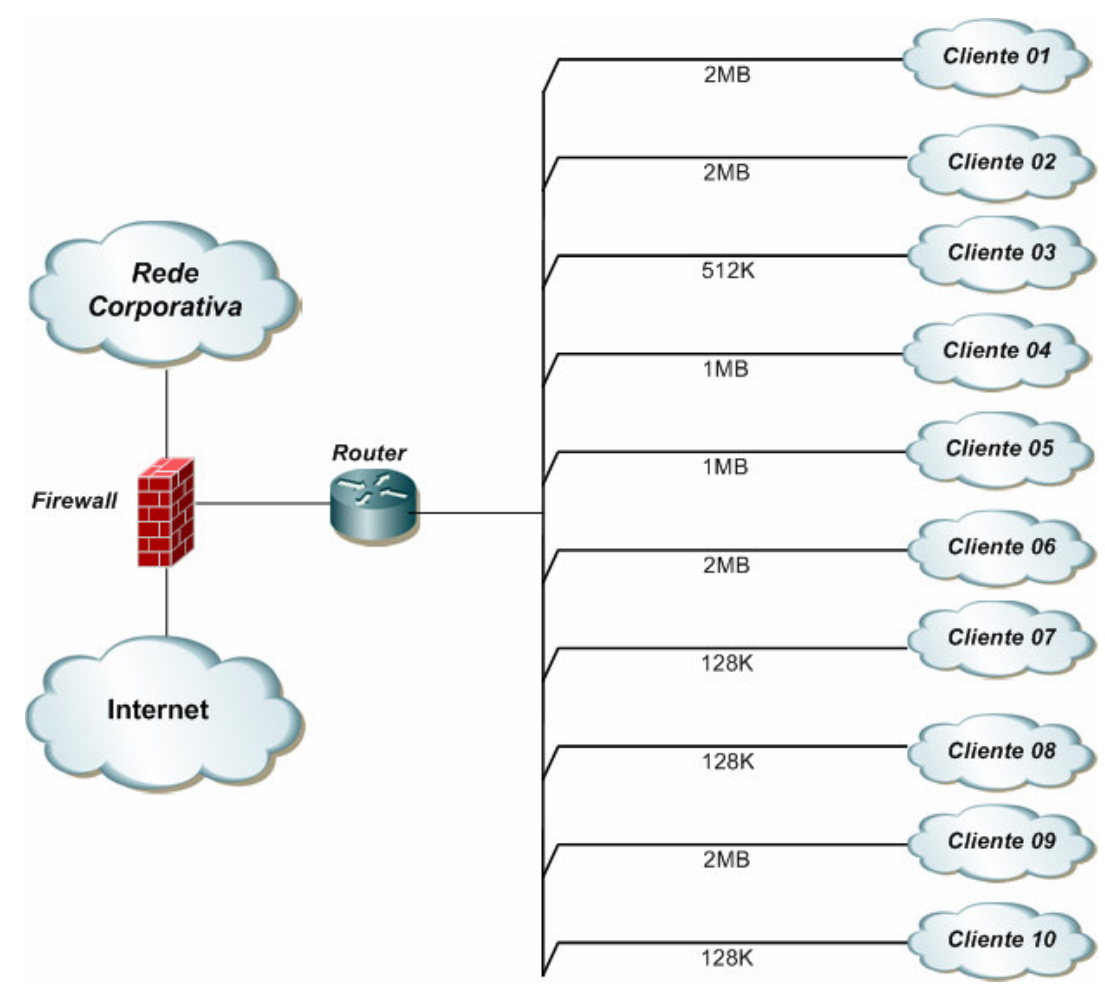

Figura 6.3 - Exemplo de enlaces utilizados em uma rede privada

Desta forma, verifica-se que, na prática, existem redes com acesso aos troncos principais das grandes redes, como redes MPLS e redes ópticas, que são conectadas através de enlaces sem grandes capacidades de recursos. Estas redes, com estas conexões de acesso mais restritas, podem não ser as principais usuárias da rede principal, com relação ao volume do tráfego, porém como estão na estrutura, também são usuárias, e podem utilizar os seus benefícios. Sendo usuárias, as mesmas devem ter garantias que sua transmissão, ao ser roteada pelas outras camadas ou domínios, possui a qualidade de sinal mínima para ser executada com sucesso. 
- Protocolo PCE Protocol: desempenha a função de carregar as requisições ao PCE e respostas aos PCCs através das suas principais mensagens, sendo elas PCReq e PCRep. Sua descrição geral é apresentada no item 4.3.2, e a forma como suas mensagens são utilizadas nos experimentos é apresentada no apêndice $A$.

\subsubsection{Definição dos Parâmetros e da Métrica Utilizada}

Os parâmetros relevantes para o objetivo da análise final, que têm seus valores variados durante os experimentos, estão identificados abaixo para que possam ser utilizados no cenário que será descrito a seguir.

- Taxa de requisição de rotas envida pelos PCCs ao PCE;

- Tamanho da mensagem PCReq do PCE Protocol;

- Tamanho da mensagem PCRep do PCE Protocol;

- Tamanho da mensagem PCReq do PCE Protocol com a proposta de extensão;

- Capacidade de transmissão dos enlaces que conectam os PCCs ao PCE ao longo do caminho.

A taxa de requisição de rotas enviadas ao elemento PCE foi modelada de acordo com uma distribuição de Poisson. Esta distribuição é comumente utilizada em ambientes de rede, pois reflete características reais nestes ambientes, onde é capaz de modelar eventos aleatórios com uma freqüência determinada, além de possibilitar a realização de uma requisição por vez, sendo que cada requisição é independente da requisição anterior.

A variação deste parâmetro segue as especificações indicadas pela padronização, onde existem valores definidos de requisições que um PCE deve suportar.

Os tamanhos das mensagens utilizadas são definidos no apêndice A. 
A capacidade dos enlaces de transmissão apresenta variações de acordo com as capacidades dos meios de transmissão atuais para redes locais (LAN - Local Area Network) e redes de longa distância (WAN - Wide Area Network).

A métrica utilizada é o tráfego gerado nos enlaces da rede, de acordo com o objetivo apresentado anteriormente. Sua medição é executada através de experimentos com a ferramenta especificada, variando-se os valores dos parâmetros descritos neste item.

\subsection{Realização dos Experimentos}

Os experimentos foram realizados através de tarefas que incluíram:

- Definição das características das mensagens PCReq e PCRep do protocolo PCE Protocol, como o seu tamanho provável utilizado para as simulações (itens 4.3.2 e apêndice $A$ ).

O Opnet permite que sejam utilizadas aplicações do tipo cliente/servidor através da definição da mensagem de solicitação do serviço e da mensagem de resposta a esta solicitação. Esta funcionalidade foi utilizada nos experimentos para cumprir o objetivo deste trabalho, devido à característica cliente/servidor assumida pelos elementos PCC e PCE da arquitetura PCE.

Desta forma, a mensagem PCReq foi definida com o valor médio de 554 bytes para ser utilizada na ferramenta.

Para a simulação da mensagem PCReq estendida, a mesma foi definida com um valor médio de 618 bytes

A mensagem PCRep foi utilizada com um valor médio de 208 bytes.

- Definição da taxa de requisições realizadas pelos PCCs ao PCE. 
A taxa das requisições enviadas ao PCE, conforme apresentada na tabela 6.2 a seguir, foi modelada através de uma distribuição de Poisson, com sua taxa variando entre um intervalo de 10 requisições/hora a 10 requisições/segundo. Sendo que um caso especial previsto pela padronização, de 100 requisições/segundo, também foi analisado.

Tabela 6.2 - Taxas de requisições utilizadas nos experimentos

\begin{tabular}{|c|c|c|}
\hline Distribuição & Requisições / hora & Requisições / segundo \\
\hline \multirow{4}{*}{ Poisson } & 10 & 0,0028 \\
\cline { 2 - 3 } & 50 & 0,0139 \\
\cline { 2 - 3 } & 100 & 0,0278 \\
\cline { 2 - 3 } & 500 & 0,1389 \\
\cline { 2 - 3 } & 1000 & 0,2778 \\
\cline { 2 - 3 } & 4000 & 1,11 \\
\cline { 2 - 3 } & 8000 & 2,22 \\
\cline { 2 - 3 } & 12000 & 3,33 \\
\cline { 2 - 3 } & 16000 & 4,44 \\
\cline { 2 - 3 } & 20000 & 5,56 \\
\cline { 2 - 3 } & 24000 & 6,67 \\
\cline { 2 - 3 } & 28000 & 7,78 \\
\cline { 2 - 3 } & 32000 & 8,89 \\
\cline { 2 - 3 } & 36000 & 10,00 \\
\cline { 2 - 3 } & 360000 & 100,00 \\
\hline
\end{tabular}

O tempo configurado para executar o experimento foi de cinco horas. Este tempo foi suficiente para gerar os dados necessários para a análise, pois foi notado que as curvas se tornam constantes após um tempo menor que cinco horas. Tempos maiores foram utilizados, porém os resultados não se alteraram.

- Configuração do ambiente na ferramenta de acordo com as descrições anteriores.

- Execução dos experimentos com a variação dos parâmetros.

Os parâmetros foram variados através do cruzamento de cada valor da tabela 6.1 com cada valor da tabela 6.2. Por exemplo, para a taxa de requisições da linha 1 da tabela 6.2 (10 requisições/hora), foram realizadas simulações com 
cada linha da tabela 6.1, ou seja, demonstrando o impacto do tráfego gerado por esta taxa de requisições para cada enlace definido.

- Coleta dos resultados dos experimentos e elaboração dos gráficos e tabelas demonstrando os resultados obtidos.

\subsection{Resultados Obtidos}

Os experimentos foram conduzidos de acordo com os detalhes descritos nos itens anteriores, e através da ferramenta Opnet foram obtidos os resultados dos comportamentos do tráfego, conforme o objetivo proposto. A seguir estes resultados são apresentados em forma de tabelas e gráficos, seguidos das análises realizadas para os mesmos.

\subsubsection{Comportamento da Mensagem PCReq}

A tabela 6.3, e a figura 6.4 a seguir, apresentam os resultados do volume do tráfego gerado pela mensagem PCReq típica presumida, apresentada no apêndice $A$, em todos os enlaces propostos.

Tabela 6.3 - Ocupação dos enlaces pela mensagem PCReq

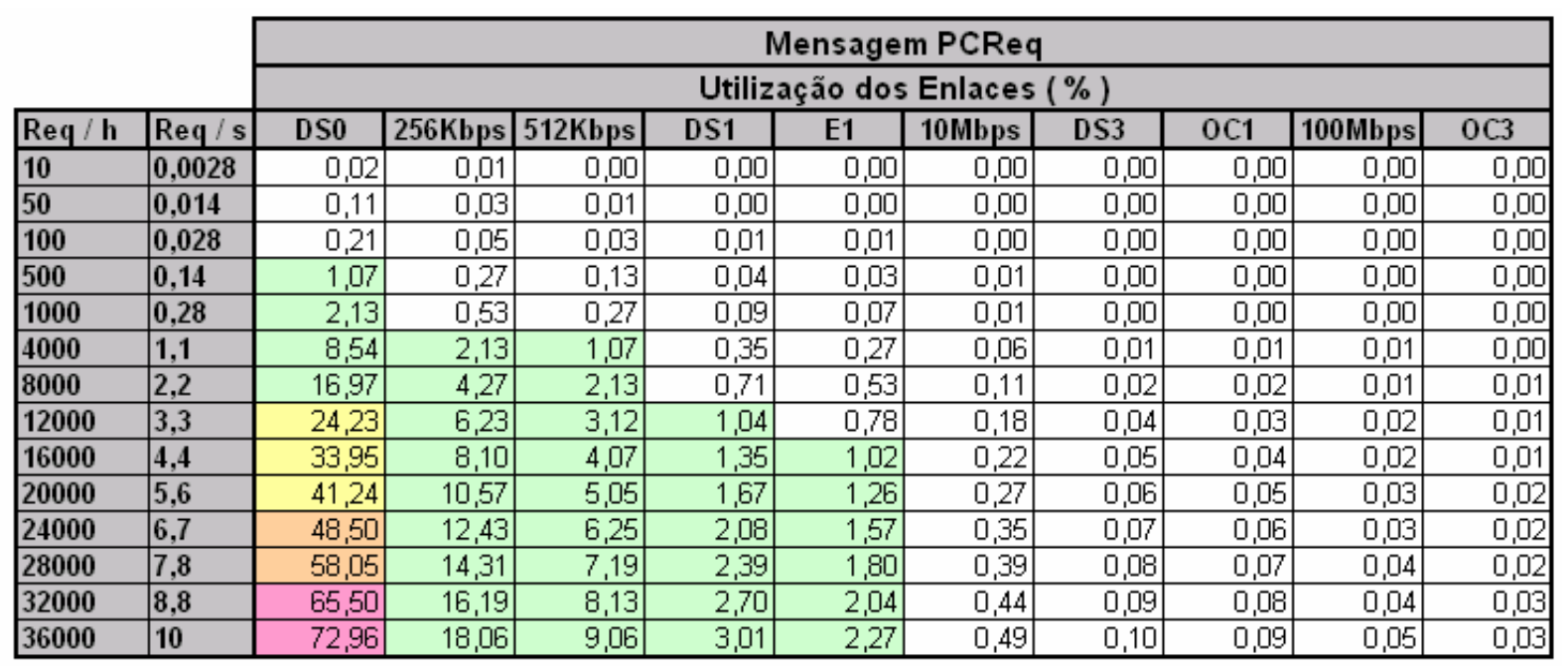




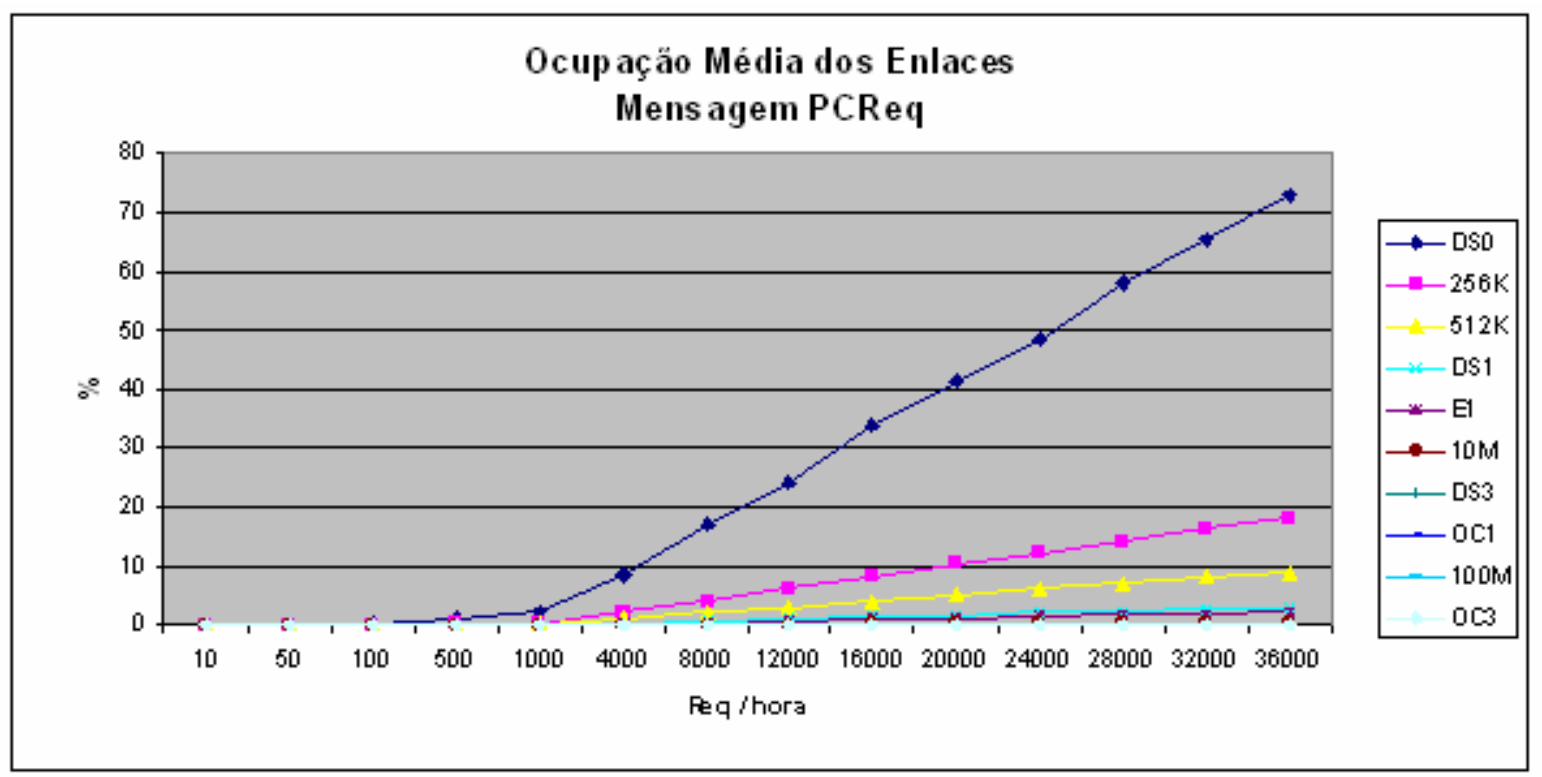

Figura 6.4 - Ocupação dos enlaces pela mensagem PCReq

A taxa de requisições, dentro do intervalo sugerido pela padronização, gerou um tráfego que não deverá causar problemas de congestionamento nos enlaces de maior capacidade, como os enlaces acima de $10 \mathrm{Mbps}$, nos quais a porcentagem de utilização pelas mensagens de requisição e resposta foram menores do que $1 \%$. Estes valores representam os enlaces com capacidades de 10 Mbps e $100 \mathrm{Mbps}$, comumente utilizados nas redes locais, e os enlaces de grande capacidade das redes de longa distância, como DS3, OC1 e OC3.

Para os enlaces com capacidades entre 512 Kbps e 2 Mbps (E1), verifica-se que o tráfego gerado esteve entre 1\% e 10\%. Em primeiro momento esta ocupação não deve ser relevante, porém por se tratar de enlaces com menores capacidades, devese ter em consideração o perfil do tráfego dos usuários para que na contabilização final não ocorra prejuízos para este último, principalmente no caso das taxas de requisição mais altas, aproximando-se a 10 requisições por segundo.

Verifica-se uma situação mais delicada com os menores enlaces utilizados nas simulações. Apesar de raros, ainda são enlaces que podem ser encontrados em certas redes de acesso, conforme descrito anteriormente. Nestes casos a ocupação foi de aproximadamente $18 \%$ para enlaces de $256 \mathrm{Kbps}$ e de até $73 \%$ em enlaces DSO com a maior taxa de requisições imposta. 
A tabela 6.4 e a figura 6.5 a seguir, apresentam os resultados do volume do tráfego gerado pela mensagem PCReq com seu maior valor presumido, apresentado no apêndice $A$, e com a maior taxa de requisições, em todos os enlaces propostos.

Tabela 6.4 - Ocupação dos enlaces pela mensagem PCReq com maior valor calculado e com a taxa máxima de requisições

\begin{tabular}{|c|c|c|c|c|c|c|c|c|c|c|c|}
\hline & \multicolumn{10}{|c|}{ Mensagem PCReq } \\
\hline & & \multicolumn{10}{|c|}{ Utilização dos Enlaces ( \%) } \\
\hline $\operatorname{Req} / \mathrm{h}$ & $\operatorname{Req} / \mathrm{s}$ & DS0 & $256 \mathrm{Kbps}$ & $512 \mathrm{Kbps}$ & DS1 & E1 & 10Mbps & DS3 & $0 \mathrm{C1}$ & $100 \mathrm{Mbps}$ & $0 \mathrm{C3}$ \\
\hline 36000 & 10 & 81,95 & 20,39 & 10,23 & 3,41 & 2,57 & 0,53 & 0,12 & 0,11 & 0,05 & 0,04 \\
\hline
\end{tabular}

\begin{tabular}{|l|l|l|l|l|l|l|}
\hline Legenda: & $0 \% \leq x<1 \%$ & $1 \% \leq x<20 \%$ & $20 \% \leq x<40 \%$ & $40 \% \leq x \leq 60 \%$ & $60 \% \leq x<80 \%$ & $80 \% \leq x<100 \%$ \\
\hline
\end{tabular}
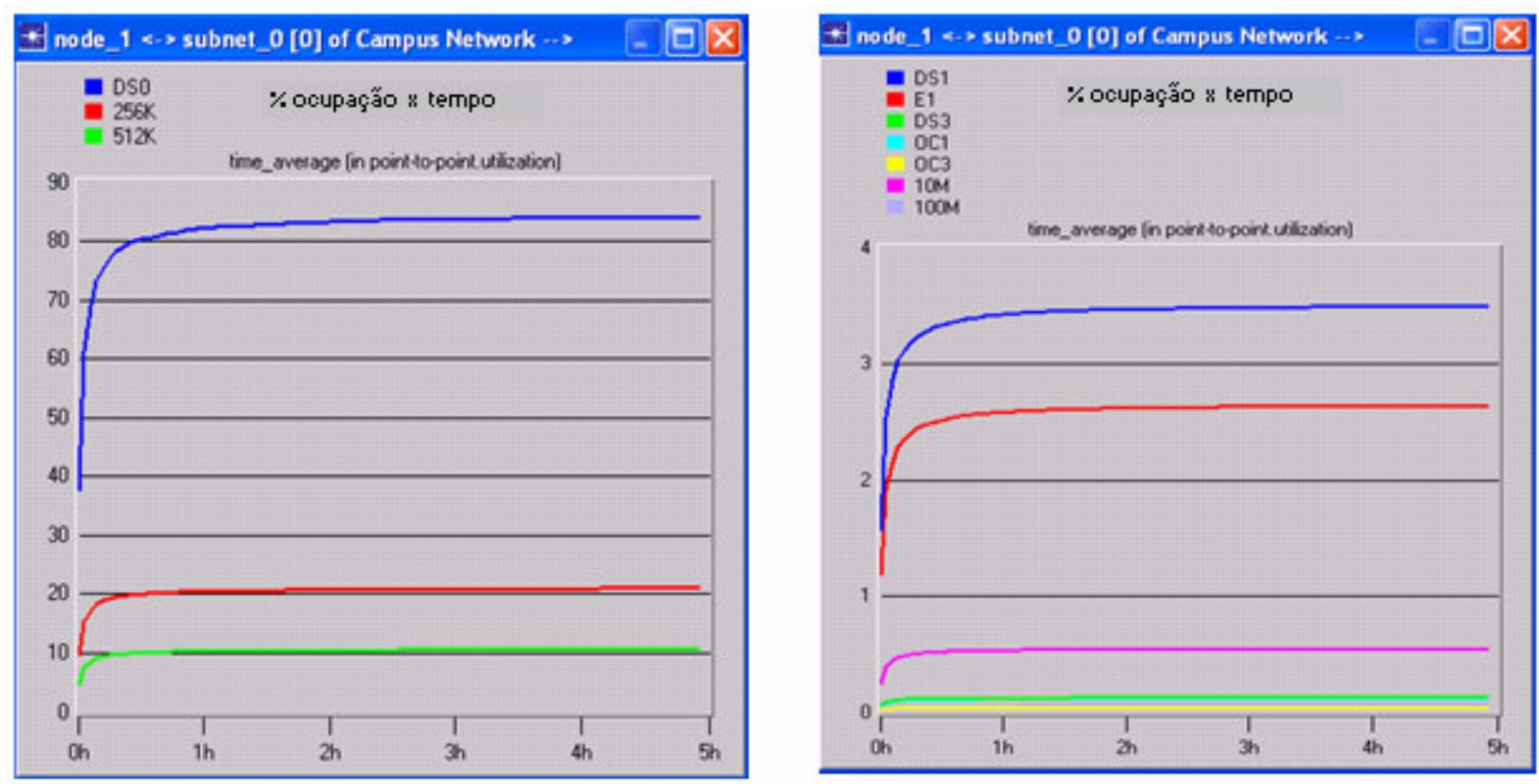

Figura 6.5 - Ocupação dos enlaces pela mensagem PCReq com a taxa máxima de requisições

Nesta situação houve um aumento do tráfego gerado, porém não significativo, e os enlaces podem ser divididos nos mesmos grupos da análise anterior, sendo que os enlaces com capacidades de transmissão maiores que 10 Mbps apresentaram menos de $1 \%$ de ocupação, aqueles com capacidade entre 512 Kbps e 2 Mbps (E1) apresentaram ocupação entre $1 \%$ e $10 \%$, e os menores enlaces, sendo eles 256 Kbps e DS0, estiveram na faixa de $20 \%$ a $82 \%$ de ocupação.

A tabela 6.5 a seguir, apresenta os resultados do volume do tráfego gerado pela mensagem PCReq típica em todos os enlaces propostos anteriormente, e com a 
taxa extraordinária de $100 \mathrm{req} / \mathrm{seg}$, proposta na padronização como uma taxa possível de ser processada pelo PCE, em caráter excepcional.

Tabela 6.5 - Ocupação dos enlaces pela mensagem PCReq com taxa extrema de requisições (100 req/s)

\begin{tabular}{|c|c|c|c|c|c|c|c|c|c|c|c|}
\hline & \multicolumn{10}{|c|}{ Mensagem PCReq } \\
\hline & & \multicolumn{10}{|c|}{ Utilização dos Enlaces (\%) } \\
\hline $\operatorname{Req} / \mathrm{h}$ & $\operatorname{Req} / \mathrm{s}$ & DS0 & $256 \mathrm{Kbps}$ & $512 \mathrm{Kbps}$ & DS1 & E1 & $10 \mathrm{Mbps}$ & DS3 & $0 \mathrm{C1}$ & $100 \mathrm{Mbps}$ & $0 \mathrm{CC3}$ \\
\hline 360000 & 100 & E- & -- & 90,60 & 30,10 & 22,70 & 4,90 & 1,00 & 0,90 & 0,50 & 0,30 \\
\hline
\end{tabular}

De acordo com a padronização, a taxa de requisições que um elemento PCE pode suportar em caso excepcional, é de 100 requisições por segundo.

Com esta configuração verificou-se uma diferença significativa na ocupação dos enlaces pelas mensagens do protocolo.

Os enlaces acima da capacidade do DS3, inclusive o mesmo, tiveram ocupação menor ou igual a $1 \%$, ficando de fora deste grupo o enlace de 10 Mbps que apresentou ocupação de aproximadamente $5 \%$. Porém o enlace OC1 quase atingiu $1 \%$.

Os enlaces DS1 e E1 tiveram uma ocupação de mais de $20 \%$, sendo de aproximadamente $23 \%$ para o E1, e $30 \%$ para o DS1.

Os enlaces de menores capacidades sofreram mais com esta carga elevada de mensagens, sendo que aproximadamente $91 \%$ foi a ocupação média para o enlace de 512 Kbps, e os enlaces de 256 Kbps e DS0 sofreram saturação, ou ocupação total depois de um tempo de simulação.

A padronização considera este caso como uma situação de extremidade, ou excepcional, porém não fornece nenhuma informação sobre como, ou sob quais condições esta situação poderá ocorrer. De qualquer forma, caso ocorra, percebe-se a inviabilidade da arquitetura PCE com enlaces que possuem capacidades de transmissão inferiores a 512 Kbps, e atenção na implementação com os enlaces DS1 e E1. 


\subsubsection{Comportamento da Mensagem PCRep}

A tabela 6.6 e a figura 6.6 a seguir, apresentam os resultados do volume do tráfego gerado pela mensagem PCRep típica presumida, apresentada no apêndice $A$, em todos os enlaces propostos.

Tabela 6.6 - Ocupação dos enlaces pela mensagem PCRep

\begin{tabular}{|c|c|c|c|c|c|c|c|c|c|c|c|}
\hline \multirow{3}{*}{$\operatorname{Req} / \mathrm{h}$} & \multirow[b]{3}{*}{$\operatorname{Req} / \mathrm{s}$} & \multicolumn{10}{|c|}{ Mensagem PCRep } \\
\hline & & \multicolumn{10}{|c|}{ Utilização dos Enlaces (\%) } \\
\hline & & DS0 & $256 \mathrm{Kbps}$ & $512 \mathrm{Kbps}$ & DS1 & E1 & 10Mbps & DS3 & $0 \mathrm{C1}$ & 100Mbps & $0 \mathrm{C3}$ \\
\hline 10 & 0,0028 & 0,01 & 0,00 & 0,00 & 0,00 & 0,00 & 0,00 & 0,00 & 0,00 & 0,00 & 0,00 \\
\hline 50 & 0,014 & 0,04 & 0,01 & 0,01 & 0,00 & 0,00 & 0,00 & 0,00 & 0,00 & 0,00 & 0,00 \\
\hline 100 & 0,028 & 0,08 & 0,02 & 0,01 & 0,00 & 0,00 & 0,00 & 0,00 & 0,00 & 0,00 & 0,00 \\
\hline 500 & 0,14 & 0,41 & 0,10 & 0,05 & 0,02 & 0,01 & 0,00 & 0,00 & 0,00 & 0,00 & 0,00 \\
\hline 1000 & 0,28 & 0,83 & 0,21 & 0,10 & 0,03 & 0,03 & 0,01 & 0,00 & 0,00 & 0,00 & 0,00 \\
\hline 4000 & 1,1 & 3,34 & 0,83 & 0,42 & 0,14 & 0,10 & \begin{tabular}{l|l|}
0,02 \\
\end{tabular} & 0,00 & 0,00 & 0,00 & 0,00 \\
\hline 8000 & 2,2 & 6,70 & 1,67 & 0.83 & 0,28 & 0,21 & 0,05 & 0,01 & 0,01 & 0,00 & 0,00 \\
\hline 12000 & 3,3 & 10,03 & 2,50 & 1,25 & 0,42 & 0,31 & 0,07 & 0,01 & 0,01 & 0,01 & 0,00 \\
\hline 16000 & 4,4 & 13,38 & 3,34 & 1,67 & 0,55 & 0,42 & \begin{tabular}{ll|}
0,09 \\
\end{tabular} & 0,02 & 0,02 & 0,01 & 0,01 \\
\hline 20000 & 5,6 & 16,70 & 4,18 & 2,09 & 0,69 & 0,52 & 0,12 & 0,02 & 0,02 & 0,01 & 0,01 \\
\hline 24000 & 6,7 & 20,08 & 5,03 & 2,51 & 0,83 & 0,63 & 0,14 & 0,03 & 0,03 & 0,01 & 0,01 \\
\hline 28000 & 7,8 & 23,38 & 5,85 & 2,92 & 0,97 & 0,73 & \begin{tabular}{ll|}
0,17 \\
\end{tabular} & 0,03 & 0,03 & 0,02 & 0,01 \\
\hline 32000 & 8,8 & 26,73 & 6,69 & 3,34 & 1,11 & 0,84 & 0,19 & 0,04 & 0,03 & 0,02 & 0,01 \\
\hline 36000 & 10 & 30,08 & 7,52 & 3,76 & 1,25 & 0,94 & 0,21 & 0,04 & 0,04 & 0,02 & 0,01 \\
\hline
\end{tabular}

\begin{tabular}{|l|l|l|l|l|l|l|}
\hline Legenda: & $0 \% \leq x<1 \%$ & $1 \% \leq x<20 \%$ & $20 \% \leq x<40 \%$ & $40 \% \leq x<60 \%$ & $60 \% \leq x<80 \%$ & $80 \% \leq x<100 \%$ \\
\hline
\end{tabular}

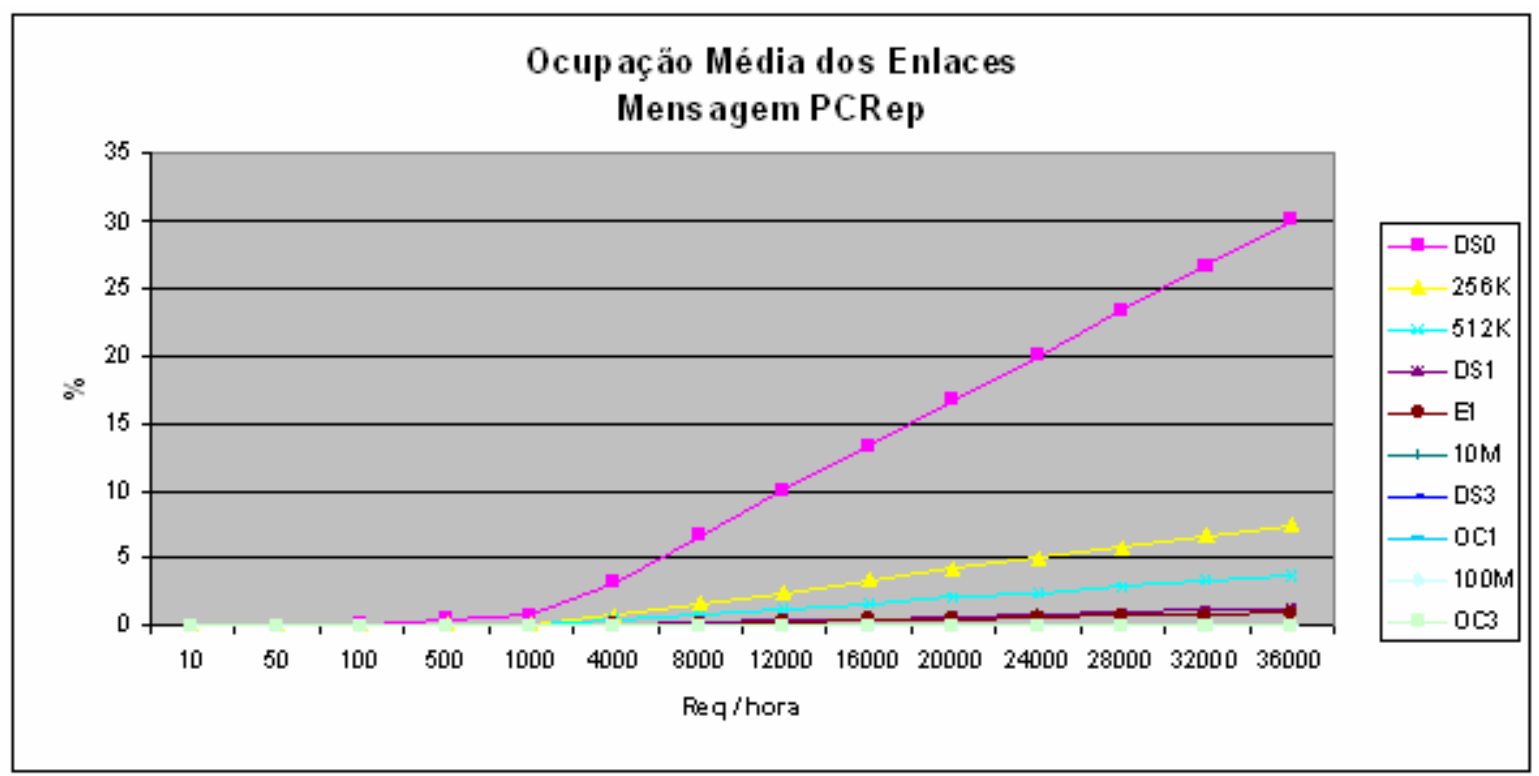

Figura 6.6 - Ocupação dos enlaces pela mensagem PCRep 
Pode-se verificar, que as mensagens de resposta às requisições, sendo menores do que as mensagens de requisição de rotas, geraram menos tráfego nos enlaces utilizados nas simulações. A partir da observação da composição das duas mensagens verifica-se que a mensagem de requisição apresenta variação no seu tamanho devido aos objetos de informação sobre as características dos enlaces, enquanto que a mensagem de reposta apresenta variação no seu tamanho devido principalmente ao objeto ERO, o qual contém a especificação da rota, representada pelos seus nós ao longo do caminho.

As mensagens de requisição, PCReq, causam mais impacto na utilização dos enlaces. As mensagens de resposta, sendo menores, causam menos impacto, o qual varia de acordo com a taxa de requisições imposta, porém sempre em menor escala comparando-se com a mensagem de requisição. Os resultados apresentados nas próximas tabelas e gráficos, sobre o comportamento da PCRep com outros tamanhos e taxas de resposta, seguem a mesma observação.

A tabela 6.7 e a figura 6.7 a seguir, apresentam os valores obtidos com o valor máximo da mensagem PCRep com seu maior valor presumido, apresentado no apêndice $A$, e com a maior taxa de requisições, em todos os enlaces propostos.

Tabela 6.7 - Ocupação dos enlaces pela mensagem PCRep com maior valor calculado e com a taxa máxima de requisições

\begin{tabular}{|c|c|c|c|c|c|c|c|c|c|c|c|}
\hline & \multicolumn{10}{|c|}{ Mensagem PCRep } \\
\hline & & \multicolumn{10}{|c|}{ Utilização dos Enlaces ( \%) } \\
\hline $\operatorname{Req} / \mathrm{h}$ & $\operatorname{Req} / \mathrm{s}$ & DS0 & $256 \mathrm{Kbps}$ & $512 \mathrm{Kbps}$ & DS1 & E1 & 10Mbps & DS3 & $0 \mathrm{C1}$ & $100 \mathrm{Mbps}$ & $0 \mathrm{C} 3$ \\
\hline 36000 & 10 & 44,18 & 11,04 & 5,52 & 1,83 & 1,38 & 0,28 & 0,06 & 0,06 & 0,03 & 0,02 \\
\hline
\end{tabular}

\begin{tabular}{|l|l|l|l|l|l|l|}
\hline Legenda: & $0 \% \leq x<1 \%$ & $1 \% \leq x<20 \%$ & $20 \% \leq x<40 \%$ & $40 \% \leq x<60 \%$ & $60 \% \leq x<80 \%$ & $80 \% \leq x<100 \%$ \\
\hline
\end{tabular} 

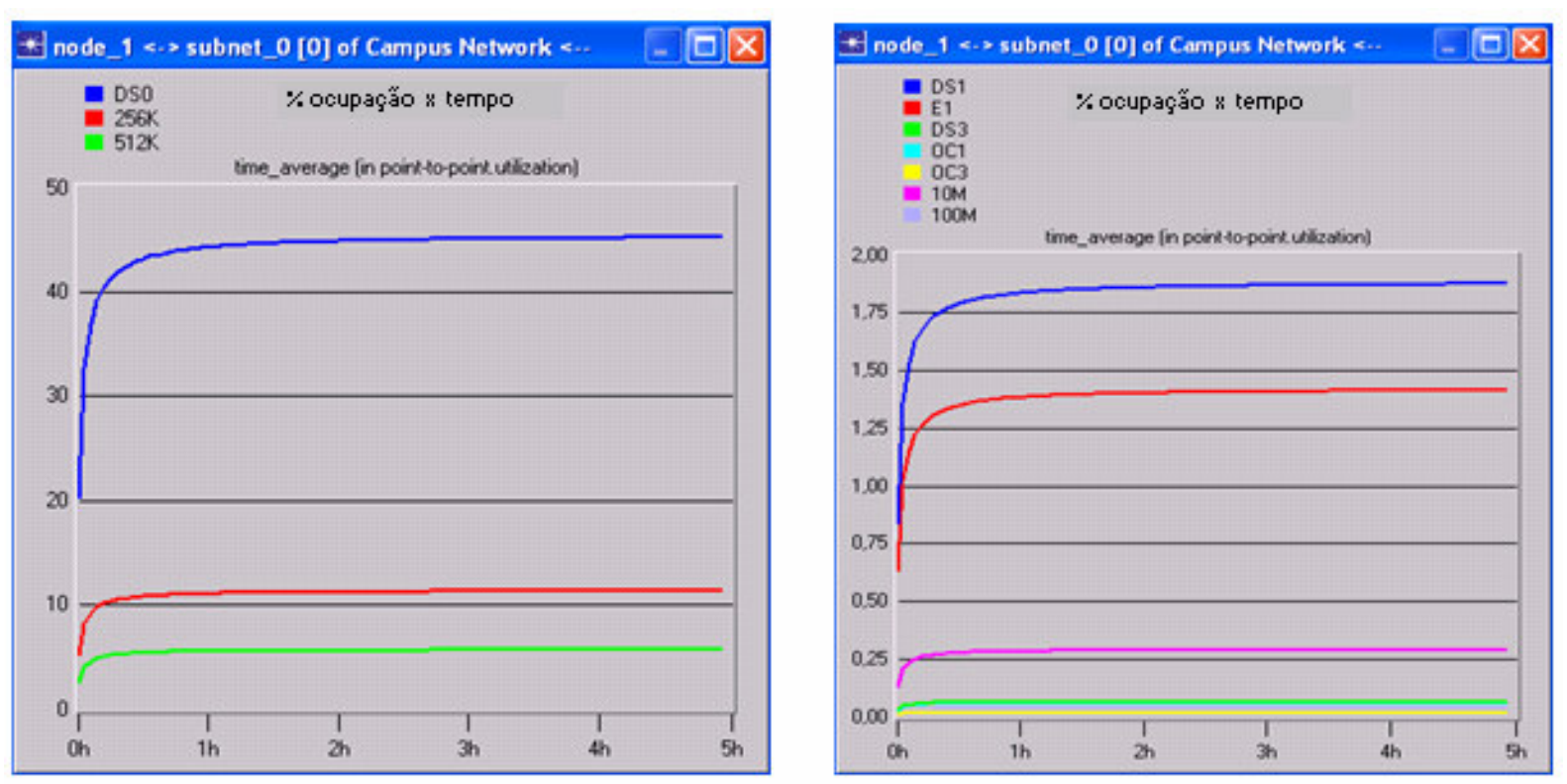

Figura 6.7 - Ocupação dos enlaces pela mensagem PCRep com a taxa máxima de requisições

A tabela 6.8 a seguir, apresenta os resultados do volume do tráfego gerado pela mensagem PCRep típica, em todos os enlaces propostos anteriormente, e com a taxa de $100 \mathrm{req} / \mathrm{seg}$, abordada como possível de ser processada pelo PCE na padronização, em caráter excepcional.

Tabela 6.8 - Ocupação dos enlaces pela mensagem PCRep com taxa extrema de requisições (100 $\mathrm{req} / \mathrm{s})$

\begin{tabular}{|c|c|c|c|c|c|c|c|c|c|c|c|}
\hline & \multicolumn{10}{|c|}{ Mensagem PCRep } \\
\hline & & \multicolumn{10}{|c|}{ Utilização dos Enlaces (\%) } \\
\hline $\operatorname{Req} / \mathrm{h}$ & $\operatorname{Req} / \mathrm{s}$ & DS0 & $256 \mathrm{Kbps}$ & 512Kbps & DS1 & E1 & \begin{tabular}{|l|l}
$10 \mathrm{Mbps}$ \\
\end{tabular} & DS3 & $0 \mathrm{C1}$ & 100Mbps & $0 \mathrm{C} 3$ \\
\hline 360000 & 100 & E- & 70,52 & 37,60 & 12,50 & 9,40 & 2,10 & 0,40 & 0,40 & 0,20 & 0,10 \\
\hline
\end{tabular}

\begin{tabular}{l|l|l|l|l|l|l|}
\hline Legenda: & $0 \% \leq x<1 \%$ & $1 \% \leq x<20 \%$ & $20 \% \leq x<40 \%$ & $40 \% \leq x<60 \%$ & $60 \% \leq x<80 \%$ & $80 \% \leq x<100 \%$ \\
\hline
\end{tabular}

\subsubsection{Comportamento da Mensagem PCReq Estendida}

A seguir são apresentadas novos experimentos, e neste momento com a mensagem PCReq estendida, conforme definida no capítulo 5.

Os experimentos são executados apenas nos cenários mais severos, com as taxas de requisição de 10req/s, sendo seus resultados apresentados na tabela 6.9, e $100 \mathrm{req} / \mathrm{s}$, sendo seus resultados apresentados na tabela 6.10, a seguir. 
Tabela 6.9 - Ocupação dos enlaces pela mensagem PCReq estendida com a taxa máxima de requisições (10 req/s)

\begin{tabular}{|c|c|c|c|c|c|c|c|c|c|c|c|}
\hline & \multicolumn{10}{|c|}{ Mensagem PCReq } \\
\hline & & \multicolumn{10}{|c|}{ Utilização dos Enlaces (\%) } \\
\hline $\operatorname{Req} / \mathrm{h}$ & $\operatorname{Req} / \mathrm{s}$ & DS0 & $256 \mathrm{Kbps}$ & $512 \mathrm{Kbps}$ & DS1 & E1 & $10 \mathrm{Mbps}$ & DS3 & $0 \mathrm{C1}$ & 100Mbps & $0 \mathrm{C3}$ \\
\hline 360000 & 100 & 75,01 & 18,74 & 9,37 & 3,12 & 2,35 & 0,50 & 0,11 & 0,10 & 0,05 & 0,03 \\
\hline
\end{tabular}

\begin{tabular}{|l|l|l|l|l|l|l|}
\hline Legenda: & $0 \% \leq x<1 \%$ & $1 \% \leq x<20 \%$ & $20 \% \leq x<40 \%$ & $40 \% \leq x<60 \%$ & $60 \% \leq x<80 \%$ & $80 \% \leq x<100 \%$ \\
\hline
\end{tabular}

Tabela 6.10 - Ocupação dos enlaces pela mensagem PCReq estendida com taxa extrema de requisições (100 $\mathrm{req} / \mathrm{s}$ )

\begin{tabular}{|c|c|c|c|c|c|c|c|c|c|c|c|}
\hline & \multicolumn{10}{|c|}{ Mensagem PCReq } \\
\hline & & \multicolumn{10}{|c|}{ Utilização dos Enlaces (\%) } \\
\hline $\operatorname{Req} / \mathrm{h}$ & $\operatorname{Req} / \mathrm{s}$ & DS0 & $256 \mathrm{Kbps}$ & $512 \mathrm{Kbps}$ & DS1 & E1 & 10Mbps & DS3 & $0 \mathrm{C1}$ & $100 \mathrm{Mbps}$ & $0 \mathrm{C3}$ \\
\hline 360000 & 100 & 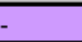 & -- & 93,70 & 31,20 & 23,50 & 5,00 & 1,10 & 1,00 & 0,50 & 0,30 \\
\hline
\end{tabular}

\begin{tabular}{|l|l|l|l|l|l|l|}
\hline Legenda: & $0 \% \leq x<1 \%$ & $1 \% \leq x<20 \%$ & $20 \% \leq x<40 \%$ & $40 \% \leq x<60 \%$ & $60 \% \leq x<80 \%$ & $80 \% \leq x<100 \%$ \\
\hline
\end{tabular}

Com relação ao objeto Quality, inserido na mensagem PCEReq, pode-se observar que o aumento desta mensagem com a extensão proposta não causou prejuízo significativo ao tráfego gerado nos enlaces testados. E todas as observações realizadas anteriormente, com o protocolo na sua forma original, continuam as mesmas para as mensagem PCReq estendida.

Sendo assim, verifica-se que parâmetros importantes sobre QoT, conforme descritos ao longo deste trabalho, podem ser contemplados nas mensagens de requisição de rotas da arquitetura PCE, sem que ocorra alteração significativa com relação ao impacto causado no tráfego dos enlaces que esta mensagem vai percorrer.

\subsubsection{Comentários Adicionais}

Este capítulo apresentou os resultados dos experimentos executados, com o objetivo de se verificar o comportamento das mensagens mais importantes do protocolo PCE Protocol, da arquitetura PCE. Resultados adicionais também foram obtidos levando em consideração a extensão proposta para que a mensagem PCReq seja capaz de lidar com parâmetros de QoT. 
Verificou-se que as mensagens do protocolo, de maneira geral, não causam impacto negativo nos enlaces, com exceção daqueles com menor capacidade, principalmente com o aumento da taxa de requisições. É importante observar que estes enlaces mais restritos não devem ser encontrados em abundância, provendo acesso aos grandes backbones. É mais provável que os usuários destas grandes redes, que requerem muita capacidade de banda, utilizem enlaces de acesso maiores. Porém, conforme apresentado em 6.1.1, ainda há possibilidade de que algumas redes periféricas utilizem enlaces com estas capacidades. Além disso, estes enlaces de baixa capacidade podem ser utilizados em determinadas redes exclusivamente pelo plano de controle, como canal de sinalização out-of-band, por isso a importância de considerá-los neste estudo. 


\section{ConCLusões}

No cenário atual as redes ópticas têm obtido grande importância, por permitir o transporte de dados a grandes distâncias e com alta vazão. Neste contexto um plano de controle eficiente, capaz de integrar as redes ópticas com as redes tradicionais possui um papel fundamental, e a arquitetura PCE se mostra como uma alternativa viável para ser adotada como mecanismo de roteamento como parte deste plano de controle.

Neste trabalho foi proposta a extensão do protocolo $P C E$ protocol da arquitetura PCE, como objetivo de que a mesma possa lidar com aspectos importantes das redes ópticas, relacionados à qualidade de transmissão, QoT, que influenciam na decisão da escolha do melhor caminho em um mecanismo de roteamento. A extensão proposta cria a possibilidade para a arquitetura prover um melhor serviço, no sentido de tomar decisões baseadas em informações que anteriormente não eram consideradas.

\subsection{Principais Contribuições}

Foi realizada neste trabalho uma pesquisa bibliográfica ampla e importante, a qual foi baseada em livros, artigos publicados, teses de mestrado e doutorado, RFCs e documentações técnicas de fabricantes e desenvolvedores, sobre redes ópticas e planos de controle, com foco no roteamento, para estas redes.

Com atenção especial ao mecanismo da arquitetura PCE, foi dada uma contribuição importante, visto que o mesmo é relativamente recente, e atualmente não existem estudos e trabalhos disponíveis de forma abundante. Desta forma, foi realizado um trabalho abrangente sobre o tema, através de informações detalhadas sobre 0 funcionamento desta arquitetura, suas principais características e dificuldades, inclusive com uma proposta de extensão para seu principal protocolo, com o objetivo de fornecer subsídios para a realização do cálculo das rotas, levando em consideração necessidades de QoT. 
Conforme apresentado e discutido anteriormente, ao longo deste trabalho, verificouse a necessidade de um plano de controle competente para lidar com as questões que aparecem quando se integram redes convencionais e redes ópticas, especialmente pelo fato do domínio óptico apresentar certas particularidades que devem ser levadas em consideração.

Este trabalho abordou o ambiente GMPLS e o mundo IETF, não sendo foco do mesmo as possíveis alternativas ITU-T. Sendo assim, dentro do escopo definido, foi notado que, no cenário intra-domínios, os protocolos de roteamento internos receberam propostas de extensões, e vários estudos foram divulgados, apresentando estas diferentes propostas e seu funcionamento para lidar com a integração citada. Porém no cenário inter-domínios, sendo este conceito, conforme apresentado, abrangente o suficiente para acomodar as redes inter-camadas, interáreas e inter-ASs, conforme definido anteriormente ao longo do trabalho, verificou-se a possibilidade do protocolo BGP como alternativa a ser utilizada para o roteamento, sendo o mesmo sugerido na própria padronização da arquitetura GMPLS. Porém verificou-se que este mecanismo encontra dificuldades neste ambiente onde os parâmetros TE entram em cena, sendo que o mesmo pode apresentar um acréscimo na taxa de bloqueio de estabelecimento de rotas devido a esta falta de informação, bem como pode alocar recursos de forma desnecessária enquanto tenta estabelecer uma rota impossível de ser estabelecida no final, devido à falta de recursos, e devido ao desconhecimento desta informação. Verificou-se que quanto maior a distância da origem do pedido de rota, o impacto negativo será pior, pois mais tempo e recursos podem ser tomados ao longo do caminho para se descobrir no final que a rota não pode ser estabelecida e o que ocorre é o mecanismo de tentativa e erro até que um caminho possível possa ser encontrado.

Foi verificado que com a adoção da arquitetura PCE esta dificuldade é contornada, pois os recursos são reservados somente com a certeza de que a rota pode ser estabelecida, ou seja, devido ao conhecimento que o elemento PCE possui da rede, ele tem a capacidade de devolver ao requisitante a rota com os recursos suficientes para estabelecer a comunicação de acordo com as necessidades solicitadas. Desta forma, não existe possibilidade de construir uma rota através de tentativa e erro, e a 
taxa de bloqueio devido à falta de conhecimento diminui, além de que recursos não são reservados de forma desnecessária. Importante notar que para uma rede com recursos limitados, ou escassos, a arquitetura PCE apresenta bloqueio de rotas, porém deve-se observar que este bloqueio se dá pela falta de recursos, como aconteceria da mesma forma com o BGP, e não pela falta de conhecimento das características das capacidades dos enlaces das redes.

Um aspecto do trabalho que deve ser destacado é a proposta da extensão da mensagem de requisições de rotas, a PCReq, através da inclusão de um novo objeto na mesma, para lidar com características da qualidade da transmissão do sinal óptico, o QoT, nos enlaces da rede.

Esta extensão foi proposta como uma informação adicional para que o PCE possa levar em consideração no momento de calcular a melhor alternativa de rota. Esta alternativa é oferecida ao PCC para que o mesmo possa obter a qualidade de transmissão, QoT, nos enlaces ópticos de acordo com suas necessidades de transmissão, com relação às exigências da sua qualidade de serviço, QoS, diferenciada, como exigências relacionadas ao atraso, variação de atraso e taxa de erros que os enlaces podem apresentar. Até este momento a abordagem do PCE considerava que todos os enlaces pudessem oferecer capacidade suficiente de transmissão com relação à qualidade do sinal óptico, porém, conforme visto ao longo deste trabalho, esta é uma abordagem que nem sempre é verdadeira, visto que há vários fatores de degradação em uma transmissão óptica. Desta forma, com a extensão sugerida, o PCC tem a possibilidade de informar as suas necessidades, e o PCE pode entender as mesmas e escolher a rota mais adequada a elas. Além disto, podem existir situações em que mesmo as necessidades mínimas de qualidade de transmissão podem não ser alcançadas, e desta forma, pode haver bloqueio devido à falta de qualidade mínima do sinal óptico. Sendo assim o PCE também pode levar em consideração a qualidade mínima, mesmo sem ter sido requisitada pelo PCC, para garantir uma rota fim-a-fim executável. 
Os experimentos e análises realizadas no capítulo 6 , demonstraram de que forma as mensagens utilizadas por este mecanismo, para requisitar e receber rotas, podem causar impacto nos enlaces das redes. Percebe-se que nas situações consideradas normais de utilização da rede, com relação ao volume de requisição e resposta de rotas definido pela padronização, e com um tamanho típico das mensagens citadas, deve-se ter atenção com os enlaces com capacidades inferiores a 2 Mbps com relação a sua ocupação natural por tráfego de aplicações e usuários. Caso estes enlaces estiverem ocupados no limite de sua capacidade, podem sofrer conseqüências negativas com a implantação do PCE.

Situações extremas foram consideradas, como a taxa de requisição extraordinária que um PCE deve suportar, definida pela padronização, e um tamanho de mensagem definido como máximo, dentro da hipótese adotada no escopo dos experimentos. No caso da alta taxa de requisições verificou-se que enlaces de 512 Kbps ficam severamente comprometidos com ocupação média acima de $80 \%$, e aqueles com capacidades inferiores apresentaram ocupação máxima. Caso este comportamento ocorra, este é um fator limitante para a adoção do mecanismo em redes com estes enlaces, porém não está claro na padronização, nem em outras fontes de consulta, em que situação poderá ocorrer este comportamento.

Novas análises foram realizadas, aumentando-se o tamanho da mensagem de requisição de rotas, através da adição do objeto relacionado à qualidade do sinal óptico. Foi constatado que este aumento não altera de forma significativa o comportamento do volume do tráfego gerado pela mensagem de requisição de rotas do protocolo do PCE. 


\subsection{Sugestões para Trabalhos Futuros}

A proposta apresentada neste trabalho sobre a extensão do PCE Protocol, com o objetivo de tratar parâmetros de QoT, será analisada com relação à viabilidade de sua submissão ao IETF, para que seja verificada a possibilidade da criação de uma futura RFC padronizando esta extensão.

No decorrer deste trabalho verificou-se a necessidade de que sejam aprofundados os estudos em alguns pontos específicos.

A análise da extensão do protocolo $P C E$ protocol foi realizada com relação ao impacto que a mesma causa no tráfego dos enlaces, porém a simulação do desempenho do protocolo PCE não foi realizada devido a dificuldade em encontrar o simulador adequado para o ambiente PCE e GMPLS, ficando como um tema em aberto para trabalhos futuros.

O escopo deste trabalho definiu a utilização de um PCE como resolvedor de rotas, e a padronização define também o mecanismo com mais de um PCE colaborando para esta tarefa, conforme apresentado no capítulo 4. A escalabildade desta arquitetura, com um ou vários PCEs em ação, é um assunto que não está claro na padronização, e merece atenção no momento da configuração do ambiente que será implantado, com o objetivo de atender à demanda gerada.

Toda a análise do impacto das mensagens de requisição e resposta ao estabelecimento de rotas foi realizada através da hipótese de que o PCE possui conhecimento das características dos enlaces sob seu domínio. Este conhecimento pode ser adquirido de forma manual, ou através de algum mecanismo de roteamento que tenha capacidade de carregar estas informações. Existem estudos sobre estes mecanismos automáticos de divulgação dos estados dos enlaces, porém ainda há espaço para mais trabalhos, principalmente quando entra em cena o aspecto da 
qualidade do sinal óptico, o qual traz consigo outras variáveis, distintas daquelas apresentadas em grande parte dos trabalhos até o momento.

Além da divulgação destes novos parâmetros, a coleta eficiente dos mesmos pela rede é um outro aspecto importante no sucesso da aplicação deste mecanismo, pois os mesmos devem estar disponíveis para que possam ser coletados a fim de serem divulgados para os PCEs.

Com estas novas informações coletadas e divulgadas, também há necessidade de que o algoritmo responsável pelo cálculo das rotas no PCE possa entendê-las, e então tenham a capacidade de lidar com as mesmas, para que realmente a rota a ser escolhida seja a mais adequada, e então possa proporcionar a qualidade suficiente para uma transmissão óptica. 


\section{Referências}

ABELÉM, A.J.G.; STANTON, M.A. Inter-redes IP baseadas em Rede Ópticas. In: SIMPÓSIO BRASILEIRO DE REDES DE COMPUTADORES, 20., 2002, Rio de Janeiro. SBC, 2002. p. 63-123.

ADEEL, M. et al. A Comparative Analysis of Routing Protocols in GMPLS. In: THE FIRST IEEE AND IFIP INTERNACIONAL CONFERENCE IN CENTRAL ASIA ON INTERNET, 2005, Bishkek, Kyrgyz Republic. IEEE, 2005. 6 p.

AL ZAHR, S. et al. Physical Layer Impairments in WDM Core Networks: a Comparison between a North-American Backbone and a Pan-European Backbone. In: INTERNATIONAL CONFERENCE ON BROADBAND NETWORKS, 2., 2005, Massachusetts. IEEE, 2005. v. 2, p. 1258-1263

ALCATEL. Traffic Engineering Solutions for Core Networks. (S.I): 2002. 18 p.

(Technical Paper). Disponível em: <www.alcatel.com>. Acesso em: Nov. 2006

ALOIA, J.E. Sistematização Crítica das Tendências de Padronização de Arquiteturas e Protocolos em Redes Ópticas. 2003. 159 p. Dissertação (Mestrado) - Escola de Engenharia de São Carlos (EESC), São Carlos, 2003.

AMAZONAS, J.R.A.; GIOZZA, W.F. Relatório 2.3 - Generalized Multiprotocol Label Switch - GMPLS. São Paulo: [s.n.], 2003. 165 p. (Relatório Técnico)

ASH, J.; LE ROUX, J.L. Path Computation Element (PCE) Communication Protocol Generic Requirements. RFC 4657. IETF: Setembro, 2006

BERGER, L. Generalized Multi-Protocol Label Switching (GMPLS) Signaling Functional Description. RFC 3471. IETF: Janeiro, 2003a

. Generalized Multi-Protocol Label Switching (GMPLS) Signaling Resource Reservation Protocol-Traffic Engineering (RSVP-TE) Extensions. RFC 3473. IETF: Janeiro, 2003b.

BITAR, N.; ZHANG, R.; KUMAKI, K. Inter-AS Requirements for the Path Computation Element Communication Protocol (PCECP). Internet Draft. IETF: Outubro, 2006 
BOFFI, P.; MARAZZI, L.; MARTINELLI, M. A Novel Interferometric Wavelenght Converter. IEEE Photonics Technology Letters, v. 11, n. 10, p. 1393-1395, 1999

CARVALHO, T.C.M.B. Arquitetura de redes de computadores OSI e TCP / IP. Rio de Janeiro: Embratel, 1994. 669 p.

CHOI, M.C; LONG, J.L. Heterogeneous Control and Transport Topologies in Optical Networks. In: SOUTHEASTCON, 2002, South Caroline. IEEE, 2002, p. 400-404

CHUNG, Y. Fluctuations of Bit-Error-Rate with randomly varying birefringence in optical fibers. Optical Society of America, Los Alamos, v. 12, n. 25, p. 6326-6334, 2004.

CUGINI, F.; ANDRIOLLI, N.; CASTOLDI, P. A Novel OSPF Extension Including Node Architectural Constraints for GMPLS Extensions. In: INTERNATIONAL TELECOMMUNICATIONS NETWORK STRATEGY AND PLANNING SYMPOSIUM, 11., 2004, Viena. IEEE, 2004. p. 291-296

DAVIE, B.; REKHTER, Y. MPLS: Technology and Applications. San Francisco: Morgan Kaufmann Publishers, 2000. c. 7. 287 p.

DIMITROPOULOS, X. et al. Revealing the Autonomous System Taxonomy: The Machine Learning Approach. Computer Science, 2006. 10 p. Disponível em: $<$ www.citebase.org $>$. Acessado em: Jan. 2007.

DURRESI, A. et al. Quality Based Optical Routing Protocol. In: ITCOMM, 2003, Orlando. Optical Transmission Systems and Equipment for WDM Networking II. SPIE, 2003. v. 5247, p. 410-420

EZZAHDI, M.A. et al. LERP: a Quality of Transmission Dependent Heuristic for Routing and Wavelength Assignment in Hybrid WDM Networks. In:

INTERNATIONAL CONFERENCE ON COMPUTER COMMUNICATIONS AND NETWORKS, 15., 2006, Virginia: IEEE, 2006. p. 125-136

FARREL, A.; VASSEUR, J.P.; ASH, J. A Path Computation Element (PCE)-Based Architecture. RFC 4655. IETF: Agosto, 2006.

FRANCISCO, J.M. et al. End-to-End Signaling and Routing for Optical IP Networks. In: IEEE INTERNATIONAL CONFERENCE ON COMMUNICATIONS, 2002, New York: IEEE, 2002. v. 5. p. 2870-2875. 
FRANCISCO, M.J.; SIMPSON, S.; PEZOULAS, L. Interdomain Routing in Optical Networks. In: OPTCOMM, 2001, Denver: Spie, 2001. v. 4599. p. 120-129

GILLESPIE, A. Broadband Access Technology, Interfaces and Management. Boston: Artech House, 2001. 380 p.

GOFF, D.R. Fiber Optic Reference Guide: A Practical Guide to Communications Technology. $3^{\text {rd }}$ ed. (S.I.): Focal Press, 2002. 260 p.

GORALSKI, W. Optical Networking \& WDM. California: McGraw-Hill/Osborne, 2001. C. 6 .

HUDGINGS, J.A.; LAU, K.Y. Step-Tunable All-Optical Wavelenght Conversion Using Cavity-Enhanced Four-Wave Mixing. IEEE Journal of Quantum Eletronics, v. 34, n. 8, 1998

KATZ, D.; KOMPELLA, K; YEUNG, D. Traffic Engineering (TE) Extensions to OSPF Version 2. RFC 3630. IETF: Setembro, 2003.

KENYON, T. Data Networks: Routing, Security, and Performance Optimization. USA: Digital Press, 2002. c. 3. 807 p.

KHAIR, M.G. An Implementation Approach for an Inter-Domain Routing Protocol for DWDM. 2004. 122 p. Thesis (Master of Applied Science) - University of Ottawa, Ottawa, 2004.

KHOSROWPOUR, M. Turmoil in the Telecommunications Industry. In: INFORMATION RESOURCES MANAGEMENT ASSOCIATION INTERNATIONAL CONFERENCE, 2000, Anchorage. Challenges of Information Technology Management in the 21st Century. Hershey: IGI Publishing, 2000. c. 298

KOMPELLA, K.; REKHTER, Y. Intermediate System to Intermediate System (IS-IS) Extensions in Support of Generalized Multi-Protocol Label Switching (GMPLS). RFC 4205. IETF: Outubro, 2005a.

. OSPF Extensions in Support of Generalized Multi-Protocol Label Switching $\overline{(G M P L S)}$. RFC 4203. IETF: Outubro, 2005b. 
Routing Extensions in Support of Generalized Multi-Protocol Label Switching (GMPLS). RFC 4202. IETF: Outubro 2005c.

KOZIEROK, C.M. The TCP/IP Guide-A Comprehensive, Illustrated Internet Protocols Reference. San Francisco: No Starch Press, Inc., 2005. 1616 p.

LACEY, J.P.R.; MADDEN, S.J. Tunability of Polarization-Insensitive Wavelenght Converters Based on Four-Wave Mixing in Semiconductor Optical Amplifiers. Journal of Lightwave Technology, v. 16, n. 12, 1998

LANG, J. Link Management Protocol (LMP). RFC 4204. IETF: Outubro, 2005

LE ROUX, J.L. et al. IS-IS protocol extensions for Path Computation Element (PCE) Discovery. Internet Draft. IETF: Dezembro, 2006a.

OSPF protocol extensions for Path Computation Element (PCE) Discovery. Internet Draft. IETF: Dezembro, 2006b.

LE ROUX, J.L. PCE Communication Protocol (PCECP) Specific Requirements for Inter-Area Multi Protocol Label Switching (MPLS) and Generalized MPLS (GMPLS) Traffic Engineering. Internet Draft. IETF: Dezembro, 2006

. Requirements for Path Computation Element (PCE) Discovery. RFC 4674. IETF: Outubro, 2006.

LEUTHOLD, J. et al. All-Optical Mach-Zender Interferometer Wavelenght Converters and Switches with Integrated Data and Control Signal Separation Scheme. Journal of Lightwave Technology, V. 17, n. 6, 1999

LIVAS, J. Optical Transmission Evolution: From Digital to Analog to ? Network Tradeoffs Between Optical Transparency and Reduced Regeneration Cost. Jornal of Lightwave Technology, Maryland, USA, v. 23, n. 1, p. 219-224, 2005

MANNIE, E. Generalized Multi-Protocol Label Switching (GMPLS) Architecture. RFC 3945. IETF: Outubro, 2004.

MELO, E.T.L. Qualidade de Serviço em Redes IP com DiffServ: Avaliação através de Medições. 2001. 136 p. Dissertação (Mestrado) - Universidade Federal de Santa Catarina, Florianóplolis, 2001. 
MESTRIC, R.; SIF, M.; FESTRAETS, E. Optimizing the Network Architecture for Triple Play. (S.I.): Alcatel, 2005. 8 p. (Technical Paper). Disponível em: $<$ www.alcatel.com>. Acesso em: Nov. 2006

MIYAMURA, T.; KURIMOTO, T.; AOKI, M. Enhancing the Network Scalability of Linkstate Routing Protocols by Reducing their Flooding Overhead. In: WORKSHOP ON HIGH PERFORMANCE SWITCHING AND ROUTING, 2003, Torino. High Performance Switching and Routing. USA: IEEE, 2003. p. 263-268

MUKHERJEE, B. Optical Communications Networks. Ontario, Canada: McGraw-Hill, 1997. $576 \mathrm{p}$.

OBERMANN, K. et al. Performance Analysis of Wavelenght Converters Based on Cross-Gain Modulation in Semiconductor-Optical Amplifiers. Journal of Lightwave Technology, v. 16, n. 1, 1998

OODAN, A. et al. Telecommunications Quality of Service Management: From Legacy to Emerging Services. London: The Institution of Electrical Engineers, 2003. 602 p.

OSBORNE, E.; SIMHA, A. Traffic Engineering with MPLS. USA: Cisco Press, 2003. $614 \mathrm{p}$.

OULD-BRAHIM, H.; FEDYK, D.; REKHTER, Y. Traffic Engineering Attribute. Internet Draft. IETF: Outubro, 2006

PADJEN, R.; LAMMLE, T. CCDP: Cisco Internetwork Design Study Guide. Alameda, USA: Sybex, 2000. c. 3. 580 p.

PERROS, G.H. Connection-Oriented Networks: SONET/SDH, ATM, MPLS and Optical Networks. Chichester, England: John Wiley \& Sons Ltd, 2005. 356 p.

RAMASWAMI, R.; SIVARAJAN, K.N. Optical Networks: A Practical Perspective. $2^{\text {nd }}$ ed. California: Morgan Kaufmann Publishers, 2002. 831 p.

REKHTER, Y.; LI, T.; HARES, S. A Border Gateway Protocol 4 (BGP-4). RFC 4271. IETF: Janeiro, 2006.

ROSEN, E.; VISWANATHAN, A.; CALLON, R. Multiprotocol Label Switching Architecture. RFC 3031. IETF: Janeiro, 2001 
SOLE-PARETA, J. et al. Some Open Issues in the Optical Networks Control Plane. In: INTERNATIONAL CONFERENCE ON TRANSPARENTE OPTICAL NETWORKS, 5., 2003, v. 1, n. 29. Warsaw, Poland. p. 76-81

STRAND, J.; CHIU, A. Impairments and Other Constraints on Optical Layer Routing. RFC 4054. IETF: Maio, 2005

STRAND, J.; CHIU, A.; TKACH, R. Issues for Routing in the Optical Layer. Topics in Lightwave, IEEE Communications Magazine, USA, v. 39, n. 2, p. 81-87, 2001

SUBBIAH, P. Bit Error Rate (BER) For High Speed Serial Data Communication. (S.I.): Cypress Semicondutor, Data Communications Division, 2006. 6 p. (Technical Paper). Disponível em: <www.cypress.com>. Acesso em Mar. 2007.

VASSEUR, J.P.; LE ROUX, J.L. Path Computation Element (PCE) communication Protocol (PCEP) - Version 1. Internet Draft. IETF: Janeiro, 2007

WRIGHT, B. Inter-area Routing, Path Selection and Traffic Engineering. Enfield, UK: Data Connection, 2003. 42 p. (Technical Paper). Disponível em: $<$ www.dataconnection.com>. Acesso em: Mai. 2006

YIN, Y.; KUO, G.S. An Improved OSPF-TE in GMPLS-Based Optical Networks. In: WORKSHOP ON HIGH PERFORMANCE SWITCHING AND ROUTING, 2005, Hong-Kong. High Performance Switching and Routing. USA: IEEE, 2005. p. 241245

ZHANG, L.; TANG, J. Characterization and performance study of IP traffic in WDM networks. Computer Communications, v. 24, n. 17, p. 1702-1713, 2001 


\section{APÊndice A - Descrição das Mensagens PCReq e PCRep do PCE Protocol Utilizadas nos EXPERIMENTOS}

Este apêndice apresenta os valores dos tamanhos das mensagens PCReq e PCRep do PCE Protocol calculados para sua utilização nos experimentos deste trabalho.

\section{I) Mensagem PCReq}

Possui dois objetos que devem estar presentes em todas as requisições, segundo definição do padrão, que são os objetos RP e End-Points. Caso um deles não esteja presente, uma mensagem de erro PCErr, deve ser enviada ao requisitante.

Sendo assim o tamanho mínimo assumido para esta mensagem é de 256 bits, considerando os cabeçalhos padrão, os cabeçalhos dos objetos e os valores mínimos para os dois objetos obrigatórios da mensagem PCReq.

O tamanho típico para esta mensagem pode apresentar uma variação considerável de acordo com a utilização dos demais objetos opcionais em uma determinada requisição. Outro aspecto importante que influencia no tamanho desta mensagem é o fato de que cada objeto opcional também pode apresentar variação no seu tamanho, de acordo com o perfil das necessidades originadas pelo requisitante do LSP.

Foram assumidas as hipóteses, descritas a seguir, com o objetivo de se obter um tamanho típico e um tamanho máximo para ser utilizado nas análises desejadas. 


\section{- Tamanho típico:}

Assume-se, na contabilização do tamanho típico, o valor do tamanho mínimo requerido por uma mensagem PCReq, com os objetos e cabeçalhos obrigatórios, somado ao valor dos tamanhos dos objetos descritos a seguir.

Objeto LSPA, com 409 bytes. Este é o objeto responsável por carregar informações parâmetros dos enlaces. Porém nenhuma TLV foi definida pela padronização, e estes campos estão em aberto, desta forma são utilizadas as mesmas informações dos estados dos enlaces trocadas por mecanismos de roteamento internos já definidas (KOMPELLA; REKHTER, 2005b).

O objeto relacionado à largura de banda neste caso não será utilizado na contabilização, pois é assumida a hipótese de que a requisição de largura de banda esteja contemplada no objeto LSPA, ou seja, esta hipótese evita a contabilização em duplicidade.

Os objetos Met e Load-Balancing são utilizados com seus valores típicos de 64 bits cada um.

Deve-se acrescentar o valor do tamanho dos cabeçalhos para cada objeto relacionado nesta mensagem que é de 32 bits para cada um dos objetos.

Sendo assim o tamanho final de uma mensagem típica, considerando as hipóteses assumidas, é: $T_{\text {típico }}=3752$ bits

\section{- Tamanho máximo:}

Para a contabilização do tamanho máximo da mensagem de requisição de rotas, novas hipóteses serão consideradas conforme descritas a seguir, as quais estão relacionadas à inserção de objetos adicionais na mensagem.

Novamente será assumido na contabilização o valor do tamanho mínimo requerido por uma mensagem PCReq, com os objetos e cabeçalhos obrigatórios. Este valor será somado ao valor dos tamanhos dos objetos descritos na contabilização do 
tamanho típico mais os valores dos tamanhos dos objetos adicionais descritos a seguir.

O tamanho do objeto LSPA terá um acréscimo de 66 bytes, aproximadamente $15 \%$, de acordo com o valor máximo que os parâmetros GMPLS poderão assumir (KOMPELLA; REKHTER, 2005).

O objeto SVEC será utilizado com 128 bits.

O objeto IRO é utilizado para indicar uma rota preferencial com cinco saltos, sendo composto desta forma por 320 bits.

Deve-se acrescentar o valor do tamanho dos cabeçalhos para cada objeto relacionado nesta mensagem que é de 32 bits para cada um dos objetos.

Sendo assim o tamanho máximo de uma mensagem, considerando as hipóteses assumidas, é: $T_{\operatorname{máx}}=4792$ bits

\section{- Valores utilizados no Opnet para a análise do tráfego:}

O tamanho da mensagem a ser utilizada para a análise do tráfego gerado é obtido através da média entre os valores típico e máximo. Será assumida a hipótese de que o valor mínimo, por não carregar nenhuma informação do estado dos enlaces, não será utilizado, devido à característica inerente da arquitetura PCE, que proporciona como sua maior contribuição, o cálculo de rotas complexas, levando em consideração os parâmetros de estado dos enlaces, como alternativa a outros mecanismos que não suportam este tipo de informação.

O valor do tamanho final da mensagem, a ser utilizada no Opnet, adiciona o valor do tamanho médio da mensagem PCReq ao valor do tamanho da mensagem Open, cuja função foi descrita anteriormente em 4.3.2. Sendo assim o valor final utilizado é de 554 bytes. 


\section{II) Mensagem PCRep}

Possui um objeto que deve estar presente em todas as requisições, segundo definição do padrão, que é o objeto RP. Caso não esteja presente, uma mensagem de erro PCErr, deve ser gerada.

A mensagem PCRep pode ser utilizada para enviar ao solicitante uma resposta positiva no caso do PCE conseguir computar uma rota de acordo com as restrições enviadas pelo PCC, ou uma resposta negativa caso esta rota não possa ser computada.

Os objetos utilizados no caso de uma resposta negativa são diferentes daqueles utilizados para a resposta positiva. Verifica-se que os seus tamanhos são menores do que os apresentados na resposta positiva, pois estes não contém informação da rota completa e sim apenas do nó onde ocorreu a falha que impossibilitou a computação da rota. Desta forma, a análise será realizada com os valores encontrados para as respostas positivas.

De maneira diferente da mensagem PCReq, o tamanho típico para esta mensagem pode apresentar outro tipo de variação. Ou seja, a variação ocorre de acordo com o número de nós presentes em uma determinada rota computada. Este valor depende diretamente do tamanho das redes conectadas que estiverem sob responsabilidade do PCE. Desta forma, foram assumidas as hipóteses descritas a seguir, com o objetivo de se obter um tamanho mínimo e um tamanho máximo para ser utilizado nas análises desejadas.

\section{- Tamanho mínimo:}

Assume-se na contabilização do tamanho mínimo o valor dos tamanhos dos objetos descritos a seguir, e considerando a rota com apenas um salto.

Cabeçalho comum com 64 bits. 
Objeto RP (obrigatório) com 64 bits.

Objeto SVEC com 128 bits.

Objeto ERO com 64 bits, indicando uma rota com um nó.

Objeto BW com 32 bits.

Objeto Met com 64 bits.

Deve-se acrescentar o valor do tamanho dos cabeçalhos para cada objeto relacionado nesta mensagem que é de 32 bits para cada um dos objetos.

Sendo assim o tamanho final de uma mensagem, considerando as hipóteses assumidas, é: $T_{\min }=576$ bits.

\section{- Tamanho máximo:}

Para a contabilização do tamanho máximo da mensagem foi considerada a hipótese de uma rota computada contendo 30 nós.

Neste caso temos o tamanho máximo de $T_{\text {máx }}=2432$ bits

\section{- Valores utilizados no Opnet para a análise de tráfego:}

O tamanho da mensagem a ser utilizada para a análise de tráfego gerado é obtido através da média entre os valores mínimo e máximo. O valor do tamanho final da mensagem adiciona o valor do tamanho médio da mensagem PCReq ao valor do tamanho da mensagem Close, cuja função foi descrita anteriormente em 4.3.2. Sendo assim o valor final utilizado é de 208 bytes. 